\title{
Psychobiological Mechanisms of Aggression in Youth
}

\author{
Sara Chiara Haden
}

Dissertation submitted to the faculty of the Virginia Polytechnic Institute and State University in

\author{
partial fulfillment of the requirements for the degree of \\ DOCTOR OF PHILOSOPHY \\ in \\ Psychology
}

Angela Scarpa-Friedman, Committee Chair

Michael Denbow

David W. Harrison

Thomas H. Ollendick

Bruce H. Scarpa-Friedman

May 11, 2006

Blacksburg, Virginia

Keywords: Aggression, Norepinephrine, Rearing Environment, Hostile, Instrumental

Copyright 2006, Sara C. Haden 


\section{Psychobiological Mechanisms of Aggression in Youth}

\section{Sara Chiara Haden}

\section{(ABSTRACT)}

Recently, models of aggressive behavior have begun to appreciate the influence of both psychological and biological predictors of maladaptive behavior. The aim of the current project was to clarify the roles that the noradrenergic system (i.e., norepinephrine metabolite, 3methoxy-4-hydroxyphenyglycol [MHPG]) and characteristics of the rearing environment play in different expressions of aggression (i.e., hostile and instrumental). It was predicted that higher concentrations of MHPG would be related to increased self-reports of aggressive behavior, especially hostile forms, while expressing aggression during an analog aggression task would lead to decreases in MHPG. It was also predicted that concentrations of MHPG would interact with childhood environment characteristics to predict aggressive behavior in youth.

A sample of 68 male youth, aged 7 to 17, were recruited from two agencies in southwest Virginia serving disadvantaged youth. They completed self-report measures on their childhood environment, aggressive and delinquent behaviors, as well as exposure to community violence and negative life events. In addition, youth played a challenging computer game with an alleged "opponent" and lost. Half of the participants were able to retaliate after the game against their "opponent." Salivary MHPG was measured once before and three times after the game. A series of ANOVAs and hierarchical regressions were conducted in order to test the main and interactive effects of punitive childhood experiences and baseline MHPG on aggressive behavior. Findings failed to support the primary predictions; however, results of supplemental analyses showed significant associations of aggression with negative mood, negative family atmosphere, and increased baseline MHPG after controlling for negative family atmosphere. Also, parental 
punishment and rejection significantly predicted delinquency, and a significant interaction effect indicated that higher recovery concentrations of MHPG placed rejected youth more at risk for engaging in delinquent behavior. Results of the present study help to enhance understanding of the differences in biological and psychological correlates of aggression and delinquency in atrisk youth, and inform prevention and intervention efforts. 


\section{Acknowledgements}

I would like to thank my mom and dad for all of their support throughout my 29 years especially these last few! I am so lucky to have parents that care for me so much. Thank you for being so understanding. And thank you for being proud of me.

I also must thank my advisor, Dr. Angela Scarpa. I know that I would not have been able to make it through these four years without her. She always knew how to fix problems and make things easier for me to move along with this project. Dr. Scarpa pushed me to excel and I found out so much about myself in the process. Her confidence in me helped me succeed during my time at Virginia Tech. I hope that we continue to collaborate with one another in the future.

I would also like to thank my committee members, Drs. Denbow, Friedman, Harrison, and Ollendick. I enjoyed working with them and learned so much from each of my committee members.

I could have not survived this process without the help of many friends - especially Banu Cankaya, Melisa Chelf, Lee Cooper, Jenifer Francisco, Laura Horsch, and Rob Walters. These people mean so much to me.

Lastly I must thank my Blacksburg animal family, Romeo, Achilles, Elvira, Bowie, Orko, and Timmy, for all the time they helped me to procrastinate via petting, playing, feeding, and walking. I especially thank Heather Brausa - she has been my motivator for many years. I know that I would not have been able to do any of this without her. 


\section{Grant Information}

This project was funded by the following grants and awards:

Clinical Child Research Fund Award. Department of Psychology.

Division 53 Society for Clinical Child and Adolescent Psychology Research Award.

Graduate Student Assembly. Virginia Polytechnic Institute and State University.

Graduate Research Development Project.

Virginia Tech Graduate School and the National Science Foundation ADVANCE Grant No. SBE-0244916. 


\section{Table of Contents}

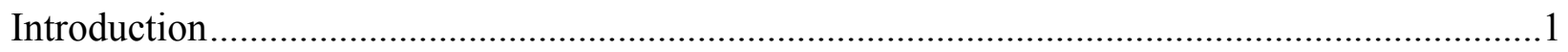

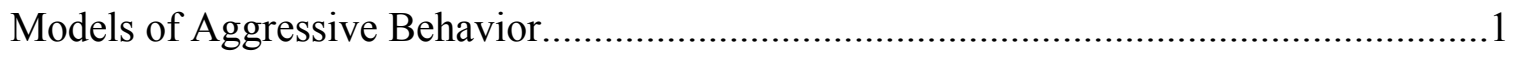

Emotion Regulation, Aggressive Responses, and Psychobiological Correlates............2

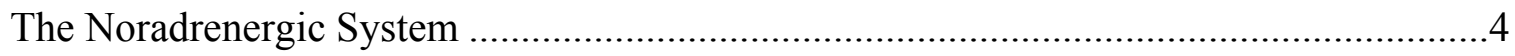

Complexity of the Noradrenergic System.................................................................

3-methoxy-4-hydroxy-phenylglycol (MHPG) ................................................

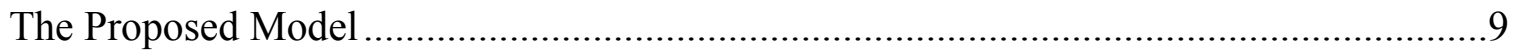

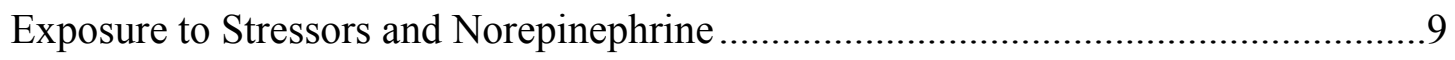

Rearing Environment and Norepinephrine .................................................... 11

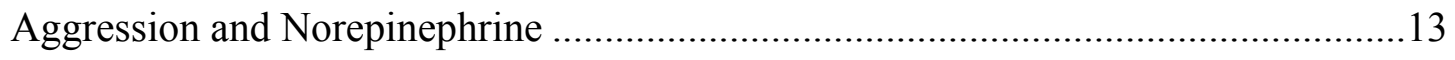

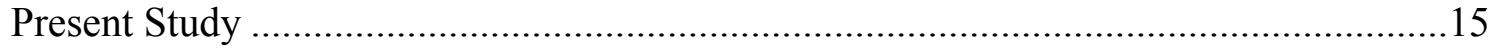

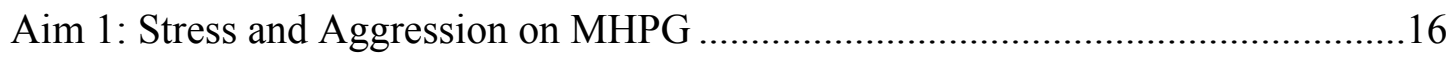

Aim 2: Hostile and Instrumental Aggression on MHPG .......................................

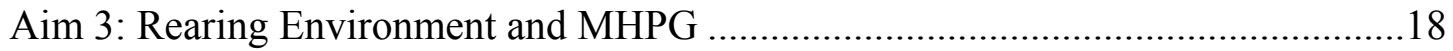

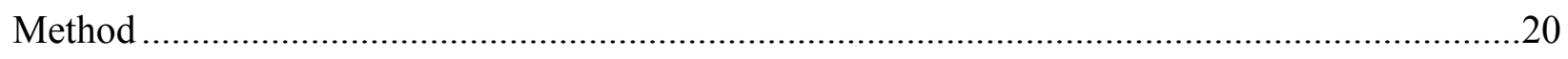

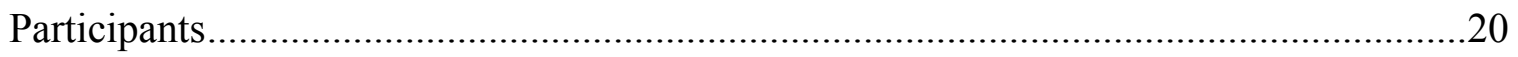

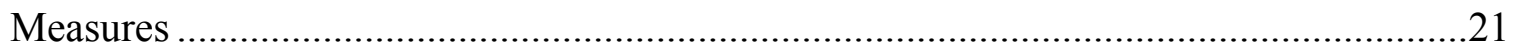

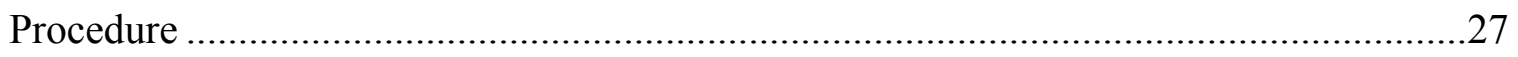

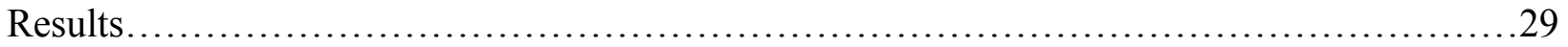


Data Screening Analyses

Site Differences

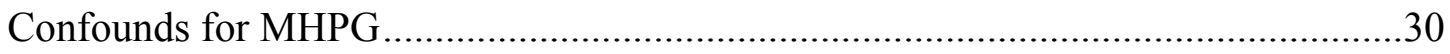

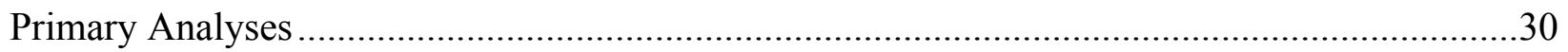

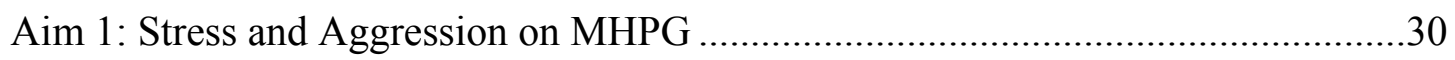

Aim 2: Hostile and Instrumental Aggression on MHPG ..............................................32

Aim 3: Rearing Environment and MHPG ……………….......................................33

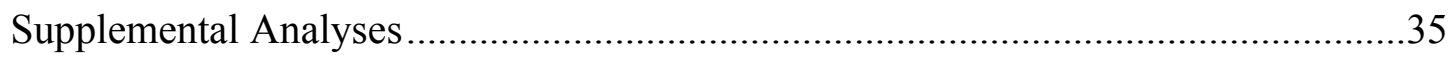

Aim 1 Supplementary Analyses: Stress and Aggression on MHPG and Mood....36

Aim 2 Supplementary Analyses: Hostile/Instrumental Aggression on MHPG and

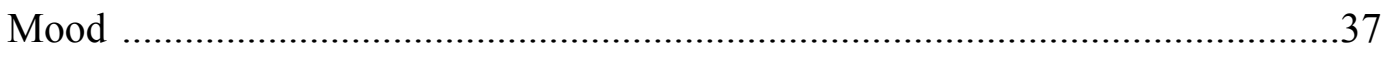

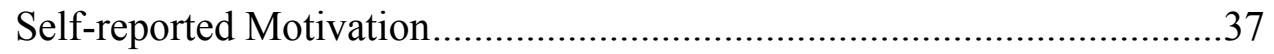

Degree of Hostile and Instrumental Aggression...........................................37

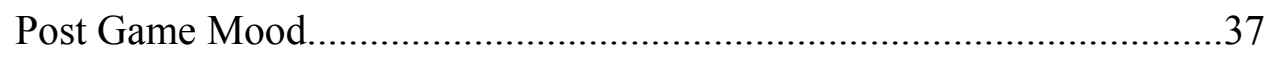

Aim 3 Supplemental Analyses: Rearing Environment and MHPG........................38

Rearing environment and post game levels of MHPG on self-reported

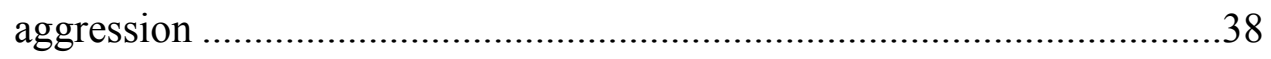

Witnessing and hearing about community violence on MHPG..................39

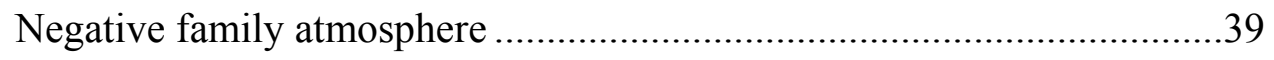

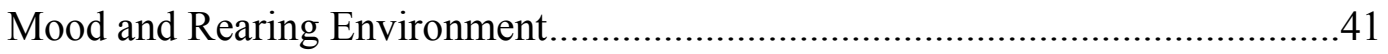




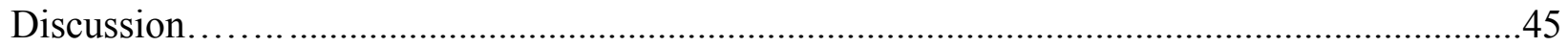

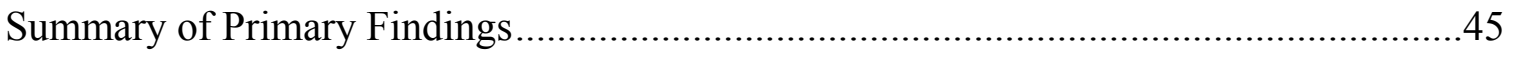

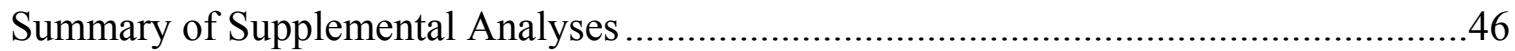

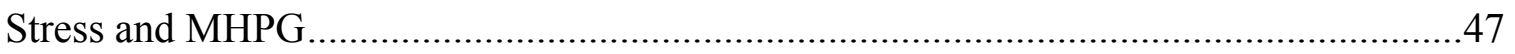

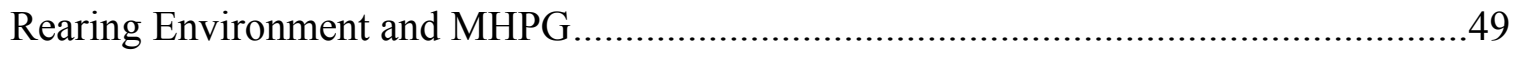

Community Violence Exposure and Negative Life Events..............................52

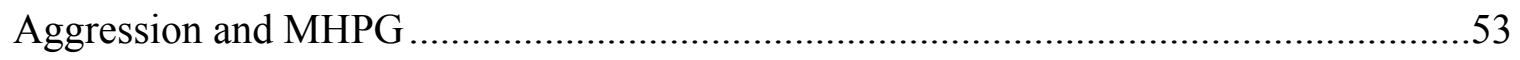

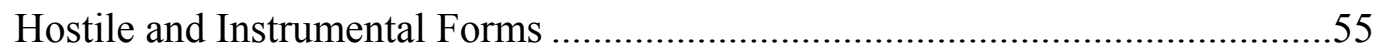

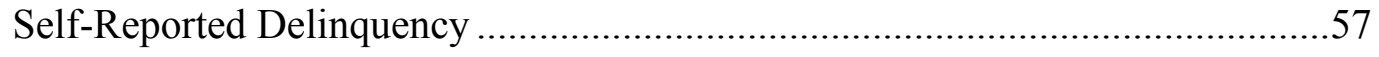

Rearing Environment, MHPG, and Aggression ...................................................58

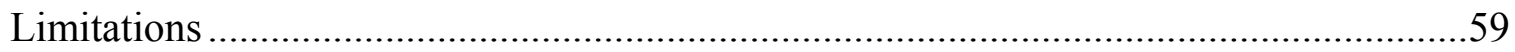

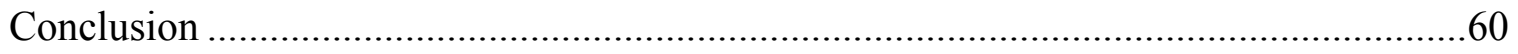

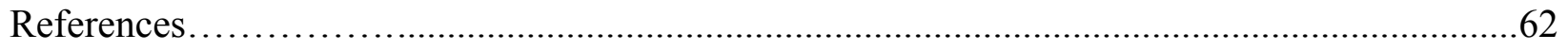

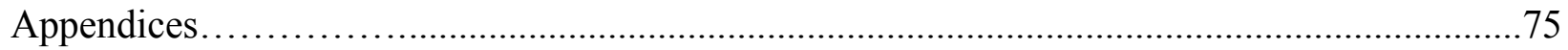

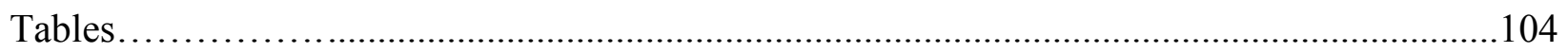

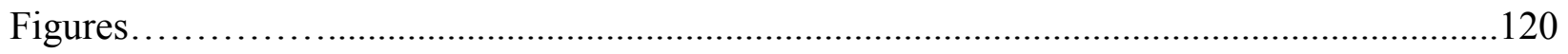

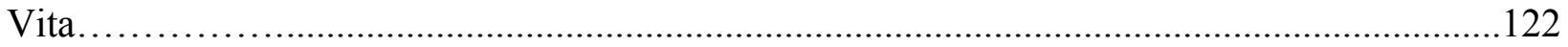




\section{List of Appendices}

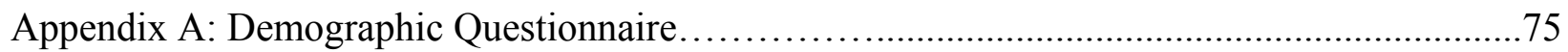

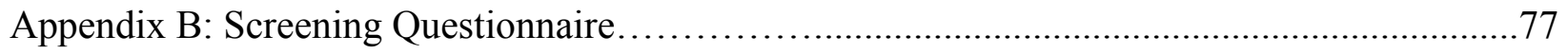

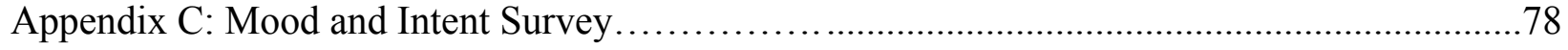

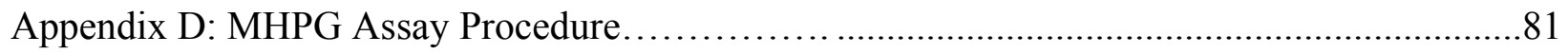

Appendix E: Self Behavior Rating Form................................................................. 83

Appendix F: Self Proactive and Reactive Aggression Scale.......................................84

Appendix G: Self Reported Delinquency Scale.................................................... 85

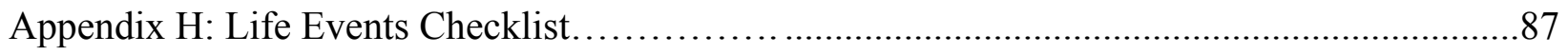

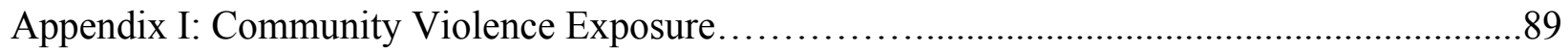

Appendix J: Parent Permission Form for Hunton..................................................93

Appendix K: Guardian Permission Form for Tekoa.........................................................98

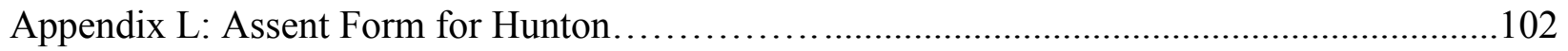

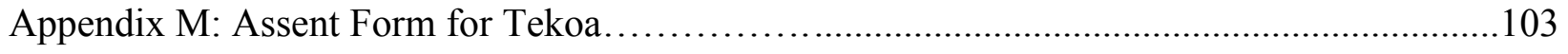




\section{List of Tables}

Table 1: Means (SD in Parentheses), F Values, and Significance Levels by Site.... .104

Table 2: Means (SD in Parentheses) for Mood Ratings Pre, During, and After Analog Aggression

Task

Table 3: Zero-order Correlations between MHPG and Self-Reported Aggression 108

Table 4: Means (SD in Parentheses) for MHPG Levels by Assigned Condition ... 109

Table 5: Zero-order Correlations between MHPG Levels, Self-Reported Aggression, and Rearing Environment Variables.

Table 6: Zero-order Correlations between Mood Ratings and Self-Reported Aggression

Table 7: Model Testing for Moderational Effects of Baseline MHPG on Negative Family Atmosphere and Total Aggression (PRA)

Table 8: Zero-order Correlations between Mood Ratings and Rearing Environment

Characteristics

Table 9: Zero order correlations between Self-Reported Delinquency, MHPG levels, and Rearing Environment 116

Table 10: Model Testing for Moderational Effects of Baseline MHPG on Physical Punishment and Self-Reported Delinquency.

Table 11: Model Testing for Moderational Effects of Post Levels of MHPG on Parental Rejection and Self-Reported Delinquency 
Table 12: Model Testing for Moderational Effects of Post Levels of MHPG on Physical

Punishment and Self-Reported Delinquency ...........................................119 
List of Figures

Figure 1: Proposed Model for Present Projection.........................................................120

Figure 2: Regression lines for High and Low Post 10 MHPG Concentrations on the Relationship between Parental Rejection and Self-Reported Delinquent Behaviors ................121 
Introduction

A recent report from the Bureau of Justice Statistics (BJS, 2003) estimated that over 60 violent crimes are committed daily. Adolescent and young adult antisocial behavior has been linked to aggression and noncompliance in school-age years (e.g., Loeber et al., 1993; Moffitt, 1990) so it is critical that the potential warning signs of subsequent violent behavior are clearly understood. To this end, the chief objective of the present research is to study the biological and psychosocial variables that are associated with aggressive behavior in children ${ }^{1}$.

\section{Models of Aggressive Behavior}

Various etiological models of violence propensity describe how biological and psychosocial factors influence emotion regulation leading to aggressive behavior. In Raine et al.'s Biosocial Model of Violence (1997), genetics and environment influence both biological and social risk factors of aggressive behavior. For example, a child's home environment, history of head injuries, socioeconomic status, hormonal/ neurochemical levels, and physiological arousal have been related to subsequent violent behavior. Moffitt's (1993) life-course-persistent model of antisocial behavior predicts continuous antisocial behavior by linking children's neuropsychological functioning with hostile environments across development. Neural developmental, temperament, parents' cognitive ability, and social/structural aspects of the home environment all impact the persistence of antisocial behaviors from childhood to adulthood.

Although these models highlight how different biological and environmental factors influence the development of aggressive behavior, these factors are generally depicted as having independent effects on violence propensity. To the author's knowledge, it is rare for researchers to focus solely on the intersection of these factors. However, Volavka's $(1999,2002)$ Intergenerational Model of Violence posits that one's propensity for aggressive behavior

\footnotetext{
${ }^{1}$ For simplicity, both children and adolescents will be referred to as children throughout the paper.
} 
depends strictly on the interaction between one's neurobiology and environment. Essentially children inherit a propensity for violence, and both pre and perinatal events interact with genetic factors to determine the likelihood that an individual will exhibit aggressive behavior (Volavka, 1999, 2002). Neurochemical traits, as well as rearing conditions, contribute to one's overall proclivity towards aggressive behavior. The intergenerational transmission model proposes interactions among many of the factors that previous social and biological literature has found to be predictive of aggressive behavior.

One of the main goals of the present research is to test such an interaction by exploring how environmental (i.e., childhood abuse, neglect, trauma) and biological (i.e., salivary metabolite of norepinephrine, 3-methoxy-4-hydroxyphenyglycol [MHPG]) factors influence expressions of aggression in youth. A model is proposed for the present study stemming from the work of Raine and colleagues (1997) and Volavka (2002). In general, it is proposed that stressful experiences and one's rearing environment impact noradrenergic functioning which is reciprocally related to expressions of aggression. Prior to detailing these particular variables and pathways, it is important to review how emotion regulation in children is related to the nature of aggressive behavior and how this particular biological system is relevant.

\section{Emotion Regulation, Aggressive Responses, and Psychobiological Correlates}

Dysregulated emotional responses are central to a child's expression of aggression.

Distinctions made among the types of aggressive behavior employed by children (hostile and instrumental) have been related to particular types of dysregulated responses (Vitiello \& Stoff, 1997). Hostile (or reactive) aggressive behavior is most often impulsive and characterized by intense anger. Oftentimes, children who employ this type of aggression are motivated by the desire to inflict harm rather than obtain some other goal. Children who display hostile 
aggressive behavior are characterized by decreased emotion regulation capacity, thus, an increased level of emotional problems, especially anxiety and depression (Dodge, Ziegler, Mills, Delehanty, \& Berry, 1997; Scarpa, Hirai, \& Hurley, 2002). Thus, hostile aggression might be considered an over-reactive emotional response. The instrumental (or proactive) subtype of aggression is not motivated by the desire to cause damage; rather, the aggressive behavior is used to achieve some other goal (i.e., obtain money or other necessity). The child is characterized by a relatively non-emotional display of aggression. A display of instrumental aggression may be considered an overly controlled dysregulated emotional response to a provocation. This type of aggression is associated with reductions in anxious arousal (Van Voorhees \& Scarpa, 2002). Similar distinctions regarding aggressive behavior have been made in the non-human animal research (Eichelman, 1987). As such, hostile and instrumental distinctions may quite possibly reflect two of the most fundamental forms of aggression in mammals. Although researchers have argued that this distinction is unnecessary and even prevents advances in the research on aggression (e.g., Bushman \& Anderson, 2001), important biological processes have been differentially associated with both forms, therefore, it is argued that the dichotomy is indeed useful and can aid in the development of future aggression-related research.

As with aggression in general, research on emotion regulation in young children has reported that both biological and behavioral processes influence their emotional reactivity to stimuli (Keenan, 2000; Vitiello \& Stoff, 1997). Regarding the biological processes, hostile aggression may be linked to increased autonomic responding, decreased serotonergic activity, and increased activity of the hypothalamic-pituitary-adrenal (HPA) axis, while the overly controlled regulation of emotions may be related to psychophysiological underarousal (Scarpa \& Raine, 1997; 2000). These findings have led to the conclusion that unique physiological and 
neurochemical mechanisms may similarly be related to different aggressive responses in humans. Regarding environmental influences, parental maltreatment, interadult violence, community violence victimization, and a general history of abuse have been found to be predictive of emotion dysregulation in children (Maughan \& Cicchetti, 2002; Schwartz \& Proctor, 2000; Shields \& Cicchetti, 2001). Specifically, physically abused impoverished, inner-city children were found to be at a greater risk for hostile aggression than non-abused impoverished inner-city children (Shields \& Cicchetti, 2001). Experiences with maladaptive parenting have been related to instrumental aggression in children and adolescents (Connor, Steingard, Cunningham, Anderson, \& Melloni, 2003). In female children, traumatic stress reported at an early age has also been correlated with instrumental aggression (Connor et al., 2003). Therefore, both environmental and biological factors seem to differentially impact the nature of aggressive responses employed by children.

Despite the different findings regarding the impact of biological and environmental factors on the nature of aggressive expressions, research has focused primarily on how these factors influence aggressive behavior in general. The present study examines how experiences in one's home environment, exposure to traumatic events and violence, and noradrenergic activation are associated with expressions of hostile and instrumental aggressive responses to stressors. In general, these factors have been found to be predictive of aggressive behavior (as described below). However, it is unclear how these factors impact the nature of aggressive expressions.

\section{The Noradrenergic System}

The noradrenergic system primarily influences an organism's arousal (Stanford, 2001). This involves the sleep/wake cycle, as well as an organism's ability to selectively attend to 
stimuli. Norepinephrine is created from specific amino acids that are prevalent in the human brain and blood plasma or obtained from the diet. The inactivation process for norepinephrine occurs in several ways. Some of the noradrenergic neurotransmitters are taken back into the cytosol of the neuron and brought into the vesicles for storage and future release (Webster, 2001). The majority of norepinephrine is catabolized into inactive compounds by an enzyme called monoamine oxidase (MAO) or catechol-O-methyl transferase (COMT) (Stanford, 2001). The inactive compounds resulting from norepinephrine's catabolism include 3-methoxy-4-hydroxyphenyglycol (MHPG) and vanillylmandelic acid (VMA, 3-methoxy-4-hydroxylmandelic acid). These metabolites can be measured in the cerebral spinal fluid (CSF), blood plasma, urine, and saliva. The activation of norepinephrine is the ratio of MHPG or VMA to norepinephrine (e.g., MHPG/NE) (Korzan, Summers, Ronan, Renner, \& Summers, 2001). High activation implies higher levels of MHPG than norepinephrine since noradrenergic receptors are being activated at a high rate. Basically, the catabolism turnover rate of norepinephrine into its metabolites is faster.

\section{Complexity of the Noradrenergic System}

The noradrenergic system is indeed complex as it involves the interaction of a variety of receptors, whose functions are not entirely clear. The role of noradrenergic synaptic receptors is to recognize NE and activate its' dependent ions. Specific presynaptic neurons release NE which then binds to a postsynaptic neuron's receptor and permits an ion channel to open, thus releasing specific ions into or out of the postsynaptic cell (Carlson, 2001). The postsynaptic receptor on the cell must recognize NE and then consequently alters the biochemical state of the postsynaptic cell in which it is a part of (Kandel, 1991). Therefore, the function of NE depends on the type of receptor on which it binds. This receptor can have 
either an excitatory or inhibitory effect on its cell. Two main classes of noradrenergic receptors that have been discovered thus far include the $\alpha$-type (with $\alpha_{1}\left[\alpha_{1 \mathrm{~A}}, \alpha_{1 \mathrm{~B}}, \alpha_{1 \mathrm{D}}\right]$ and $\alpha_{2}\left[\alpha_{2 \mathrm{~A} / \mathrm{D}}, \alpha_{2 \mathrm{~B}}, \alpha_{2 \mathrm{C}}\right]$ subtypes) and $\beta$-type (with $\beta_{1}, \beta_{2}$, and $\beta_{3}$ subtypes). Research regarding the action of these receptors is conflicting. While it has been proposed that the $\alpha$ - or $\beta$-type receptors are generally excitatory (Stanford, 2001), a number of subtypes have been reported to be inhibitory including the $\alpha_{2}$ subtype (Minneman, 1981) and $\alpha_{2 \mathrm{~A} / \mathrm{D}}$ (Stanford, 2001). Moreover, some receptors are found on both pre- and postsynaptic cells therefore, making its action even more complicated.

These complexities certainly have implications for behavior. For example, Pohl and colleagues (1990) found that panic symptoms were mediated by the $\beta$-type receptors. A variant of the $\beta_{2}$-type receptor has been implicated in hypertension in certain cultures (Kotanko et al., 1997). A decreased affinity of $\alpha_{2}$ type receptors to bind with noradrenergic agonists have been reported in patients with generalized anxiety disorder (e.g., Cameron et al., 1990); however, more binding sites for agonists were found in these receptors for patients diagnosed with obsessive compulsive disorder (Lee et al., 1990).

The functional anatomy of the noradrenergic system is also intricate. Compared to other catecholaminergic systems that are more localized and have restricted distributions, the noradrenergic system has considerably more wide-spread projections throughout the central (CNS) and peripheral nervous systems (PNS) (Glover, 1994). Concentrations of norepinephrine can be found throughout the brain. Noradrenergic cell bodies are in the CNS and most are located in the reticular formation of the pons and medulla $\left(\alpha_{1}, \alpha_{2}, \beta_{1}\right.$, and $\beta_{2}$-type of receptors) and hypothalamus ( $\beta_{3}$ receptors) (Giacobino, 1995). The locus coeruleus holds most of these cell bodies from which the majority of noradrenergic pathways originate from traveling to both the cortex and cerebellum. The locus coeruleus controls projections to the frontal cortex, hippocampus, and olfactory bulb. The brainstem nucleus also sends extensive projections throughout the nervous system and is considered the primary source of 
noradrenergic innervation of the forebrain, while the lateral tegmentum storage area projects to the lower brainstem and dorsal medulla (Berridge \& Waterhouse, 2003; Deutch \& Roth, 1999). Lesions in the nucleus locus coeruleus of nonhuman primates result in heightened norepinephrine turnover in the hypothalamus and amygdala which has implications for psychological stress responses in humans (Redmond \& Huang, 1979). Intense stressors such as footshock actually increase the release of NE from the locus coeruleus within seconds of administering the stress. NE is then projected to the hypothalamus, cerebral cortex, and hippocampus to initiate the stress response which is found to precipitate, and possibly aggravate, mental symptoms (Svensson, 1987). The biological changes accompanying the NE projections characterize the fight-or-flight response (De Bellis \& Putnam, 1994). This activation is also accompanied by other changes including increases in the turnover of other catecholamines, sympathetic nervous system, and the adrenal medulla secreting cortisol and epinephrine. The organism's heart rate, blood pressure, and metabolic rate are elevated due to this activity. Structurally, the locus coeruleus stimulates the amygdala (regulating emotion and anxiety) which then stimulates the hypothalamus releasing corticotrpin-releasing hormone (CRH). This, in turn, leads to the secretion of other hormones and neurotransmitters eventually guiding heightened attention and cognitive processes required to cope with the perceived stressor.

Norepinephrine is not only used at CNS synapses. It can also be found in the PNS and, in particular, is released by postganglionic neurons of the sympathetic branch of the autonomic nervous system (Stern, Ray, \& Quigley, 2001). Acetylcholine released from preganglionic neurons helps to stimulate action potentials in the postganglionic neurons to release NE onto target organs, muscles, and glands (with the exception of sweat glands where acetylcholine is the neurotransmitter released). The action of NE can be either excitatory or inhibitory in this system as well. For example, excitatory actions include: stimulation of heart rate, rises in blood pressure, dilation of the pupils, trachea, and bronchi, and stimulation of liver 
glycogenolisis. Inhibitory actions include slowing down peristalsis of the gastrointestinal tract as well as bladder and rectum contractions.

For the present study, it is important to note racial effects that have been examined in relation to catecholamine levels. Findings have been mixed, so there is no definitive conclusion regarding race differences in catecholamine levels presently. Dimsdale and colleagues (1990) found no differences in plasma concentrations of NE in white and black hyper- and normotensive men. Rowlands et al. (1982) also found that resting plasma NE levels were similar for untreated black and white mild- and hypertension patients. More recently, levels of plasma catecholamines before and after acute stress tasks were found to be similar for black and white men and women (Gillan et al., 1996). However, in a study of children aged 10 to 17 years of hypertensive parents, post exercise plasma levels of NE were lower for black children than for white children (Hohn et al., 1983). Arguably, the lack of consistent findings regarding race differences in catecholamines may be due to the lack of its systematic measurement and comparisons across different types of samples.

\section{3-methoxy-4-hydroxy-phenylglycol (MHPG)}

In the present study, measures of a metabolite of NE, MHPG, are taken. MHPG has been used as a measure of noradrenergic activation in various studies. For example, panic patients showed greater declines in MHPG following administration of an antagonist than control subjects (Abelson \& Cameron, 1994). The present study employed salivary measures of MHPG. This is a recent way of determining central NE levels via a non-invasive procedure, especially in studies involving children. Salivary MHPG has been found to be highly correlated with plasma MHPG ( $r=.46$, Drebing, Freedman, Waldo, \& Gerhardt, 1989) as well as CSF MHPG ( $r=.76$, Reuster, Rilke, \& Oehler, 2002). Salivary concentrations of VMA, another metabolite of NE, have not been significantly correlated to these measures. The rationale for using salivary MHPG is that it actually reflects both plasma MHPG levels 
(which the brain contributes 30\% towards, Kopin et al., 1984) as well as local MHPG synthesis. Saliva itself is partially derived from blood and, therefore, saliva is related to plasma (Drebing et al., 1989). Salivary measures of MHPG are considered valuable in detecting pathological anxiety (Yamada et al., 2000) and as adequate markers for testing improvement in mental status after administering a noradrenergic agonist (Reuster, Buechler, Winiecki, \& Oehler, 2003). In fact, salivary MHPG in college students has been found to increase in response to stress prior to taking an academic exam (McClelland, Ross, \& Patel, 1985). This increase was also related to increased anxiety and depressed immune functioning. In general, salivary MHPG may provide a satisfactory non-invasive measure of central noradrenergic functioning.

\section{The Proposed Model}

The present project focused on relationships between stress, rearing environment factors, MHPG levels, and aggression. The proposed model (see Figure 1) illustrates the predicted significant relationships that will be tested: 1) Stressful provocations will impact the noradrenergic system resulting in higher levels of MHPG. 2) Characteristics of the rearing environment will have a significant impact on this system. Specifically, more physical abuse/punishment in the rearing environment will increase MHPG, while more neglect/parent rejection will decrease MHPG. 3) Expressing aggression will lower MHPG and high MHPG will increase aggressive expressions. Moreover, significant relationships between MHPG and degrees of hostile and instrumental aggression are predicted. In particular, it is presumed that more hostile, over-reactive, forms of aggression would be linked with higher MHPG while more instrumental, over-controlled, forms would be associated with lower MHPG. Evidence for these three relationships will now be explored. 
Exposure to Stressors and Norepinephrine

Norepinephrine is necessary for maintaining the alert waking state of organisms and responding to stressors (i.e., seeing a rival, experiencing a traumatic event) (Berridge \& Waterhouse, 2003). The entire catecholaminergic system (norepinephrine, dopamine, and epinephrine) is among the fastest neurochemical systems to react (Haller, Makara, \& Kruk, 1998). Research has also shown that the levels of norepinephrine increase when an organism is exposed to noise, new events, or the sight of a rival (Haller \& Barna, 1995). Overall, norepinephrine plays an important role in an organism's ability to collect and process information that is most significant or relevant to its well-being. Therefore, an increase in noradrenergic activation is generally found in response to stressful provocations (reviewed by Charney, Deutch, Krystal, Southwick, \& Davis, 1993). In fact, direct and indirect activation of the sympathetic nervous system leads to increases in central and peripheral catecholaminergic turnover. It is important to review how psychological stress induced in the lab for human animals is also related to noradrenergic responses.

Psychological stress in humans activates catecholamine release (Nelesen \& Ziegler, 1994). An increase in catecholamines (as well as adrenocorticotropic hormone and cortisol) in response to stress is considered a coping strategy involving HPA axis activation and sympathetic system reaction (Gerra et al., 1997). These catecholaminergic changes are reflected in both the central and peripheral nervous systems (Abercrombie \& Zigmond, 1995). Stress induced in lab experiments has been found to impact this system. For example, asking research participants to perform mental arithmetic resulted in immediate increases in plasma NE for diagnosis-free individuals as well as those diagnosed with schizophrenia, anxiety, and depression disorders (Albus, Müller-Spahn, Ackenheil, \& Engel, 
1987). These increases were pronounced in response to this stressor task as opposed exposure to $95 \mathrm{~dB}$ noise tones. Recently, it was shown that mild psychological stress induced by a competitive video game (participants were asked to kill as many enemies as possibly before being killed) resulted in high $\alpha$-amylase concentrations (a correlate of plasma catecholamines, $r=.64$ ) in the saliva immediately after, as well as 20 minutes after playing (Skosnik, Chatterton, Jr., Swisher, \& Park, 2000).

An interesting pair of studies conducted by Fukuda and colleagues (1996) examined plasma MHPG in relation to self-reported psychological stress on the Psychological Stress Response Scale. Although they found that plasma MHPG was unrelated to perceived psychological stress in their cross-sectional study, in the single case longitudinal study of a college female Olympic swimmer, plasma MHPG was significantly correlated with psychological stress. The authors argued that in the latter study, the stress due to competing was more pronounced and thus resulted in higher levels of this metabolite.

\section{Rearing Environment and Norepinephrine}

In general, the noradrenergic system is involved with how a child regulates his/her experience with the environment. Therefore, it is no doubt that intense stressors such as community violence, familial abuse, and trauma impact this system. In fact, psychological trauma experienced during the early years of life may result in (permanent) alterations of behavioral and neurochemical responsiveness (Cicchetti, 2003; Rogeness \& McClure, 1996). However, it seems that noradrenergic functioning depends on the type of early traumatic experiences. Essentially, children who experience familial abuse and/or frequent "active" traumas (e.g., sexual abuse), tend to have a more active noradrenergic system than children who 
do not experience such events. On the other hand, children who report neglect in their home environment, tend to have lower activation of this system than non-neglected children.

Regarding increases in noradrenergic activation, baseline levels of catecholamines tend to be high in traumatized children (De Bellis \& Putnam, 1994). In particular, De Bellis and his colleagues (1994) found that sexually abused girls excreted significantly greater amounts of NE and MHPG in urine than a control group of girls. In a more recent study, children who 1) experienced physical/sexual abuse or witnessed domestic violence, 2) experienced severe maltreatment per Child Protective Services, and 3) met the Diagnostic Statistical Manual for Mental Disorders (DSM-IV, APA, 2000) posttraumatic stress disorder (PTSD) criteria excreted significantly greater urinary levels of norepinephrine concentrations than a group of healthy controls (De Bellis et al., 1999). Moreover, levels were positively correlated with the duration of the maltreatment. In general, children who have experienced traumas and those meeting DSMIV criteria for post-traumatic stress disorder have abnormally high levels of NE/MHPG suggesting chronic hyperarousal.

The impact of childhood neglect on the noradrenergic system is different from that of childhood abuse/trauma. Childhood neglect generally involves less "active" trauma in that the child is generally not attended to and provided for. This is differentiated from abuse since, in the latter, the child is not deprived of attention per say, albeit, the attention in the form of abuse is no doubt maladaptive and detrimental to any child. Rogeness and colleagues $(1989,1990,1991)$ have conducted a series of studies examining how the noradrenergic system is influenced by environmental stressors. In general, they have found that children with a history of neglect, as opposed to only abuse or neglect and abuse, show low noradrenergic activation. In particular, in a group of neglected boys, 24 hour urinary levels of norepinephrine were lower than that of a 
group of boys without a history of neglect (Rogeness, 1991). In fact, the effect of neglect on noradrenergic functioning was stronger than that of abuse (Rogeness, Amrung, Macedo, Harris, \& Fischer, 1986). In accordance with Kraemer's (1992) theory of maternal attachment and noradrenergic functioning, maternal deprivation was found to predict difficulties with future social separation situations as well as the dysregulation of biogenic amine systems, especially norepinephrine.

These studies provide support for the notion that a child's exposure to traumatic events and violence, experience with childhood abuse, and neglect impact noradrenergic activation. The present study seeks to replicate these findings by examining the effects of physical punishment and parental rejection, and their effects on the expression of aggressive behavior in children.

Aggression and Norepinephrine

Most often, reviews of the neurochemical correlates of aggressive behavior describe a positive relationship between levels of norepinephrine and aggression (e.g., Coccaro \& Kavoussi, 1996; Kavoussi, Armstead, \& Coccaro, 1997; Raine, 1993; Volavka 1997, 1999, 2001). A series of studies conducted by Gerra and his colleagues $(1997,1999,2001)$ support this conclusion. In their analog aggression experiments, participants compete in a free-operant game such that they earn money by pressing a button and are subsequently provoked by the subtraction of money attributed to a fictitious competitor. Aggressive behavior in response to the provocation and levels of plasma NE are measured. Participants rated as aggressive on selfreport measures tended to have increased levels of plasma NE and more severe aggressive responses to provocations. Pharmacological studies have also reported that noradrenergic antagonists are beneficial in decreasing violent outbursts in multiple patient populations (e.g., Silver et al., 1999). Observation and self-report measures of aggression have also found a 
positive relationship with levels of norepinephrine (e.g., Brown, Goodwin, Ballenger, \& Goyer, 1981; Placidi et al., 2001).

Although past research regarding the relationship between norepinephrine and aggression is informative, many questions remain unanswered. First, it is unclear whether elevations in norepinephrine can be attributed to generic stressful experiences or the actual aggressive response. Research using non-human animals has been able to differentiate between noradrenergic activation in response to the stressful experience and as a symptom of the aggressive behavior. Tsuda et al. (1988) along with Tanaka, Yoshida, Tomita, \& Tanaka (1998) conducted experiments with rats such that the effect of aggressive behavior upon the activation of norepinephrine was isolated from that of the stressor. In one study, half of the rats were only subjected to restraint stress (immobilizing rats in the supine position for a period of ten minutes), while the other half were jabbed at with a stick and able to express their aggression by biting it (Tsuda et al., 1988). Immediately upon the rats' release, both groups showed similar levels of MHPG; however, when measured fifty minutes post-stress, MHPG and norepinephrine levels were significantly lower for biters than the non-biters. In a similar study, rats were subjected to a cold restraint stress (restricting rats in a box filled with shaved ice) for a period of one hour and half were given the opportunity to express aggression by biting a stick (Tanaka et al., 1998). Both biters and non-biters showed increases in extracellular noradrenergic levels following the stress. However, the elevation of amygdalar norepinephrine in the non-biting group remained significantly higher than the biting group throughout the stressor and over an hour after its termination. Moreover, norepinephrine levels of the biting group, unlike the non-biting group, returned to basal levels immediately following the cessation of stress and expression of aggression. It is argued that the expression of aggression during stress exposure attenuated the increase of noradrenergic activation. It seems that engaging in aggressive behavior might decrease the activation of norepinephrine caused by a stressful experience. It may also be the case that humans' expressions of aggression may be an attempt at self regulating and thereby an effort to reduce the stressful experience. To the author's knowledge, experiments involving 
isolating the impact of aggressive behavior on noradrenergic levels from the impact of stress have not been conducted using human samples. Although it would be highly unethical to subject humans to similar experimental designs, it is possible to stress humans using suitable laboratory paradigms and only give half of the sample an opportunity to respond to the experience aggressively.

Second, to the author's knowledge, research regarding the noradrenergic correlates to aggressive behavior has failed to differentiate between hostile and instrumental expressions of aggression. Although, Bushman and Anderson (2001) argue that this dichotomous view of aggression is limited, given the physiological and biological differences related to degrees of these to forms, it would be worthwhile to understand how they are linked to noradrenergic activation. In general, it is believed that data have supported a stronger relationship between certain biological factors and the hostile, rather than the instrumental, subtype of aggression (Coccaro \& McNamee, 1998). However, this may be due to the focus on more hostile aggressive behaviors. For example, many studies evaluating the link between neurochemical and aggressive behavior use violent patient samples (Brown et al., 1981). In these cases, aggression is measured by physical fights with staff and other hospital members, as well as other more of hostile forms of aggression. Pharmacological studies generally examine the effects of noradrenergic antagonists on overt reactive aggression in patients (e.g., Yudofsky, Williams, \& Gorman, 1981). Research regarding the relationship between noradrenergic activation and aggressive behavior may be more informative if the nature of the aggressive behavior was considered.

Third, the environmental impact on the noradrenergic system, as well as the aggressive behavior, has not been studied in relation to the norepinephrine-aggression connection. In general, studies have only reported on this relationship and have not included data regarding any environmental factors that might influence noradrenergic activation and the expression of aggression.

\section{Present Study}


The major purpose of the present study is to extend the research regarding the psychobiological correlates of aggressive responses in children by examining the impact of the noradrenergic functioning, traumatic experiences, childhood abuse, and childhood neglect on responses to stress. Specifically, the three objectives are to: 1) focus on separating the stress and aggressive response to understand their relationship with MHPG, 2) explore how hostile and instrumental aggression are related to stress and MHPG, and 3) evaluate how rearing environment impacts MHPG and its relationship with aggression.

Children participated in an analog aggression task in which some participants had the opportunity to respond aggressively to stressful provocations they experienced during the task. Salivary MHPG was collected before and several times after the task. Self-report measures of aggressive behaviors, rearing environment, community violence exposure, and negative life events were also gathered. By gathering behavioral, neurochemical, and self-report measures, the present study addresses these specific research questions and tests their respective hypotheses:

\section{Aim 1: Stress and Aggression on $M H P G$}

The primary aim of the project is to evaluate the independent effects of stress and aggressive expressions on noradrenergic functioning. In order to test this, the author will test the following hypothesis:

\section{What is the relationship between self-reported general aggressive behavior and} salivary MHPG? Although previous research has not examined salivary measures, it has been found that CSF, plasma, and urinary norepinephrine is positively related to self-reported aggression (e.g., Brown et al., 1981; Gerra et al., 1997; Placidi et al., 
2001), it is predicted that there will be a positive relationship between general aggressive behavior and salivary measures.

2. How is salivary MHPG associated with stressful experiences in youth? Consistent with previous research using urinary, plasma, and CSF measures of norepinephrine and MHPG (Berridge \& Waterhouse, 2003; Charney et al., 1993), it is hypothesized that there will be increases in levels of salivary MHPG when children experience a mild laboratory stressor.

3. Are there differences in salivary levels of MHPG between the stress-only and expressed-aggression groups? Consistent with the non-human animal research, it is hypothesized that both groups will have an increase in salivary MHPG shortly after the task; however, it is predicted that the levels for the stress-only group will decrease at a slower rate than those given the opportunity to express their aggression, such that post measures of salivary MHPG will be higher from the stress-only group than the expressed-aggression group.

Aim 2: Hostile and Instrumental Aggression on $M H P G$

The second aim of the project explores how hostile and instrumental expressions of aggression are related to noradrenergic functioning and the following research question and respective hypothesis is addressed:

1. Is there a difference in salivary MHPG levels based on a) type of aggression expressed in response to stress and b)degree of self-reported hostile and instrumental aggression? Since hostile aggression is generally considered an overly emotional response accompanied by high physiological arousal (Scarpa \& Raine, 2000), it is predicted that children who engage in and report more hostile aggressive responses to 
stress will have higher salivary levels than those engaging in and reporting instrumental aggressive responses.

\section{Aim 3: Rearing Environment and $M H P G$}

The third aim of the project is to evaluate how aspects of the rearing environment are related to baseline MHPG and aggression. The following research questions and hypotheses are proposed:

1. How does the child's home environment influence baseline levels of salivary MHPG? Consistent with previous research, it is hypothesized that children who report more physical punishment in their home will have higher levels than those not reporting abuse (De Bellis et al., 1994). In addition, children who report parental rejection will have lower levels of salivary MHPG than those children not reporting rejection (Rogeness, 1991).

2. What is the relationship between traumatic/violent experiences and baseline salivary levels? Consistent with previous research, it is hypothesized that a positive relationship exists between negative experiences or direct exposure to victimization in the child's community and salivary MHPG (De Bellis et al., 1994).

3. Is there an interaction between home environment and salivary MHPG levels that influences the nature of aggressive behavior? In particular, do children who have been abused or neglected in their families respond differently to stressful provocations based on their baseline salivary MHPG levels? Since the home environment is not an independent predictor of aggressive behavior (Raine et al., 1997; Volavka, 2002), it is hypothesized that salivary MHPG levels will impact the home environment-aggressive behavior relationship. In particular, since 
noradrenergic activation is a response to stress, it is hypothesized that the relationship between family environment and overall aggressive behavior will be strongest when children have high concentrations of baseline salivary MHPG. 
Psychobiological Mechanisms 20

\section{Method}

\section{Participants}

The sample consisted of 68 youth recruited from two primary sites, Hunton Inc. $(N=54)$ and Tekoa Inc. $(N=14)$. Hunton Inc. is a community service organization for local disadvantaged youth in Lynchburg, Va. Parent permission was obtained prior to recruiting youth from this site (Appendix $\mathrm{J}$ or $\mathrm{K}$ ). Tekoa Inc. is a residential treatment center for youth in the New River Valley community. Youth from Tekoa Inc. were in custody of the Department of Social Services. Therefore, social worker permission was obtained prior to recruiting children from this site (Appendix L or M). Descriptive information for all the measures in this sample can be found in Table 1.

The sample ranged in age from 7 to 17 years $(M=12.57, S D=2.46)$. It was comprised of primarily Black youth $(N=54,79.6 \%)$, followed by 12 White participants $(17.6 \%)$ and 2 Hispanic youth (2.9\%). All of the Black participants were recruited from Hunton Inc., while the White and Hispanic youth were recruited from Tekoa Inc. All of the children attended school at the time of testing with current grades ranging from $2^{\text {nd }}$ to $12^{\text {th }}$. The majority were in $6^{\text {th }}$ grade $(N=17,25 \%)$, followed by $5^{\text {th }}, 9$ th, and $10^{\text {th }}(N=8$ for each, $35.4 \%), 7^{\text {th }}$ and $8^{\text {th }}(N=6$ for each, $17.6 \%), 3^{\text {rd }}$ and $4^{\text {th }}(N=4$ for each, $11.8 \%), 11^{\text {th }}(N=3,4.4 \%)$, and the $2^{\text {nd }}$ and $12^{\text {th }}$ grades $(N=2$ for each, 5.8\%).

The majority of the sample reported that their primary parent was their biological mother $(N=55,80.9 \%)$, followed by biological father or grandmother ( $N=4$ each, $11.8 \%)$, grandmother, aunt $(N=3,4.4 \%)$, and foster mother $(N=2,2.9 \%)$. Of those living with their biological mothers, 13 also reported living with their biological father, 10 with their step fathers, 4 also with grandmother, 2 with their uncles, and 1 also living with their foster father. Of those who 
identified a mother figure, $51(75 \%)$ reported that she had a job, while of those who reported a father figure, $42(63.6 \%)$ reported that he had a job.

Participants were randomly assigned by the computer to either the stress-only $(N=29$, $45.3 \%)$ or expressed aggression groups $(\mathrm{N}=37,56.1)$, including the hostile $(N=19,28.8 \%)$ or instrumental $(N=18,27.3 \%)$ groups. Two of the participants withdrew from the study prior to assignment of groups.

Measures

Demographic Questionnaire (Appendix A). Participants were asked questions regarding their background including age, education, family's socioeconomic status, etc. described above.

Screening Questionnaire (Appendix B). Participants were asked about their recent habits such as sleep, food/drinks consumed, etc. that may interfere with salivary measures of norepinephrine.

Hostile and Instrumental Aggressive Responses. Participants were asked to play a computerized game (The Key Game) designed by the researcher. The goal of the game was to earn money by tapping the spacebar key faster than a fictional "opponent" over the internet. The game was piloted with a subset of participants and was considered a stressful task for the participants. They were instructed that the first participant (either themselves or their "opponent") to win five trials would be able to either send blasts of noise or take away their “opponent's" winnings. However, participants were only able to win four trials. The game consisted of 20 trials and every participant won money during the first several trials (Trials 1, 3, 4, and 5), lost Trial 2 and consequently lost all the money during remaining trials. Thus, the “opponent" took away the participant's winnings in addition to sending blasts of noise through a speaker. This served as a stressor for the participant. 
At the end of the game, each participant was told that the opponent had won. Based on random assignment by the computer game, $56.1 \%(N=35)$ of the participants had the opportunity to respond aggressively to the "opponent" as described below while viewing the winning opponent's next game with another player (Expressed Aggression group). The remaining 43.9\% of participants did not have an opportunity to respond aggressively to their "opponent," and thus did not have the opportunity to retaliate (Stress Only group, $N=29$ ). Of the Expressed Aggression group, participants were randomly assigned to either send blasts of noise while viewing the next game (Expressed Hostile Aggression group, 51.4\%, $N=17$ ) or take away their “opponent's” winnings (Expressed Instrumental Aggression group, 48.6\%, $N=18$ ). The Expressed Hostile Aggression group sent a mean of $29.35(S D=30.82)$ blasts, ranging from 0 to 112 blasts. The Expressed Instrumental Aggression group took an average of $\$ 16.73$ $(S D=14.63)$, ranging from $\$ 0$ to $\$ 50$.

Mood and Intent Surveys (Appendix C). All of the participants answered a survey regarding how they felt before, during, and after the task. The majority of participants answered 'yes' that they liked the game $(N=51,75 \%)$. Moreover, participants indicated significant changes in their mood using a scale ranging from 0 ("not much at all") to 4 ("very very much") for the various moods (i.e., frustrated, angry, nervous, bored, excited, happy, sad) (see Table 2). In particular, they reported feeling more nervous prior to the game than afterwards $(t(66)=2.68$, $p=.01)$. During the game, they reported feeling more frustrated $(t(66)=-6.71, p<.01)$, angry $(t(66)=-4.77, p<.01)$, and excited $(t(66)=-2.47, p=.02)$ than prior to the game. They also felt more frustrated $(t(66)=-3.97, p<.01)$ and angry $(t(66)=-3.26, p<.01)$ after the game than beforehand. After the game, they reported feeling less frustrated $(t(66)=2.74, p=.01)$, angry 
$(t(66)=2.24, p=.03)$, nervous $(t(66)=2.49, p=.02)$, and excited $(t(66)=3.06, p<.01)$ than during the game.

To assess attributions of intent, the participants were also asked what they believed motivated their opponent to remove points or blast them with noise throughout the game. The majority attributed instrumental motives to the "opponent" taking their money away $(N=48$, $71.6 \%)$ and sending them blasts of noise $(N=42,62.7 \%)$. For example, one child stated that "he wanted to make money," while another child attributed to noise blasts to "wanting to beat me and make money." Similarly, those in the Expressed Aggression group were asked motives for their own behavior during and after the game. Responses were coded as hostile if the response indicated a malicious, vindictive, or primarily penalizing purpose. Responses were coded as instrumental if the child indicated a purposeful, goal-directed reason including trying to win the game. In both the Expressed Hostile and Instrumental Aggression groups, participants' reasons for taking money away from the "opponent" and sending noise to the "opponent" tended to be characterized by instrumental aggression $(N=10,58.8 \%$ and $N=11,55 \%$, respectively). For example, many participants reported taking money away or sending blasts of noise to make the "opponent" lose because the "opponent" beat the participant.

Salivary Noradrenergic Functioning (Appendix D). Salivary measures of a metabolite of norepinephrine, 3-methoxy-4-hydroxyphenyglycol (MHPG), were taken prior to the beginning of the game (baseline), directly after the game (post), as well as 10 (10 post) and 40 (40 post) minutes after the game had ended. The participant was asked to soak a piece of gauze in his mouth for 60 seconds, which he then placed in a test tube. Levels of MHPG were recorded across the four times. Saliva samples were stored in a freezer at 0 degrees Fahrenheit immediately upon collection of all four samples. Approximately 500 micro liters of saliva were 
extracted and analyzed with high performance liquid chromatography using electrochemical detection (HPLC-ECD). The assay method used was developed at the toxicology lab of the Virginia-Maryland Regional College of Veterinary Medicine (see Appendix D). Each sample was calculated using the same method and was read off identical standard curves.

Concentrations of MHPG were measured in moles per liters (mol/L). Baseline levels ranged from 7.7E-09 to $8.8 \mathrm{E}-08 \mathrm{~mol} / \mathrm{L}(M=3.6 \mathrm{E}-08, S D=1.83 \mathrm{E}-08)$. Post game MHPG levels ranged from 2.1E-09 to $7.9 \mathrm{E}-08 \mathrm{~mol} / \mathrm{L}(M=3.6 \mathrm{E}-08, S D=1.8 \mathrm{E}-08)$. Post $10 \mathrm{MHPG}$ levels ranged from 3.6E-09 to $8.5 \mathrm{E}-08 \mathrm{~mol} / \mathrm{L}(M=3.2 \mathrm{E}-08, S D=1.6 \mathrm{E}-08)$. Post 40 MHPG levels ranged from 1.5E09 to $6.2 \mathrm{E}-08 \mathrm{~mol} / \mathrm{L}(M=3.0 \mathrm{E}-08, S D=1.37 \mathrm{E}-08)$.

Self Behavior Rating Form (SBR; Appendix E). Participants were asked to complete the SBR to assess for the presence of hostile and instrumental aggression (Brown, Atkins, Osbourne, \& Milnanow, 1996). This is a modified version of the original scale that was validated by teachers. The child reported on his own behavior and indicated how often $(1=$ never, $2=$ sometimes, $3=$ very often) he shows each behavior (e.g., "does sneaky things," "fights with other children for no good reason"). A separate sum for overall, hostile, and instrumental aggressive behavior was calculated. The Hostile scale consisted of 6 items and demonstrated good reliability (Cronbach alpha=.78). Scores ranged from 5 to $17(M=9.06, S D=2.46)$. The Instrumental scale consisted of 10 items and demonstrated good reliability (Cronbach alpha=.68). Scores ranged from 10 to $23(M=14.02, S D=3.20)$. The overall aggression score was the sum of all the hostile and instrumental items and ranged from 16 to $40(M=23.07$, $S D=5.19)$, with a Cronbach alpha of .78.

Self Proactive and Reactive Aggression Scale (PRA-Self, Appendix F). The PRA-Self is an alternative measure of emotional/hostile (i.e. reactive) and instrumental (i.e., proactive) 
aggression used, consisting of 3 items each (Dodge, 2003). The participant responded to each item on a 5 point scale depending on the extent to which the statement applies ranging from 1 ('never true') to 5 ('almost always true'). Separate sums were computed for overall, hostile, and instrumental aggression. The Hostile scale ranged from 3 to $14(M=7.81, S D=2.92)$ with an internal consistency of .43 . The Instrumental scale ranged from 3 to $11(M=4.44, S D=2.22)$ with an internal consistency of .68. The overall aggression scores ranged from 6 to $21(M=12.27$, $S D=4.38)$ with an internal consistency of .60 .

Assessing Environments III (AEQIII). In order to measure the participant's experience with childhood rejection and abuse in the family, participants were asked to complete three scales from the Assessing Environments III (Berger, Knutson, Mehm, \& Perkins, 1984): Feeling of Parental Rejection with 7 items (e.g., "I think my mother has a good attitude toward me. [reversed]"), Physical Punishment with 12 items, (e.g., "I was physically abused by my parents when I was a child.”) and Negative Family Atmosphere with 8 items (e.g., "My parents were always very supportive of me [reversed].”). Cronbach alphas showed poor to moderate reliability, $.39, .65, .56$, respectively. Two items from the Feeling of Parental Rejection scale were dropped - "I never felt my parents really loved me" and "My parents used to hold me on their laps (reversed)". It is possible that these items may have been confusing to participants. Removing these items resulted in an improved Cronbach alpha of .60. Sum scores were calculated for each scale. Scores for modified Feeling of Parental Rejection ranged from 0 to 4 $(M=.53, S D=1.11)$. Scores for the Physical Punishment scale ranged from 0 to $8(M=2.14$, $S D=1.94)$. Severe physical punishment has been defined as endorsing five or more items on the AEQ (Knutson \& Selner, 1994). The prevalence rate for the present sample endorsing five or more items on the physical punishment scale was $10.5 \%$ which is comparable to past reports 
ranging from $8.5-10.5 \%$. Scores for the Negative Family Atmosphere scale ranged from 0 to 7 $(M=1.71, S D=1.63)$.

Self-Reported Delinquency Scale (SRDS; Appendix G). The SRDS is a 13 item survey measuring the child's frequency of self-reported offenses (e.g., "Have you taken part in 'gang fights'?") (Elliott \& Voss, 1974). The participants indicated how often they had engaged in each behavior from 1 ("no") to 4 ("very often.)" The SRDS is considered a valid measure of selfreported delinquency and shows good reliability (.88). Although some underreporting has been found, Elliott and Voss (1974) argue that the SRDS is a valid indicator of the nature and extent of participant's involvement in delinquent activities. A sum delinquency score was calculated for the present project as an alternative way of measuring aggression and other antisocial behavior and ranged from 13 to $44(M=18.94, S D=7.14)$.

Life Events Checklist (LEC, Appendix H). The LEC (Johnson \& McCutcheon, 1980) was completed by participants to assess their experiences with significant positive or negative life events. The LEC lists 46 different events likely to have been experienced by young people. The participant indicated whether he experienced such an event and then was asked whether it was a "positive" or "negative" event. The amount of impact the event had on his life was then rated $(0=$ "no effect," $1=$ ="some effect," 2="moderate effect," or 3="great effect"). Total "positive life change' and 'negative life change' scores were computed by summing the level of impact for each type of event as either a positive or negative event. Participants reported experiencing 1 to 11 events characterized as 'positive' with a mean number of 5.08 events $(S D=2.54)$. The corresponding life change score ranged from 1 to $12(M=5.20, S D=2.64)$. Regarding events perceived as negative, participants reported experiencing 1 to 18 such events $(M=6.48, S D=4.15)$ with life change scores ranging from 1 to $18(M=6.45, S D=4.13)$. 
Community Violence Exposure (CREV; Appendix I). In order to measure experiences with violence that participants had been exposed to in their community, they were asked to complete the CREV. This survey contains a list of 32 violent incidents in the community in which the participants report their lifetime frequency of having directly experienced, witnessed, or heard about (Cooley, Turner, \& Beidel, 1995). Only direct victimization was included in the primary analyses for the present project. Participants report how often from "no/never" (0) to "everyday" (4) they have been the victim of being chased or threatened with bodily harm, beaten up, robbed/mugged, shot, or stabbed. This scale included 4 items and ranged from 0 to 8 $(M=2.28, S D=2.43)$. This scale showed a poor internal reliability of .42 as expected given the diverse nature of the questions. The total sum of participants' lifetime frequency of victimizations in their community was also calculated and ranged from 6 to 75 ( $M=32.94$, $S D=18.04)$

\section{Procedure}

The procedure lasted approximately 1 hour and consisted of the participant questionnaires, the computer game, and physiological assessment. Youth were offered the opportunity to participate after receiving the parents' or social workers' permission (Appendix I and Appendix J). Once the participant arrived to the testing session, the study was described and he was asked to give assent to participate in the project (Appendix K and Appendix L). In most instances, at least one research assistant ran the research session and another was available to read the items to the participant. A research assistant also screened for invalid responses after data was collected. An initial salivary sample was collected and served as the arrival MHPG measure. Arrival measures were not assayed for the current study. Participants completed a portion of the measures (the order of surveys was randomized prior to the sessions). A salivary 
baseline MHPG sample was collected after completing the pre-game mood questions whereby the participant sat for a 3 minute rest period and then the salivary sample was collected. Participants were then instructed on how to play the Key Game. After the completion of the game, participants were randomly selected into the Expressed Aggression Group and observed their former "opponent" play another game. They were either randomly selected into the Expressed Hostile Aggression Group (i.e., sending the blasts of noise) or Expressed Instrumental Aggression Group (i.e., removing their “opponent's" points). The computer screen directed all the Expressed Aggression participants, "Your opponent just beat you and you have lost all of your money. Now you can get a chance to get him back while he plays someone else. Wait until the next game starts on your screen." For the Expressed Hostile Aggression Group, the screen read "Now you can send him blasts of noise," while participants in the Expressed Instrument Aggression Group read "Now you can take his money." The screen then displayed a new window upon which they could move their cursor to click the amount of money or sounds they wanted to send throughout the three trials they viewed.

The post game salivary sample was taken immediately following the game for all groups. After the participant completed the during- and after-game mood ratings, participants were interviewed regarding their "opponent's" intent, as well as their own intentions if in the Expressed Aggression group. While the remaining surveys were completed, salivary samples were originally taken at 10,20 and 40 minutes post game. Pilot analyses of 5 subjects' samples indicated that changes in MHPG levels were noted between baseline, post, post-10, and post-40 samples. Therefore, the post-20 samples were not assayed. 


\section{Results}

Prior to testing the hypotheses, data were thoroughly examined. First, variables were screened for normality, linearity, and heteroscedasticity. Second, differences between all variables were assessed between the two data collection sites, Hunton and Tekoa. Third, possible confounds of noradrenergic activation (e.g., hours of sleep, distractibility) were assessed. Results of this data screening are presented prior to explaining the primary findings testing the hypotheses.

\section{Data Screening Analyses}

Distributions of several variables were negatively skewed and thus violated the assumption for normality for the primary analyses. These skewed distributions were found for Physical Punishment, Feelings of Parental Rejection, and Negative Family Atmosphere, Direct CV Victimization, as well as the Expression of Hostile Aggression for the retaliation phase of the game. In order to normalize these distributions, values were log transformed. Transformed values will be used in all analyses.

\section{Site Differences}

Prior to performing the primary analyses, data were evaluated for differences between the two data collection sites. A series of paired-samples t-tests were conducted and results are displayed in Table 1. In addition to the fact that all participants from Hunton were Black and all participants from Tekoa were White or Hispanic, a number of other significant differences were found. Participants from Tekoa were significantly older than those of Hunton and also reported experiencing more difficulties at home including Physical Punishment, Feelings of Parental Rejection, and Negative Family Atmosphere. These participants also reported more direct community violence victimization and engaging in more delinquent behavior. On the other 
hand, participants from Hunton reported experiencing significantly more positive events in their lives and, as a result, a larger positive life change score, than participants from Tekoa. Regarding MHPG values, Hunton participants had significantly higher baseline levels than Tekoa participants. They also evidenced a trend for higher MHPG values at all time points. The primary analyses will include all participants ${ }^{2}$.

\section{Confounds for $M H P G$}

In an effort to determine any confounds for MHPG values, relationships between baseline MHPG and a number of variables proposed to affect noradrenergic functioning (e.g., height, weight, hours of sleep, degree of feeling rested, time, and degree of distractibility) were evaluated. Scatterplots were produced with baseline MHPG on the y-axis and the possible confound on the x-axis. Plots were examined for any possible linear or non-linear relationship. No obvious relationships or significant correlations were found.

\section{Primary Analyses}

A series of analyses were conducted in order to test the primary aims of the present study. Zero-order correlations were performed to evaluate the relationship between self-reported aggression and MHPG. A repeated measures analysis of variance (ANOVA) was conducted to evaluate a variety of relationships (effect of task on post MHPG levels, impact of retaliation conditions on course of MHPG, differences in types of retaliation conditions on MHPG). Lastly, hierarchical regression analyses examined the effect of rearing environment on MHPG and their interactive effects on aggressive behavior. Results are described following the three primary aims of the project.

\section{Aim 1: Stress and Aggression on $M H P G$}

\footnotetext{
${ }^{2}$ All primary and supplementary analyses were repeated using only the Hunton Inc. sub sample. Results indicated no substantial differences with findings using the original total sample. Thus, findings remained unchanged, despite differences in variables between the two sites.
} 
This set of analyses addressed the primary aim of the project - to evaluate the independent effects of stress and aggressive expressions on noradrenergic functioning. In order to do this a series of four analyses were conducted.

First, the relationship between aggressive behavior and MHPG was tested. It was predicted that a positive relationship would exist between self-reported overall aggressive behavior and measures of MHPG. To test this, bivariate two-tailed correlations were computed between the sum overall and subscale aggressive behavior scores on both the SBR and PRA with the baseline, post, 10- and 40-minute measures for salivary MHPG (Table 3). No significant correlations were found between any of the MHPG measures and self-reported aggression.

Second, the effect of stress on the noradrenergic system was examined. It was hypothesized that participants' salivary levels of MHPG would increase after experiencing a mild stressor and therefore post game values of MHPG would be significantly higher than baseline MHPG. To test this, a repeated measures ANOVA was conducted with MHPG time (baseline, post game, 10 minutes post game, and 40 minutes post game) as the within subjects factor and assigned condition as the between-subjects factor (no retaliation, hostile retaliation, or instrumental retaliation). Since the assumption of variance-covariance homogeneity was violated for MHPG (Mauchly's $\mathrm{W}=.731, \chi^{2}(5)=16.18, p=.01$ ), the Greenhouse-Geisser epsilon value $(.817)$ was used as the adjustment to the degrees of freedom. Thus, all $F$ statistics are based on the Greenhouse-Geisser adjustment. Descriptive statistics are displayed in Table 4. In order to evaluate whether post game MHPG was indeed higher than baseline MHPG, the within subjects main effect was examined. This effect was significant, $F(2.45,129.87)=6.15, p<.01$, $\eta^{2}=.10$. However, pairwise comparisons did not support the hypothesis that post game MHPG would be higher than baseline MHPG. As displayed in Table 4, values for post MHPG were not 
significantly different from those of baseline MHPG $(p=.88)$. Rather, several pairwise comparisons revealed that post $40 \mathrm{MHPG}$ values were significantly lower than baseline values $(p<.01)$. Furthermore, post MHPG values were significantly higher than post $10(p=.02)$ and post 40 values $(p<.01)$. Thus, MHPG values seemed to habituate and decrease over time.

Third, the course of MHPG was compared across the retaliation and no retaliation groups in order to evaluate the effects of expressing aggression (either hostile or instrumental) on MHPG. It was predicted that the within-subjects factor (i.e., MHPG) would interact with the between-subjects factor (i.e., condition), such that all baseline and post measures would be similar across conditions but post 10 and post 40 MHPG values would be higher for the no retaliation group than the two retaliation groups. To test this, the MHPG by condition interaction effect was examined in the repeated measures ANOVA. The effect was not significant, $F(2.45$, $129.87)=.53, p=.75, \eta^{2}=.02$.

\section{Aim 2: Hostile and Instrumental Aggression on MHPG}

This second set of analyses addressed the second aim of the project - exploring how hostile and instrumental expressions of aggression are related to noradrenergic functioning.

First, differences in noradrenergic functioning were explored in relation to the expressed aggression in response to provocations of the analog aggression task. It was hypothesized that participants who engage in the hostile retaliation condition (those who sent blasts of noise to the “opponent") would have higher levels of MHPG than those in the instrumental retaliation condition (those who took their "opponent's" money away). To test this, the between-subjects main effect of the repeated measures ANOVA was examined. The effect approached significance, $F(1,53)=2.83, p=.07, \eta^{2}=.10$. Post hoc Bonferroni tests showed no significant differences between the instrumental and hostile retaliation groups $(p=.29)$. Rather, there was a 
trend such that MHPG for the instrumental retaliation group was significantly lower than the no retaliation group $(p=.07)$ (see Table 4$)$. This is explained by the lower MHPG concentrations at baseline $^{3}$, post 10 , and post 40 for the instrumental group versus the no retaliation group.

Second, differences in MHPG levels were explored in relation to the self-report measures of hostile and instrumental aggression. This was tested by examining the associations between self reported aggression scales from the SBR and PRA with the salivary MHPG (Table 3). It was hypothesized that mean baseline, post, post 10, and post 40 minute levels of MHPG would be positively correlated with self-reported hostile aggression and negatively correlated with reported instrumental aggression. No significant relationships were found.

\section{Aim 3: Rearing Environment and $M H P G$}

The last set of analyses addressed the third aim of the project - evaluating how aspects of the rearing environment are related to baseline MHPG and aggression. Total aggression scores from the PRA and SBR were used as the dependent variables.

First, the association between aspects of the rearing environment and noradrenergic functioning was evaluated. It was hypothesized that physical punishment would be positively associated with baseline MHPG, while parental rejection would be negatively associated. A hierarchical linear regression was conducted testing both the main effects for physical punishment and parental rejection, as well as their interaction effect, on baseline MHPG. Physical punishment and parental rejection variables were entered simultaneously in Block 1 while the interaction term, physical punishment $\mathrm{x}$ parental rejection, was entered in Block 2 . In order to reduce multicollinearity between the interaction term and the independent variables,

\footnotetext{
${ }^{3}$ Additional analyses were performed in an effort to explain how participants in the assigned conditions differed on baseline values of MHPG. However, no significant differences were found for any of the demographic (e.g., age, weight) or psychological constructs (e.g., community violence exposure, childhood variables) between the no, sound, and money retaliation conditions.
} 
values were centered by subtracting their means from the transformed values. The model was not significant, $F(3,55)=.25, p=.86$ and accounted for only $1.4 \%$ of the total variance in baseline $\operatorname{MHPG}\left(R^{2}=.01\right)$.

Second, associations between exposure to community violence and negative life events with MHPG values were evaluated. It was predicted that a positive relationship would exist between exposure to these events and salivary MHPG. To test this, correlations between the CREV victimization scores, negative life change score as measured by the LEC, and baseline MHPG were conducted. None of these relationships were significant.

Third, the association between characteristics of the rearing environment and MHPG on aggression was further explored. In particular, the interaction between these factors (physical punishment by baseline MHPG and parental rejection by baseline MHPG) was evaluated in terms of their cumulative effect on general aggressive behavior. It was hypothesized that MHPG levels would impact the rearing environment-aggressive behavior relationship, such that the relationship between family environment and overall aggressive behavior would be strongest when children from abusive or rejecting family environments display high levels of baseline salivary MHPG. Zero order correlations between these variables for those participants whose MHPG was measured $(N=56)$ are displayed in Table 5. The relationship between parental rejection and physical punishment was not significant, $r(55)=.19, p=.16$, therefore, analyses do not control for the other rearing environment variable. In order to test the hypothesis, separate hierarchical regression analyses (as recommended by Aiken \& West, 1981) were conducted to predict overall aggressive behavior as measured by the SBR and PRA. For each dependent measure of general aggression, two regressions were conducted. One model examined the relationship between physical punishment, baseline MHPG, and overall aggression, while the 
other regression examined the relationship between parental rejection, baseline MHPG, and overall aggression. In Block 1, the centered sum family environment variable (physical punishment or parental rejection) was entered. In Block 2, the centered mean salivary MHPG variable was entered. After computing the interactions between the family environment variable from Block 2 and salivary MHPG, the moderational term was entered in Block 3. Both models examining the interactive effects of baseline MHPG and physical punishment on aggression were not significant, $F(3,55)=.74, p=.53, R^{2}=.04$ (regressing on PRA) and $F(3,55)=.1 .09, p=.36$, $R^{2}=.06$ (regressing on SBR). Both models examining the interactive effects of baseline MHPG and parental rejection on aggression were also not significant, $F(3,55)=1.08, p=.37, R^{2}=.06$ (regressing on PRA) and $F(3,55)=.59, p=.62, R^{2}=.03$ (regressing on SBR). Neither main effects nor interaction effects were significant.

\section{Supplemental Analyses}

A number of supplemental analyses were conducted in order to explore alternatives to the hypotheses for aims of the project. ${ }^{4}$ First, associations between mood scores, post task MHPG concentrations, self-reported aggression and assigned retaliation conditions were examined to determine whether these emotional reactions were related to physiological reactivity and assigned experimental condition. Second, regarding the effect on MHPG based on assigned retaliation conditions, additional analyses explored these relationships in terms of the participants' intention for sending blasts of noise or taking the opponent's points away, as well as the degree of noise sent and money taken. The effect of assigned relation conditions on post game mood was also assessed. Third, analyses that tested for effects of baseline MHPG were

\footnotetext{
${ }^{4}$ All primary analyses were repeated with a smaller sample with a more restricted age range, 7 to 11 years $(\mathrm{N}=24)$. Findings were identical to those of the larger sample. In addition to these findings, as predicted, experiencing negative events and hearing about violence in one's community was positively associated with baseline MHPG $(r(23)=.44, p=.44$ and $r(23)=.58, p<.01)$.
} 
repeated for all post game values of MHPG (post, post 10 minutes, and post 40 minutes).

Fourth, associations between alternate forms of community violence exposure were examined. Fifth, associations between Negative Family Atmosphere and MHPG were also explored. Sixth, associations between negative mood reactions after the game and rearing environment were assessed. The following section considers these additional analyses in terms of the aims of the present project. In addition, all primary analyses including relationships with total aggression were repeated with self-reported delinquency.

\section{Aim 1 Supplementary Analyses: Stress and Aggression on MHPG and Mood}

In an effort to determine whether mood ratings before, during, and after the game were related to noradrenergic functioning and self-reported aggression, zero-order correlations were conducted between several of the moods ratings (frustration and anger) and all post MHPG concentration levels. None of the mood ratings were related to post task MHPG concentrations.

Several positive correlations were found between mood and self-reported aggression (see Table 6$)^{5}$. In particular, feeling frustrated during and after the game was related to higher selfreported hostile and instrumental aggression on both measures. Feeling angry during the game was related to all of these scales as well. However, an angry mood before and after the game was positively correlated only with the SBR self-report.

In order to evaluate whether the ability to retaliate after the tasks decreased negative mood ratings after the game (i.e., frustration and anger), two additional repeated measures ANOVA were conducted with either frustrated or angry mood (before, during, and after) as the within subjects factor and assigned condition as the between-subjects factor (no retaliation, hostile retaliation, or instrumental retaliation). The interaction effects were not significant and

\footnotetext{
${ }^{5}$ Correlations were also conducted with self-reported delinquency and no significant relationships were found.
} 
all groups evidenced similar changes in frustration $\left(F(2,63)=.75, p=.48, \eta^{2}=.02\right)$ and anger $\left(F(2,63)=.39, p=.68, \eta^{2}=.01\right)$ regardless of whether or not participants were able to retaliate.

Aim 2 Supplementary Analyses: Hostile/Instrumental Aggression on MHPG and Mood

In addition to the primary analyses exploring the hostile-instrumental dichotomy, three alternate analyses were performed: 1) a multivariate ANOVA tested for the effect of selfreported motivation for sending blasts of sound or taking the "opponent's" money away as measured by the post game interview on post values of MHPG, 2) zero-order correlations to assess the relationship between degree of hostile (number of sounds) or instrumental (amount of money) and post values of MHPG, and 3) repeated measures ANOVA testing differences in mood rating based on assigned condition.

Self-reported motivation. A multivariate ANOVA tested the effect of self-reported motivation for retaliation (either hostile of instrumental) on 3 dependent variables: 1) post MHPG, 2) post $10 \mathrm{MHPG}$, and 3) post $40 \mathrm{MHPG}$. It was hypothesized that post MHPG levels would be higher for those participants endorsing hostile, versus, instrumental, motivations. However, means were similar across self-reported motivation groups. Main effects were not significant for any of the post MHPG values across the entire sample (post: $F(1,29)=.55, p=.46$, $\eta^{2}=.02$, post 10: $F(1,29)=.31, p=.58, \eta^{2}=.01$, post $\left.40: F(1,29)=.31, p=.58, \eta^{2}=.01\right)$.

Degree of Hostile and Instrumental Aggression. Zero-order correlations were performed using the amount of instrumental and hostile aggression employed during the retaliation task with the post MHPG values. None of the associations were significant.

Post Game Mood. Exploratory analyses tested for differences in reported negative mood after the task based on the nature of the retaliation condition - either hostile or instrumental. To test this, the between-subjects main effects of assigned condition were evaluated in the two 
previous repeated measures ANOVAs including frustration and angry mood measures. The effect was not significant for either $\operatorname{mood}$ (frustration: $F(1,63)=.90, p=.41, \eta^{2}=.03$, anger: $F(1$, $\left.63)=.02, p=.98, \eta^{2}=.00\right)$.

Aim 3 Supplemental Analyses: Rearing Environment and MHPG

Supplemental analyses for the third aim included: 1) Hierarchical regressions testing the interactive effects of rearing environment with post values of MHPG together on self-reported aggression, 2) Zero-order correlations between other forms of community violence exposure and MHPG, 3) Zero-order correlations between post game negative mood ratings and rearing environment variables, and 4) Zero-order correlations between rearing environment and mood ratings. Findings for each of these additional supplemental analyses are described below. Rearing environment and post game levels of MHPG on self-reported aggression. The following analyses examined how post measures of MHPG levels (immediately after the game, 10 minutes after, and 40 minutes after) might interact with the rearing environment to predict self-reported aggression levels in the same model. These analyses are exploratory considering the small sample size; however, findings may give insight on how rearing environment interacts with post stress MHPG functioning to impact aggression. First, zero order correlations between post MHPG values, rearing environment, and self-reported aggression were conducted. No relationships were significant.

Hierarchical analyses were similar to those of the primary analyses for the third aim; however, the effects of post, post 10, and post 40 MHPG values and their interactions with rearing environment were explored together. For the following models, Block 1 tested for the main effect of one of the rearing environment variables (physical punishment or parental rejection), Block 2 tested for the main effects for all post MHPG values together, and Block 3 
tested for the interactions (either physical punishment x post MHPG, physical punishment x post 10 MHPG, physical punishment x post $40 \mathrm{MHPG}$, or parental rejection punishment $\mathrm{x}$ post MHPG, parental rejection punishment x post $10 \mathrm{MHPG}$, or parental rejection punishment $\mathrm{x}$ post 40 MHPG). These models were regressed on self-reported aggression as measured by the PRA and SBR. The overall models were not significant for parental rejection on PRA aggression, $F(7,55)=.59, p=.76, R^{2}=.08$, nor SBR aggression, $F(7,55)=.66, p=.71, R^{2}=.09$. Likewise, overall models were not significant for physical punishment on PRA aggression, $F(7,55)=.78, p=.61$, $R^{2}=.10$, nor SBR aggression, $F(7,55)=.44, p=.88, R^{2}=.06$. In sum, post game levels of MHPG did not appear to interact with rearing environment to impact self-reported aggression.

Witnessing and hearing about community violence on MHPG. Zero order correlations were conducted to explore the associations between witnessing and hearing about violence in one's community on all measures of MHPG. There was a significant correlation between post 10 MHPG and witnessing violence, $r(56)=.26, \mathrm{p}=.05$.

Negative Family Atmosphere. Another aspect of the rearing environment measured by the AEQ, negative family atmosphere, was assessed in terms of its relationship with MHPG and self-reported aggression. Negative family atmosphere examines the child's perception of how his family gets along based on arguments between family members, eating supper together, whether parents insulting the child, etc. This set of additional analyses examined relationships between scores on negative family atmosphere, all levels of MHPG, and self-reported aggressive behavior. Primary analyses from the third aim of this project using reports of physical punishment and parental rejection were repeated with the negative family atmosphere variable and are described below. 
Zero order correlations revealed significant relationships between negative family atmosphere and physical punishment $(r(55)=.33, p=.01)$, as well as negative family atmosphere and parental rejection $(r(55)=.34, p=.01)$. First, the main effect of negative family atmosphere and its interaction with physical punishment and parental rejection on MHPG levels were evaluated. Separate hierarchical linear regressions were conducted controlling for effects of physical punishment and parental rejection in Block 1, testing for the main effect of negative family atmosphere in Block 2, and the interactive effects of negative family atmosphere by physical punishment, as well as negative family atmosphere by parental rejection in Block 3 . The overall model was not significant $\left(R^{2}=.15, F(5,50)=1.70, p=.15\right)$.

Similarly with physical punishment and parental rejection, the association between negative family atmosphere and baseline MHPG on aggression was explored. A hierarchical regression was conducted controlling for the effects of physical punishment and parental rejection in Block 1, testing the effect negative family atmosphere in Block 2, baseline MHPG in Block 3, and their interaction in Block 4 on self-reported aggression as measured by the PRA and separately on aggression measured by the SBR. The model regressing negative family atmosphere on PRA aggression was significant, $F(5,55)=3.66, p=.01, R^{2}=.27$ (Table 7). Coefficients for negative family atmosphere $(\beta=.49$, partial $t(55)=3.55, p<.01)$ and baseline MHPG $(\beta=.32$, partial $t(55)=2.39, p=.02)$ were significant for PRA. The model regressing negative family atmosphere on SBR aggression was not significant, $F(5,55)=1.32, p=.27, R^{2}=.12$.

Exploratory models also assessed the interactions between negative family atmosphere and post values of MHPG on aggression. Similarly, a hierarchical regression was conducted controlling for the effects of physical punishment and parental rejection in Block 1, testing the effect of negative family atmosphere in Block 2, post, post 10, and post 40 MHPG in Block 3 , 
and their interactions (negative family atmosphere $\mathrm{x}$ post MHPG, negative family atmosphere $\mathrm{x}$ post 10 MHPG, negative family atmosphere x post 40MHPG) in Block 4 on self-reported aggression as measured by the PRA and the SBR. The models predicting PRA and SBR aggression were not significant for, $F(9,55)=1.62, p=.14, R^{2}=.24$ and $F(5,55)=1.12, p=.37$, $R^{2}=.18$, respectively

In sum, findings regarding negative family atmosphere indicated significant positive relationships with self-reported aggression, as measured by the PRA. Baseline MHPG was also significantly and positively associated with aggression on the PRA.

Mood and Rearing Environment. Relationships between negative (frustrated and angry) mood reactions and characteristics of the rearing environment were examined (see Table 8). Zero order correlations revealed significant relationships between negative family atmosphere and during $(r(66)=.25, p=.04)$ and post game anger $(r(66)=.29, p=.02)$, well as post game frustration $(r(66)=.24, p=.05)$. Parental rejection was significantly correlated with anger before the game $(r(66)=.32, p=.01)$ No significant relationships were found with physical punishment.

In order to look at whether rearing environment predicted post game negative mood, hierarchical regressions regressed negative family atmosphere on post game anger and frustration. Both models were significant (anger: $F(3,65)=5.88 p=.01, R^{2}=.06$, frustration: $\left.F(3,65)=3.99, p=.05, R^{2}=.06\right)$ with significant positive coefficients for rearing environment (anger: $\beta=.29, t(65)=2.42, p=.02$, frustration: $\beta=.23, t(65)=2.00, p=.05) .^{6}$

\section{Findings for Self-Reported Delinquency}

\footnotetext{
${ }^{6}$ Additional analyses also explored the moderating role of negative reactions after the game on the relationship between rearing environment characteristics and self-reported aggression and delinquency. None of these relationships were significant and no interaction effects were found.
} 
A correlate of aggression is delinquent behavior. To examine how hypotheses might map on to delinquency, the primary analyses for self-reported aggression were repeated substituting self-reported delinquency as the dependent variable.

First, zero order correlations between MHPG levels, all rearing environment scales, and self-reported delinquency were performed (Table 9). None of the MHPG levels were significantly related to delinquency; however, physical punishment $(r(66)=.39, p<.01)$, parental rejection $(r(66)=.25, p=.04)$, and negative family atmosphere $(r(66)=.52, p<.01)$ were each positively correlated with frequency of delinquent behavior.

Second, similar to the primary and supplemental analyses examining effects of rearing environment and MHPG on aggression, the following analyses examined the main effect of rearing environment and MHPG levels, as well as their interactive effects, on delinquency. A series of hierarchical regression models were conducted such that the rearing environment variable was entered in Block 1 (parental rejection or physical punishment), baseline MHPG was entered in Block 2, and the respective interaction was entered in Block 3 (parental rejection $\mathrm{x}$ baseline MHPG or physical punishment x baseline MHPG). The model including physical punishment and baseline MHPG was significant, $F(3,55)=4.33, p=.01, R^{2}=.20$ (Table 10). The significance was explained by the prediction of physical punishment on self-reported delinquency $(\beta=.43$, partial $t(55)=3.44, p<.01)$.

Exploratory hierarchical regressions examining rearing environment variables and post values of MHPG on self-reported delinquency were also conducted. The model with parental rejection approached significance (Table $\left.11, F(7,55)=2.12, p=.06, R^{2}=.24\right)$ Significant interaction coefficients were found for post 10 MHPG by parental rejection $(\beta=1.10$, partial $t(55)=2.82, p=.01)$ and post 40 MHPG by parental rejection $(\beta=-.72$, partial $t(55)=-2.12, p=.04)$. 
Post hoc probing was conducted as described by Aiken and West (1991) and Holmbeck (2002) to clarify these potential moderating effects. First, reduced hierarchical models were conducted such that only post $10 \mathrm{MHPG}$ and its corresponding interaction term with parental rejection were tested. This was also conducted for the post 40 MHPG values. The reduced model including post 40 MHPG was not significant, $F(3,55)=1.10, p=.36, R^{2}=.06$. However, the reduced model for post 10 MHPG continued to approach significance, $F(3,55)=2.30, p=.09, R^{2}=.18$, and the post 10 MHPG by parental rejection term also approached significance $(\beta=.26$, partial $t(55)=1.94$, $p=.06)$.

Therefore, in order to verify the potential moderating relationship between parental rejection and post 10 MHPG on self-reported delinquency, conditional moderators were created by adding and subtracting one standard deviation from the centered moderator to create low and high post 10 MHPG groups. Conditional interaction terms were also computed with parental rejection. Two simultaneous regressions were then conducted by regressing the main effect of parental rejection, one of the conditional moderators, and their respective interaction. Regression lines were graphed using the beta coefficients for each predictor and the error term (see Figure 2). As the figure illustrates, the interaction remained. In conditions of low post 10 MHPG concentrations, parental rejection was slightly inversely related to self-reported delinquency. However, this relationship reversed and strengthened under conditions of high post 10 MHPG, where parental rejection was positively related to delinquency. This interaction effect was found beyond any direct main effects for these variables.

The model including physical punishment and post MHPG values was also significant, $F(7,55)=2.44, p=.03, R^{2}=.26$ (Table 12 ) such that physical punishment was a significant 
independent predictor of delinquent behaviors, $\beta=.57$, partial $t(55)=4.00, p<.01$. These results are similar to the model including baseline MHPG.

In sum, characteristics of the negative family rearing environment were positively related to self-reported delinquency. Physical punishment, in particular, was predictive of delinquency above MHPG levels. Furthermore, recovery values for MHPG interacted with parental rejection to predict delinquency. Parental rejection was positively related to delinquency under conditions of greater post 10 MHPG levels. 


\section{Discussion}

The main goal of the present research was to evaluate how environmental (i.e., rearing environment) and biological factors (i.e., salivary metabolite of norepinephrine, MHPG) are associated with one another and interact to influence the nature of aggression in youth. The present project explored how these variables impact both hostile and instrumental aggressive expressions. A summary of the primary analyses pertaining to the main hypotheses is provided. Summary of Primary Findings

Regarding the first aim of the project, it was hypothesized that aggression would be positively related to MHPG. This prediction was not supported. Self-reports of total aggressive behavior were not significantly related to MHPG values. However, in supplemental analyses, when effects of negative family atmosphere were controlled, baseline MHPG was positively related to aggressive behavior. This effect will be discussed below in the section on Rearing Environment and MHPG.

It was also predicted that MHPG would significantly rise after playing the game and that recovery would be slower for those participants who were unable to retaliate compared to those who were able to retaliate. This hypothesis also was not supported. Immediate post game values of MHPG were similar to baseline values suggesting that MHPG did not increase in response to the stressor. Moreover, recovery MHPG values (10 and 40 minutes post task) seemed to habituate across time for all participants, regardless of whether they could or could not retaliate. Participants retaliating with instrumental aggression did demonstrate lower recovery MHPG (post 10 and post 40 minutes) compared to participants who did not retaliate, but contrary to predictions, they were also lower at baseline. Differences in MHPG for the instrumental condition group will be discussed below in the section on Aggression and MHPG. 
Regarding the second aim of the project, MHPG was also evaluated in terms of the quality of aggression - either hostile or instrumental forms. It was predicted that hostile aggression would be positively related, and instrumental aggression negatively related, to MHPG. The results indicated that neither form of aggression was significantly related to noradrenergic functioning. Moreover, supplemental analyses indicated that hostile and instrumental aggressive responses (actual and motivated responses) to the task did not lead to differences in post task MHPG. However, those in the instrumental (versus hostile) condition showed lower levels of MHPG at baseline and continued to show low MHPG levels 10 minutes after the game.

Regarding the third aim of the project, the relationships between rearing environment and baseline MHPG, as well as their interaction on self-reported aggression were explored. It was predicted that physical punishment and exposure to negative life events and community violence would be positively related to MHPG, while parental rejection would evidence lower MHPG values. This hypothesis was not supported and no significant effects for environmental variables on MHPG were found, with the exception of negative family atmosphere (discussed in supplemental analyses below). Lastly, no significant interactions between rearing environment and baseline, nor post task, MHPG on self-reported aggression were found.

\section{Summary of Supplemental Analyses}

Several significant relationships were found for self-reported delinquent behavior that will be summarized here and discussed in the section on Self Reported Delinquency below. While reports of punishment and parental rejection did not predict aggression, physical punishment was a positive predictor of delinquent behavior. Moreover, parental rejection and MHPG concentrations during the 10 minute recovery period interacted to predict delinquency. 
Specifically, the positive relationship between parental rejection and self-reported delinquency was strongest at high levels of MHPG 10 minutes after the task, whereas parental rejection was not significantly related to delinquency at low levels of MHPG.

Supplemental analyses examining negative family atmosphere also revealed some interesting findings. Heightened frustration and anger after the task were related to negative family atmosphere and to aggression. Also, after controlling for the effects of physical punishment and parental rejection, negative family atmosphere and baseline MHPG were significant positive predictors of self-reported aggression as measured by the PRA. This effect will be further discussed below.

\section{Stress and $M H P G$}

Contrary to previous findings, the stressor employed in the present task (The Key Game) did not result in higher elevations of MHPG. Although participants in the instrumental condition had higher immediate post task MHPG levels than baseline MHPG, this effect was not significant. Previous research has consistently reported increases in plasma or salivary MHPG in response to specific stressors including taking an academic exam (McClelland et al., 1985), doing mental arithmetic (Albus et al., 1987), being provoked by a fictitious competitor in a game (e.g., Gerra et al., 1997,1999, 2001), and playing violent video games (Skosnik et al, 2000). This discrepancy has several possible explanations.

First, it could be argued that the lack of findings in the present study is due to a less intense laboratory stressor. Support for this comes from Fukuda et al. (1996) who reported that the level of stress experienced by a competitive Olympic swimmer resulted in higher plasma MHPG compared to individuals who experienced less intense daily life stressors. Although individuals reported feeling significantly more frustrated and angry while playing the game, 
these emotions were not reflected in concentrations of MHPG. Supplemental analyses also did not reveal any associations between post task concentrations of MHPG and their self-reported negative mood during and after the game. Some of the negative emotions, however, were indeed related to total aggression scores on the PRA and SBR, as well as the hostile and instrumental aggression subscales. The apparent dissociation between emotional and physiological responding suggests that the emotions youth reported experiencing were not reflected in their noradrenergic functioning. Since this system is generally activated when an individual experiences anger, frustration, anxiety, etc., these findings may be indicative of the system not functioning appropriately. Ideally, these biological responses lead to appropriate attention and cognitive processes that are needed to cope with stress (De Bellis \& Putnam, 1994). It is possible that if this system is deficient, youth may have a more difficult time dealing with psychological stress and may engage in more "stressful" risky behavior.

Furthermore, no significant differences were found in negative mood based on assigned retaliation conditions, possibly suggesting that the forms of retaliation used in the game (sending blasts of noise or subtracting points from an "opponent") were not potent enough to substantially decrease negative mood. Another explanation for these findings could be that, although negative mood is associated with increased aggression, retaliatory aggression does not function to alleviate this distress.

The lack of findings also might be due to individual differences in the proportion of plasma MHPG originating from the CNS and consequently affecting salivary MHPG levels, thereby washing out any group effect. Although, generally $30 \%$ of CNS NE is reflected in plasma levels of MHPG (Kopin et al., 1984) and this proportion is considered relatively stable

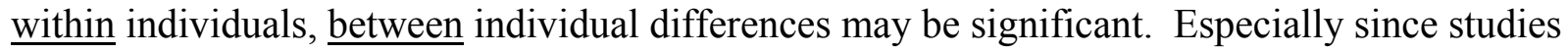


have found that environmental factors impact noradrenergic functioning in terms of plasma MHPG (e.g., history of neglect [Rogeness, 1991], history of trauma [De Bellis \& Putnam, 1994]), perhaps noradrenergic responsiveness to stress is also altered. In a study examining individual differences in rats' reactivity to stress (Rosario \& Abercrombie, 1999), rats were grouped based on their high, middle, or low locomotor activity in a novel open field. In response to a tail-pinch stressor, rats in the high activity group showed significantly elevated NE release in the hippocampus compared to the other groups. These findings suggest that neural correlates might exist between individuals based on behavioral reactivity to stress.

Likewise, another way of looking at responses to stress is to evaluate MHPG reactivity compared to baseline MHPG (e.g., Scarpa \& Luscher, 2002). This technique would evaluate changes in MHPG specifically in response to the Key Game stressor thereby classifying participants as either reactors or non-reactors. Rather than evaluating increases from baseline to post-task MHPG, this method may help explain interindividual differences in MHPG levels.

\section{Rearing Environment and $M H P G$}

Although previous literature has reported significant differences in catecholaminergic activation based on characteristics of the rearing environment, the present study found no relationships between physical punishment and parental rejection with MHPG levels at baseline, as well as levels after the task. Perhaps, physical punishment and parental rejection are more subtle forms of abuse and neglect that are not strong enough to impact the noradrenergic system. Also, previous studies that focused on rearing environment used samples of children that could be considered more "at-risk" and measured more severe forms of child maltreatment. For example, Rogeness (1991) assessed abuse and neglect by reviewing hospital chart records, including extensive family data and documented history of maltreatment in boys housed at a 
psychiatric hospital for children. Similarly, De Bellis and colleagues (1994) recruited children from outpatient clinics and private mental health agencies who had reported and substantiated reports of maltreatment from Child Protective Services. However, many of the items on the AEQIII physical punishment and parental rejection subscales do coincide with abuse and neglect experiences that would be considered maltreatment by Child Protective Services. In fact, it is argued that physical punishment is synonymous with abuse because child physical abuse tends to occur in the context of physical punishment (Gil, 1979; Turner \& Finkelhor, 1996). Moreover, retrospective accounts of parents' regular use of physical punishment measured by the AEQIII were associated with various negative outcomes including psychiatric disorders, substance abuse, and adult criminal offending (Fergussen \& Lynskey, 1997). Perceptions of parental rejection have also been linked to aggression and depression in early and middle adolescent boys and girls (Akse, Hale, Engels, Raaijmakers, \& Meeus, 2004; Hale, Van Der Valk, Engels, \& Meeus, 2005). Therefore, although it might be argued that physical punishment and perceptions of parental rejection are less severe forms of child maltreatment, given the findings that these characteristics of the rearing environment are indeed associated with negative outcomes, examining them in the context of the present study is certainly valuable. Furthermore, although these punitive family variables were not linked to forms of aggression, they were related to selfreported delinquent behavior (discussed in self-reported delinquency section below). This suggests that the variables may relate to general antisocial tendencies, rather than being specific to aggressive behavior.

It is also possible that hypotheses were not supported concerning these rearing environment variables because majority of the participants reported experiencing low levels of each, especially parental rejection. Perhaps it would be more valuable to examine relationships 
between these rearing conditions, biological factors, and aggressive behavior in a sample of children who have had more of these experiences. Although $10.5 \%$ of the participants in the present sample endorsed at least 5 or more physical punishment items constituting severe levels of punishment as defined by Knutson and Selner (1994), as described above, most of the studies reviewed that explored these relationships used samples of children that went through Child Protective Services or at least were hospitalized for psychiatric problems, thereby most likely sampling a higher prevalence rate of maladaptive childhood experiences. Although the present sample was certainly a disadvantaged sample of children (i.e., growing up in impoverished neighborhoods, living at a residential treatment center), perhaps these youth could still be considered less at-risk compared to those of prior studies.

Although physical punishment and feelings of parental rejection did not emerge as significant predictors of baseline MHPG or aggression, ratings for negative family atmosphere appeared to be positively related to aggression, especially as measured by the PRA (Dodge, 2003). This scale on the AEQIII does not include items on specific punitive family experiences such as punishment or neglect, but rather assesses the child's perception of how well the family gets along in general. For example, are there a lot of fights between family members at home? Does the family eat supper together? Although no specific hypotheses were proposed regarding this characteristic of the family environment, certainly it would be reasonable to predict that aggression is related to a negative family atmosphere. Although ratings for this scale were generally low, similar to the other AEQIII scales, this encompassing characteristic of one's rearing conditions may be a more potent predictor of aggression in the present sample.

It is also noteworthy that no significant relationship existed between parental rejection and physical punishment. Punitive family characteristics often co-occur - as much as $94 \%$ of 
maltreating children experiencing more than one form of maltreatment (McGee, Wolfe, \& Wilson, 1997). One study found that of 28 children reporting more than one form of maltreatment, 25 reported both harsh parenting and neglect (Bolger \& Patterson, 2001). Therefore, it would be assumed that the particular family characteristics measured in the present study would also co-occur. However, physical punishment and parental rejection were not significantly correlated with one another suggesting that these two characteristics did not cooccur in the present sample. This finding may be the result of the low occurrence of both rearing conditions. However, negative family atmosphere was significantly related to these more specific forms of negative family functioning.

\section{Community Violence Exposure and Negative Life Events}

Other environmental variables that were posited to be related to baseline MHPG included exposure to community violence and negative life events. Although witnessing violence in the community was related to initial recovery concentrations of MHPG, all of the other relationships were not significant. Past research has suggested that the effect of exposure to violence impacts a child's arousal and ability to react appropriately to stressful experiences. De Bellis and Putnam (1994) found that the chronicity of such exposure was the key fact in predicting increases in catecholaminergic activity. This persistent exposure was also predictive of PTSD symptoms. Therefore, the present study may have been unable to find significant relationships between exposure and MHPG because the frequency, and not the chronicity, of such exposure were evaluated. Furthermore, youth were not assessed for anxiety at the time of screening. In order to evaluate how such exposure impacts MHPG concentrations, it would be worthwhile to include a measure of PTSD related to any traumatic events experienced. 


\section{Aggression and $M H P G$}

Several hypotheses were proposed regarding the relationship between self-reported and behaviorally expressed aggression with MHPG levels. In general, it was hypothesized that selfreported aggression would be linked to higher baseline MHPG while actively expressing aggression in response to a stressor would eventually attenuate noradrenergic functioning resulting in a decrease in post stressor MHPG concentrations. However, these trends were not entirely supported. Self-reported aggression using the SBR and PRA was not significantly related to baseline MHPG. Furthermore, no differences were found regarding the course of salivary MHPG between participants expressing aggression during the analog aggression task and those who did not.

Past literature using self-reports of aggression has been mixed. For example, positive associations have been found between CSF MHPG and aggression scores using the BrownGoodwin Aggression Scale with adult participants (Placidi et al., 2001) as well as between plasma NE and dominant aggressive behavior measured by the Children's Personality Questionnaire (CPQ, Gerra et al., 1997). However, no significant associations were reported using total aggression scores from the Buss-Durkee Hostility Inventory (BDHI) for violent male subjects and CSF MHPG (Brown et al., 1982). In fact, Gerra et al. (1997) also reported no significant differences in plasma NE based on total scores from the BDHI scale, but did report a significant correlation between a subscale tapping irritability and plasma NE. Interestingly, the report by Gerra et al. (1997) examining CPQ scores and plasma NE found no differences in baseline NE between the low and medium-normal aggressiveness groups, though those children in the high aggressive group did have significantly higher NE concentrations. The results of the current study support no relationship between self-reported aggression on the SBR/PRA and salivary MHPG. Although previous studies have not employed these two types of measures for both variables (MHPG via saliva and aggression via SBR and PRA), these results do not support findings from studies using other measures (e.g., Gerra et al., 1999; Placidi et al., 2001). Perhaps it would be beneficial to employ the technique used by Gerra et al. (1999) and focus on 
differences between high and low aggression groups based on PRA and SBR. Likewise, Gerra et al. (1997) also reported that only the middle aggressive group of their present sample actually had significantly higher concentrations of NE in response to a stressor task. In other words, youth that were in the low and high aggression groups did not evidence significant spikes in NE after the experimental psychological stress task.

Despite findings for these primary analyses, when the influence of all rearing environment characteristics (physical punishment, parental neglect, and negative family atmosphere) was controlled for, baseline MHPG was in fact positively related to self-reported aggression as measured by the PRA. This finding is consistent with the hypotheses and suggests that the variance associated with rearing environment in this sample was acting to suppress the main effect of baseline MHPG. This also underscores the importance of including the effects of environmental variables when evaluating biological contributions to behavior. Previous studies that have focused on the relationship between noradrenergic functioning and self-reported aggression have not considered the effect of rearing environment. The discovery that baseline MHPG was only related to self-reported aggression once the effects of physical punishment, parental rejection, and negative family atmosphere were assessed may help explain why other researchers (e.g., Brown et al., 1982) have not reported significant relationships between NE/MHPG and self-reported aggression.

Participants were also asked to rate their negative mood before, during, and after the Key Game. Overall, youth reported feeling more frustrated and angry during the game compared to before and after the game. This finding suggests that the task did increase participants' negative mood. Mood ratings during and after the game were also significantly associated with selfreported aggression as measured by the PRA and SBR; however, they were not affected by condition assignment. In other words, being able to retaliate (either in a hostile or instrumental manner) against one's opponent did not decrease concentrations of MHPG nor youth's frustration and anger. Therefore, expressing aggression after the task did not help alleviate distress as measured by MHPG and mood. 


\section{Hostile and Instrumental Forms}

To the author's knowledge, the present study is the first to examine catecholamines and their relationship with both hostile and instrumental forms of aggression. Although it was predicted that hostile aggression would be positively related to baseline salivary MHPG, this was not found using either the PRA or SBR. In fact, both scales were unrelated to baseline MHPG. Most scales evidenced similar associations with baseline MHPG, with the exception of hostile aggression as measured by the SBR with a correlation of zero. These findings suggest that perhaps this aggression distinction, as measured by self-reports, does not lend itself to differences in baseline MHPG.

The present study was also able to examine behavioral hostile and instrumental aggression as related to post task salivary MHPG concentration, based on assigned retaliation conditions. Although it was predicted that those in the hostile condition would have higher salivary MHPG than those in the instrumental condition, this effect was not found. Although recovery salivary MHPG was higher for those in the hostile than instrumental condition, the difference was not significant. It is noteworthy that recovery MHPG (specifically 10 and 40 minutes post task) was significantly lower for the instrumental group compared to the condition that did not have the opportunity to retaliate. Although it was predicted that both retaliation groups would evidence faster decreases in MHPG than the no retaliation group, it appears that the instrumental aggression is related to faster recovery. However, this finding should be interpreted with caution since these groups also had significantly different baseline levels of MHPG to start off with. Regardless, this condition was the only condition to actually show the predicted course of MHPG (higher salivary MHPG immediately after the stressor and significant decreases at recovery time points). Albeit the course was not significantly different in all 
respects to the other groups, this finding might suggest that a more controlled emotional response to the task's provocation is more likely to affect fluctuations in salivary MHPG concentrations. This finding is worth mentioning especially since the data have generally supported stronger relationships between biological factors and the hostile, rather than the instrumental, subtype of aggression (Coccaro \& McNamee, 1998). However, past literature's findings may be due to a lack of measuring instrumental aggressive behaviors. Most of the previous work examining neurotransmitter responses to analog aggression tasks tends to employ only one form of aggressive retaliation; however, the findings of the present study lend support to the inclusion of different forms of retaliation in these tasks.

Another explanation for the general lack of findings regarding the experimental psychological stress paradigm might be that the task did not adequately operationalize hostile (i.e., sending blasts of noise to the opponent) and instrumental (e.g., taking the opponent's money away) forms of aggression. The majority of participants in these two conditions stated that their motivations were actually instrumental regardless of retaliating in a hostile or instrumental manner. It could be argued that the hostile condition was not hostile enough. This type of aggression is considered more impulsive than instrumental forms. So, conceivably, assigning individuals to this more spontaneous form of retaliation is inappropriate. With a larger sample, it may be worthwhile to have participants choose their preferred mode of responding rather than assigning them to conditions. Offering a choice to participants between both forms of retaliation may be better aligned with their more commonly used forms of aggression and their motivation for choosing each form, thereby strengthening the relationship between expressing aggression and noradrenergic functioning. 


\section{Self-Reported Delinquency}

Although no specific predictions were made regarding delinquent behavior and salivary MHPG, analyses revealed that recovery MHPG concentrations were positively related with delinquency. One previous study found no significant relationships between delinquency as measured by the Child Behavior Checklist and Teacher Report Form and plasma MHPG measured on two consecutive mornings (van Goozen, Matthys, Cohen-Kettenis, Westenberg, \& van Engeland, 1999). However, although this study did use an analog aggression task to evaluate children's aggressive behavior, MHPG was only measured on the day before the task. Therefore, the results of the present study support those of van Goozen and colleagues (1999) in terms of baseline MHPG and delinquency; however, they also extend their findings by suggesting that recovery MHPG and delinquency may in fact be related.

The recovery period is essentially the period of time after the stressor that it takes for MHPG to return to normal and no longer be influenced by the stressor. For youth who reported engaging in more delinquent behavior, this period was characterized by higher MHPG concentrations. However, since the stressor itself did not impact MHPG concentrations immediately after it was completed, no recovery was truly needed. In fact, examination of the four levels of MHPG suggests that baseline and immediate post task MHPG concentrations were unrelated to self-reported delinquency. Another way to interpret these findings, then, may be that a delayed stress response was occurring. Perhaps it is the stress experienced after the offset of the stressor that impacts the risk for delinquency. Future research should attempt to employ more intense stressors and longer recovery periods in order to adequately examine the course of MHPG fluctuations, especially for youth who report delinquent behaviors. 


\section{Rearing Environment, MHPG, and Aggression}

One of the primary aims of the present project was to explore how MHPG concentrations might moderate the impact of rearing environment characteristics on problem behavior in youth. Several different interactions were examined considering the effect of MHPG concentrations on the relationship between characteristics of the rearing environment (physical punishment, parental neglect, or negative family atmosphere), and either aggression or delinquent behavior. Overall, MHPG concentrations (both baseline and post task values) did not seem to influence relationships between rearing environment and problem behavior. Although negative family atmosphere and baseline MHPG seem to be independent positive predictors of self-reported aggression as measured by the PRA and physical punishment was also a significant positive predictor of self-reported delinquency, interaction effects were not significant. One notable exception is that the relationship between parental rejection and delinquency was moderated by 10 minute post task MHPG concentrations. When these recovery MHPG levels were high, parental rejection seemed to have the strongest impact on self-reported delinquency. In other words, high recovery MHPG was a risk factor, while low recovery MHPG buffered the relationship between parental rejection and delinquent behaviors. No direct effects were found for recovery MHPG and parental rejection, so the presence of a significant interaction is striking. High MHPG after the task is indicative of greater activation of the noradrenergic system which is a characteristic of the fight-or-flight or freeze reaction (De Bellis \& Putnam, 1994). The present finding implies that this type of reaction in youth who feel unloved and unwanted by their parents engage in more antisocial behavior including abusing substance, stealing, and vandalizing property. Perhaps these youth have more difficulty regulating their emotional reactivity to stressors and, thereby, engage in risky criminal behavior. 


\section{Limitations}

The present study has several limitations. Primarily, the small sample size limits the strength of the significant findings. A larger sample size is needed to uncover more subtle differences, as well as to replicate the present findings of this smaller sample. Since the present study sampled children from a wide age range ( 7 to 17 years), it is especially important to have a larger sample in order to evaluate the effect of developmental levels. Second, a more intense (and perhaps believable) provocation is needed to differentiate between MHPG differences due to experiencing a stressor versus expressing aggression. Third, future studies that investigate noradrenergic functioning should include multiple measures of this factor - salivary MHPG, plasma MHPG and NE, as well as urinary and possibly CSF samples. The present study is one of the few to employ salivary measures of this metabolite. Although a convenient method for examining noradrenergic functioning, not enough studies have employed this method in addition to other method in order to verify that MHPG in the saliva is reflective of plasma and CSF MHPG. Fourth, significant site differences existed for several of the variables. Although the findings for the sub sample were comparable to the total sample, ideally, future studies should use larger samples of similar at-risk youth. Fifth, it can be argued that instrumental aggression was not adequately operationalized in the Key Game given that participants did not actually gain anything from removing the "opponent's" winnings. A more accurate way to represent instrumental aggression would be to include a way to retaliation that would directly benefit the participant. Sixth, many of the scales used to measure the constructs (e.g., parent rejection, physical punishment, self-reported aggression) had only moderate reliability. Lastly, any implications of the present study are limited because a non at-risk control group was not included. 


\section{Conclusion}

In sum, the primary hypotheses of the present study were not supported; however, there were a few significant direct psychological and biological effects, or interactive effects, on selfreported aggression. Aggressive children were more likely to describe a less supportive and cooperative family life, and reported greater levels of anger and frustration during and after the provocation task. Moreover, after controlling for the influence of rearing environment characteristics on aggressive behavior, negative family atmosphere and baseline concentrations of MHPG were positively related to self-reported aggressive behavior. Concerning self-reported delinquency, both direct and moderating effects were found. Reports of physical punishment at home positively predicted more antisocial behavior in youth, while high recovery MHPG concentrations placed youth rejected by their parents at risk for delinquency.

These findings emphasize the importance of examining psychological and biological mechanisms of aggression and antisocial behaviors in at-risk youth. Understanding the direct and collective effects that these variables have on children's behavior has implications for proper prevention as well as pharmacological and psychological treatment. For example, programs can focus on increasing family support for at-risk youth. It would be beneficial for prevention and treatment programs (e.g., Head Start, FAST Track) to include families rather than strictly focusing efforts on the child. It may be particularly important for at-risk youth to feel as though their families are supporting them in these programs in addition to including a parent training component. Treatment programs might benefit from understanding both the psychological and biological influences of a child's behavior. For example, clonidine (an adrenergic agonist that targets the inhibitory $\alpha_{2}$ subtype receptor) has been used to treat agitation and aggression in children with Attention Deficit Hyperactivity Disorder and Obsessive Compulsive Disorder 
(Brown \& Cooke, 1994). However, although the present finding requires replication, administering clonidine to children who feel rejected by their parents may actually lead to more delinquency in these children.

Recent research on youth violence has focused on applying a systems approach to its study by examining multiple origins to this behavior and acknowledging the dynamic processes between these different variables (e.g., Moffitt, 1993; Raine et al., 1997; Volavka, 1999, 2002). The findings of the present study encourage continued research in the field that appreciates the interplay between bodily processes, environmental influences, and psychological factors. 


\section{References}

Abelson, J.L., \& Cameron, O.G. (1994). Adrenergic dysfunction in anxiety disorders. In O.G. Cameron (Ed.), Adrenergic dysfunction and psychobiology (pp. 403-446). Washington, D.C.: American Psychiatric Press, Inc.

Abercrombie, E.D., \& Zigmond, M.J. (1995). Modification of central catecholaminergic systems by stress and injury: Functional significance and clinical implications (pp. 355-361). In F.E. Bloom and D.J. Kupfer (Eds.), Psychopharmacology: The Fourth Generation of Progress. Raven Press Ltd.: New York.

Aiken, L.S., \& West, S.G. (1991). Multiple regression: Testing and interpreting interactions. Newbury Park, CA: Sage Publications.

Albus, M., Müller-Spahn, F., Ackenheil, M., \& Engel, R.R. (1987). Psychiatric patients and their response to experimental stress. Stress Medicine, 3, 233-238.

American Psychiatric Association (2000). Diagnostic and statistical manual of mental disorders (4 $4^{\text {th }}$ ed.). Washington, D.C.: American Psychiatric Association.

Akse, J., Hale, W.W. III, Engels, R., Raaijmakers, Q., \& Meeus, W. (2004). Personality, perceived parental rejection and problem behavior in adolescence. Social Psychiatry and Psychiatric Epidemiology, 39, 980-988.

Berger, A.M., Knutson, J.F., Mehm, J.G., \& Perkins, K.E. (1984). The self-report of punitive childhood experiences of young adults and adolescents. Child Abuse and Neglect 12, 251-262. 
Berridge, C.W., \& Waterhouse, B.D. (2003). The locus coeruleus-noradrenergic system: Modulation of behavioral state and state-dependent cognitive processes. Brain Research Reviews, 42, 33-84.

Bolger, K.E., \& Patterson, C.J. (2001). Pathways from child maltreatment to internalizing problems: Perceptions of control as mediators and moderators. Development and Psychopathology, 13, 913-940.

Brown, C.S., \& Cooke, S.C. (1994). Attention deficit hyperactivity disorder: Clinical features and treatment options. CNS Drugs, 1(2), 95-106.

Brown, K., Atkins, M., Osborne, M., \& Milnanow, M. (1996). A revised teacher rating scale for reactive and proactive aggression. Journal of Abnormal Child Psychology, 24, 473-480.

Brown, G.L., Goodwin, F.K., Ballenger, J.C., \& Goyer, P.F. (1981). Cerebrospinal fluid amine metabolites and cyclic nucleotides in human aggression. Psychopharmacology Bulletin, $17(1), 63-65$.

Bureau of Justice Statistics [BJS]. (2003, June). http://www.ojp.usdoj.gov/bjs.

Bushman, B.J., \& Anderson, C.A. (2001). Is it time to pull the plug on the hostile versus instrumental aggression dichotomy? Psychological Review, 108(1), 273-279.

Cameron, O.G., Smith, C.B., Lee, M.L., Hollingsworth, P.J., Hill, E.M., \& Curtis, G.C. (1990). Adrenergic status in anxiety disorders: Platelet alpha2-adrenerhioc receptor binding, blood pressure, pulse, and plasma catecholamines in panic and generalized anxiety disorders patients and in normal subjects. Biological Psychiatry, 28(1), 3-20.

Carlson, N.R. (2001). Physiology of behavior. Massachusetts: Allyn and Bacon. 
Charney, D. S., Deutch, A.Y., Krystal, J. H., Southwick, S. M., \& Davis. (1993). Psychobiologic mechanisms of posttraumatic stress disorder. Archives of General Psychiatry 50(4), 294305.

Cicchetti, D. (2003). Neuroendocrine functioning in maltreated children. In D. Cicchetti \& E. Walker (Eds.), Neurodevelopmental mechanisms in psychopathology (pp. 345-365). New York: Cambridge University Press.

Cooley, M.R., Turner, S.M., \& Beidel, D.C. (1995). Assessing community violence: The children's report of exposure to violence. Journal of American Academy of Child and Adolescent Psychiatry, 34(2), 201-208.

Coccaro, E.F., \& Kavoussi, R.J. (1996). Neurotransmitter correlates of impulsive aggression. In D.M. Stoff and R. B. Carins (Eds.), Aggression and violence: Genetic, neurobiological, and biosocial perspectives (pp. 67-85). New Jersey: Lawrence Erlbaum Associates, Inc.

Coccaro, E.F., \& McNamee, B. (1998). Biology of aggression: Relevance to crime. In A.E. Skodol (Ed.), Psychopathology and violent crime. Review of psychiatry series. (pp. 99128). Washington, D.C.: American Psychiatric Press.

Connor, D. F., Steingard, R. J., Cunningham, J. A, Anderson, J., J., \& Melloni, R. H. (2003). Proactive and reactive aggression in referred children and adolescents. American Journal of Orthopsychiatry 74(2), 129-136.

De Bellis, M.D., Baum, A.S., Birmaher, B., Keshavan, M.S., Eccard, C.H., Boring, A.M., Jenkins, F.J., \& Ryan, N.D. (1999). Developmental traumatology Part 1: Biological stress systems. Biological Psychiatry, 45, 1259-1270. 
De Bellis, M.S., Lefter, L., Trickett, P.K., \& Putnam, F.W. (1994). Urinary catecholamine excretion in sexually abused girls. Journal of the American Academy of Child and Adolescent Psychiatry 33(3), 320-327.

De Bellis, M.S., \& Putnam, F.W. (1994). The psychology of childhood maltreatment. Child and Adolescent Psychiatric Clinics of North America 3(4), 663-678.

Deutch, A.Y., \& Roth, R.H. (1999). Neurotransmitters. In M.J. Zigmond, F.E. Bloom, S.C.

Landis, J.L. Roberts \& L.R.Squire (Eds.), Fundamental neuroscience (pp. 193-234). San Diego, California: Academic Press.

Dimsdale, J.E., Ziegler, M., Mills, P., Delehanty, S.G., \& Berry, C. (1990). Effects of salt, race, and hypertension reactivity to stressors. Hypertension, 16(5), 573-580.

Dodge, K.A. (2003). The Proactive and Reactive Aggression Scale. Available from Kenneth Dodge, PhD, Duke University, Center for Child and Family Policy, Box 90264, Durham, NC 27708; dodge@pps.duke.edu.

Drebing, C.J., Freedman, R., Walso, M., \& Gerhardt, G.A. (1989). Unconjugated methoxylated catecholamine metabolites in human saliva. Quantitation methodology and comparison with plasma levels. Biomedical chromatography, 3(5), 217-221.

Eichelman, B.S. (1987). Neurochemical bases of aggressive behavior. Psychiatric Annals, 17(6), $371-374$.

Elliott, D.S., \& Voss, H.L. (Eds.) (1974). Delinquency and Dropout. Lexington, Massachusetts, Lexington Books.

Fergussen, D.M., \& Lynskey, M.T. (1997). Physical punishment/maltreatment during childhood and adjustment in young adulthood. Child Abuse and Neglect, 20, 689-699. 
Fukuda, M., Hata, A., Niwa, S., Hiramatsu, K., Honda, H., Nakagome, K., \& Iwanami, A. (1996). Plasma vanillylmadelic acid level as an index of psychology stress response in normal subjects. Psychiatry Research, 63, 7-16.

Gerra, G., Zaimovic, A., Giusti, F., Baroni, M.C., Delsignore, R., Raggi, M.A., \& Brambilla, F. (2001). Privagbine effects of neuroendocrime responses to experimentally-induced psychology stress in humans. Behavioural Brain Research, 122, 93-101.

Gerra, G., Zaimovic, A., Ampollini, R., Giusti, F., Delsignore, R., Raggid, M.A., Laviola, G., Macchia, T., \& Brambilla, F. (2001). Experimentally induced aggressive behavior in subjects with 3,4-methylenedioxy-methamphetamine ("Ecstasy") use history: Psychobiological correlates. Journal of Substance Abuse, 13, 471-491.

Gerra, G., Zaimovic, A., Avanzini, P., Chittolini, B., Giucastro, G., Caccavari, R., Palladino, M., Maestri, D., Monica, D., Delsignore, R., \& Brambilla, F. (1997). Neurotransmitterneuroendocrine responses to experimentally induced aggression in humans: Influence of personality variable. Psychiatry Research, 66, 33-43.

Gerra, G., Zaimovic, A., Sartori, R., Raggi, M.A., Bocchi, C., Zambelli, U., Timpano, M., Zanichelli, V., Delsignore, \& Brambilla, F. (1999). Experimentally induced aggressiveness in adult children of alcoholics (ACOAs): Preliminary behavioral and neuroendocrine findings. Journal of Studies on Alcohol, 60, 776-783.

Giacobino, J.P. (1995). $\beta_{3}$-Adrenoceptor: An update. European Journal of Endocrinology, 132, $377-385$.

Gil, D.G. (1979). Unraveling child abuse. In D.G. Gil (Ed.), Child abuse and violence (pp. 3-17). New York: AMS Press. 
Gillan, J.L., Mills, P.J., Nelesen, R.A., Dillon, E., Ziegler, M.G., \& Dimsdale, J.E. (1996). Race and sex difference in cardiovascular recovery from acute stress. International Journal of Psychophysiology, 23, 83-90.

Glover, R.A. (1994). The functional anatomy of adrenergic neuron systems. In O.G. Cameron (Ed.), Adrenergic dysfunction and psychobiology (pp. 9-32). Washington, D.C.: American Psychiatric Press, Inc.

Hale, W.W., Van Der Valk, I., Engels, R., \& Meeus, W. (2005). Does perceived parental rejection make adolescent sad and mad? The association of perceived parental rejection with adolescent depression and aggression. Journal of Adolescent Health, 36, 466-474.

Haller, J., \& Barna, I. (1995). Hormonal and metabolic responses during psychosocial stimulation in aggressive and nonaggressive rats. Psychoneuroendocrinology, 20, 65-74.

Haller, J., Makara, G.B., \& Kruk, M.R. (1998). Catecholaminergic involvement in the control of aggression: Hormones, the peripheral sympathetic, and central noradrenergic systems. Neuroscience and biobehavioral reviews, 22(1), 85-97.

Hohn, A.R., Riopel, D.A., Keil, J.E., Loadhold, C. B., Margolius, H.S., Halushka, P.V., Privitera, P.J., Webb, J.G., Medley, E.S., Schuman, S.H., Rubin, M.I., Pantell, R.H., \& Braunstein, M.L. (1983). Childhood familial and racial difference in physiologic and biochemical factors related to hypertension. Hypertension, 5(1), 56-70.

Holmbeck, G.N. (2002). Post-hoc probing of significant moderational and mediational effects in studies pf pediatric populations. Journal of Pediatric Psychology, 27(1), 87-96.Johnson, J.H. (1986). Live events as stressors in childhood and adolescence. Newbury Park: Sage Publications. 
Johnson, J.H., \& McCutcheon, S. (1980). Assessing life stress in older children and adolescents: Preliminary findings with the life events checklist. In I.E. Sarason \& C.D. Spielberger (Eds.), Stress and anxiety (pp. 111-125). New York: Hemisphere Publishing Corporation.

Kandel, E.R. (1991). Transmitter release. In E.R. Kandel, J.H. Schwartz, \& T.M. Jessell (Eds.), Principles of neural science $\left(3^{\text {rd }}\right.$ ed., pp. 194-212). Norwalk, Connecticut: Appleton \& Lange.

Kavoussi, R., Armstead, P., \& Coccaro, E. (1997). The neurobiology of impulsive aggression. The Psychiatric Clinics of North America, 20(2), 395-403.

Keenan, K. (2000). Emotion dysregulation as a risk factor for child psychopathology. Clinical Psychology-Science \& Practice 7(4), 418-434.

Knutson, J.F., \& Selner, M.B. (1994). Punitive childhood experiences reported by young adults over a 10-year period. Child Abuse and Neglect, 18(2), 155-166.

Korzan, W.J., Summers, T.R., Ronan, P.J., Renner, K.J., \& Summers, C.H. (2001). The role of monoaminergic nuclei during aggression and sympathetic social signaling. Brain, Behavior, and Evolution, 57, 317-327.

Kotanko, P., Binder, A., Tasker, J., DeFreitas, P., Kamdar, S., Clark, A.J.L., Skrabal, F., \& Caulfied, M. (1997). Essential hypertension in African Caribbeans associates with a variant of the ${ }^{\beta 2-}$ adrenoceptor. Hypertension, 30, 773-776.

Kopin, I.J., Blombery, P., Epert, M.H., Gordon, E.K., Jimerson, D.C., Marjey, S.P., \& Polinskey, R.J. (1984). Disposition and metabolism of MHPG-CD3 in humans: Plasma MHPG as a 
principal pathway of norepinephrine metabolism and as an important determinant of CSF levels of MHPG. Advanced Biochemical Psychopharmacology, 39, 57-68.

Kraemer, G.W. (1992). A psychobiological theory of attachment. Behavioral and Brain Sciences, 15, 493-541.

Lee, M.A., Cameron, O.G., Gurguis, G.N.M., Glitz, D., Smith, C.B., Hariharan, M., Abelson, J.L., \& Curtis, G.C. (1990). Alpha 2 -adrenoceptor status in obsessive compulsive disorder. Biological Psychiatry, 27(10), 1083-1093.

Loeber, R., Wung, P., Keenan, K., Giroux, B., Southamer-Loeber, M., Van Kammen, W.B., \& Maughan, B. (1993). Developmental pathways in disruptive child behavior. Development and Psychopathology, 5, 103-133.

Maughan, A., \& Cicchetti, D. (2002). Impact of child maltreatment and interadult violence on children's emotion regulation abilities and socioemotional adjustment. Child Development 73(5), 1525-1542.

McClelland, D.C., Ross, G., \& Patel, V. (1985). The effect of an academic examination on salivary norepinephrine and immunoglobulin levels. Journal of Human Stress 11(2), 5259.

McGee, R. A., Wolfe, D.A., \& Wilson, S.K. (1997). Multiple maltreatment experiences and adolescent behavior problems: Adolescents' perspectives. Development and Psychopathology, 9, 131-149.

Minneman, K.P. (1981). Adrenergic receptor molecules. In H.I. Yamamura \& S.J. Enna (Eds.), Neurotransmitter receptors: Part 2 biogenic amines (pp. 185-268). London: Chapman \& Hall. 
Moffitt, T.E. (1990). Juvenile delinquency and Attention Deficit Disorder: Boys' developmental trajectories from age 3 to age 15. Child Development, 61(3), 893-910.

Moffitt, T.E. (1993). Adolescent-limited and life-course-persistent antisocial behavior: A developmental taxonomy. Psychological Review, 100(4), 674-701.

Nelesen, R.A., \& Ziegler, M.G. (1994). Techniques of adrenergic functional assessment. In O.G. Cameron (Ed.), Adrenergic dysfunction and psychobiology (pp. 146-176). Washington, D.C.: American Psychiatric Press, Inc.

Placidi, G.P.A., Oquendo, M.A., Malone, K.M., Huang, Y., Ellis, S.P., \& Mann, J.J. (2001). Aggressivity, suicide attempts, and depression: Relationship to cerebrospinal fluid monoamine metabolite levels. Biological Psychiatry, 50, 783-791.

Pohl, R., Yeragani, V., Balon, R., Ortiz, A., \& Aleem, A. (1990). Isoproterenol-induced panic: A $\beta$-adrenergic model of panic anxiety. In J.C. Ballenger (Ed.), Neurobiology of panic disorder. New York: Wiley-Liss.

Raine, A. (1993). The psychopathology of crime. London: Academic Press, Inc.

Raine, A., Brennan, P., \& Farrington, D.P. (1997). Biosocial bases of violence: Conceptual and theoretical issues. In A. Raine, P.A. Brennan, D.P. Farrington, \& S.A. Mednick (Eds.), Biosocial bases of violence. New York: Plenum Press.

Redmond, D.E., Jr., \& Huang, Y.H. (1979). New evidence for a locus-coeruleus norepinephrine connection with anxiety. Life Sciences, 25(26), 2149-2162.

Reuster, T., Buechler, J., Winiecki, P., \& Oehler, J. (2003). Influence of reboxetine on salivary MHPG concentration and cognitive symptoms among patients with alcohol-related Korsakoff's syndrome. Neuropsychopharmacology 28(5), 974-978. 
Reuster, T., Rilke, O., \& Oehler, J. (2002). High correlation between salivary MHPG and CSF MHPG. Psychopharmacology 162(4), 415-418.

Rogeness, G.A. (1991). Psychosocial factors and amine systems. Psychiatry Research, 37, $215-$ 217.

Rogeness, G.A., Amrung, S.A., Macedo, C.A., Harris, W.R., \& Fischer, C. (1986).

Psychopathology in abused or neglected children. Journal of the American Academy of Child and Adolescent Psychiatry, 25, 659-665.

Rogeness, G.A., \& McClure, E.B. (1996). Development and neurotransmitter-environmental interactions. Development and Psychopathology, 8, 183-199.

Rogeness, G. A, Javors, M. A, Maas, J. W., \& Macedo, C. A. (1990). Catecholamines and diagnoses in children. Journal of the American Academy of Child \& Adolescent Psychiatry, 29(2), 234-241.

Rogeness, G. A, Crawford, L., \& McNamara, A. (1989). Plasma dopamine- $\beta$-hydroxylase and preschool behavior in children with conduct disorder. Child Psychiatry \& Human Development 20(2), 149-156.

Rosario, L.A., \& Abercrombie, E.D. (1999). Individual differences in behavioral reactivity: Correlation with stress-induced norepinephrine efflux in the hippocampus of SpragueDawley rats. Brain Research Bulletin, 48(6), 595-602.

Rowlands, D.B., DeGiovanni, J., McLeay, R., Watson, R., Stallard, R., \& Littler, W. (1982). Cardiovascular response in black and white hypertensives. Hypertension, 4(6), 817-820. 
Scarpa, A., Hirai, M., \& Hurley, J. (July, 2002). Emotional and behavioral correlates of reactive and proactive aggression in children. Presented at the XV world meeting of the International Society for Research on Aggression, Montreal, Canada.

Scarpa, A., \& Luscher, K. (2002). Self-esteem, cortisol reactivity, and depressed mood mediated by perceptions of control. Biological Psychology, 59, 93-103.

Scarpa, A., \& Raine, A. (1997). Psychophysiology of anger and violent behavior. The Psychiatric Clinics of North America, 20, 375-394.

Scarpa, A., \& Raine, A. (2000). Violence associated with anger and impulsivity. In J.C. Borod (Ed.), The neuropsychology of emotion (pp. 320-339). Oxford: Oxford University Press.

Schwartz, D., \& Proctor, L. J. (2000). Community violence exposure and children's social adjustment in the school peer group: The mediating roles of emotion regulation and social cognition. Journal of Consulting \& Clinical Psychology 68(4), 670-683.

Shields, A., \& Cicchetti, D. (2001). Parental maltreatment and emotion dysregulation as risk factors for bullying and victimization in middle childhood. Journal of Clinical Child Psychology 30(3), 349-363.

Silver, J.M., Yudofsky, S.C., Slater, J.A., Gold, R.K., Stryer, B.L.K., Williams, D.T., Wolland, H., \& Endicott, J. (1999). Propranolol treatment of chronically hospitalized aggressive patients. Journal of Neuropsychiatry and Clinical Neurosciences, 11, 328-335.

Skosnik, P.D., Chatterton, R.T., Jr., Swisher, T., \& Park, S. (2000). Modulation of attentional inhibition by norepinephrine and cortisol after psychological stress. International Journal of Psychophysiology, 36, 59-68.

Stanford, S.C. (2001). Noradrenaline. In R.A. Webster (Ed.), Neurotransmitters, drugs, and brain function (pp. 163-186). London: Wiley \& Sons, Ltd. 
Stern, R.M., Ray, W.J., \& Quigley, K.S. (2001). Psychophysiological recording. $2^{\text {nd }}$ ed. New York, NY: Oxford University Press.

Svensson, T.H. (1987). Peripheral, autonomic regulation of locus coeruleus noradrenergic neurons in brain: Putative implication for psychiatry and psychopharmacology. Psychopharmacology, 91(1), 1-7.

Tanaka, T., Yoshida, M., Yokoo, H., Tomita, M., \& Tanaka, M. (1998). Expression of aggression attenuates both stress-induced gastric ulcer formation and increases in noradrenaline release in the rat amygdala assessed by intracerebral microdialysis. Pharmacology, Biochemistry, and Behavior, 59(1), 27-31.

Turner, H.A., \& Finkelhor, D. (1996). Corporal punishment as a stressor among youth. Journal of Marriage and the Family, 58, 155-166.

Tsuda, A., Tanaka, M., Ida, Y., Shirao, I., Gondoh, Y., Oguchi, M., \& Yoshida, M. (1988). Expression of aggression attenuates stress-induced increases in rat brain noradrenaline turnover. Brain Research, 474, 174-180.

Van Goozen, S.H.M., Matthys, W., Cohen-Kettenis, P.T., Westenberg, H., \& van Engeland, H. (1999). Plasma monoamine metabolites and aggression: Two studies of normal and oppositional defiant disorder children. European Neuropsychopharmacology, 9, 141-147.

Van Voorhees, E., \& Scarpa, A. (2002). Psychophysiological variables in childhood proactive and reactive aggression. Psychophysiology, 39(Supp), 82.

Vitiello, B., \& Stoff, D.M. (1997). Subtypes of aggression and their relevance to child psychiatry. Journal of the American Academy of Child and Adolescent Psychiatry, 36, 307-315. 
Volavka, J. (1997). Genetic and neurochemical correlates of violence. Psychiatric Annals, 27(10), 679-682.

Volavka, J. (1999). The neurobiology of violence: An update. Journal of Neuropsychiatry and Clinical Neuroscience, 11(3), 307-314.

Volavka, J. (2002). Neurobiology of violence. (2 ${ }^{\text {nd }}$ ed.). Washington, D.C., American Psychiatric Press.

Webster, R.A. (2001). Neurotransmitters, drugs and brain function. Chichester, UK: John Wiley \& Sons, LTD.

Yamada, S., Yamauchi, K., Yajima, J., Hisadomi, S., Maeda, H., Toyomasu, K., \& Tanaka, M. (2000). Saliva level of free 3-methoxy-4-hydroxyphenylglycol (MHPG) as a biological index of anxiety disorders. Psychiatry Research 93, 217-223.

Yudofsky, S., Williams, D., \& Gorman, J. (1981). Propranolol in the treatment of rage and violent behavior in patients with chronic brain syndrome. American Journal of Psychiatry, 138(2), 218-220. 


\section{Appendix A}

\section{Demographic Questionnaire}

1. Age

2. Sex: Male

3. What is your race/ethnic origin? (Please circle one)

White Black Asian Hispanic other

4. Do you go to school? Yes No

4a. If yes, what grade are you in?

5. Which of the following adults do you currently live with? (circle all that are applicable)
a. Biological Mother
b. Biological Father
c. Foster Mother
d. Foster Father
e. Step-Mother
f. Step-Father
g. Grandmother
h. Grandfather
i. Adult Sister
j. Adult Brother
k. Aunt
1. Uncle

6. Is the person whom you identify as your mother employed? Yes No

7. Is the person who you identify as your father employed? Yes No

Health Information:

Do you have any of the following medical conditions?

$\begin{array}{lll}\text { 8. Heart conditions? } & \text { No } & \text { Yes } \\ \text { 9. Low blood pressure? } & \text { No } & \text { Yes } \\ \text { 10. High blood pressure? } & \text { No } & \text { Yes } \\ \text { 11. Fainting spells or bouts of dizziness? } & \text { No } & \text { Yes } \\ \text { 12. Diabetes? } & \text { No } & \text { Yes } \\ \text { 13. Asthma? } & \text { No } & \text { Yes } \\ \text { 14. Hearing loss or damage? } & \text { No } & \text { Yes }\end{array}$


15. If yes to any of the above, please describe

16. Take medication? $\quad$ No $\quad$ Yes

16a. If yes to medication, please list the medications currently taken

16b. If yes to medication, is it taken regularly as prescribed? No Yes

17. Do you have any other medical condition or physical illness that we should be aware of? (if yes, same as above) No Yes

17a. If yes, please describe 


\section{Appendix B \\ Screening Questionnaire}

Time of Day:

1. What, if anything, have you had to eat today?

2. Have you consumed any caffeinated beverages today?

3. What time did you fall asleep last night?

4. What time did you wake up this morning?

5. How many hours of sleep do you generally get per night?

6. On a scale of 1 (not at all rested) to 10 (very well rested), how rested do you currently feel?

7. Did your mouth bleed at all last night and/or today while brushing your teeth, etc.?

8. Do you regularly engage in physical exercise?

What kind and how often? (Type of exercise and days per week) 


\section{Appendix C}

Mood and Intent

Surveys

\begin{tabular}{ll} 
Child Name: & CHILD QUESTIONS \\
Rater: & Code \# \\
\hline & Date:
\end{tabular}

PRE-GAME MOOD QUESTIONS

I'D LIKE TO ASK YOU A FEW QUESTIONS BEFORE YOU BEGIN THE GAME.

1. How do you feel right now?

NOW YOU CAN CHOOSE 1 OF 4 DIFFERENT ANSWERS (use feelings thermometer):

\begin{tabular}{|c|c|c|c|c|c|c|}
\hline 0 & 1 & 2 & & 3 & & 4 \\
\hline Not Much at All & A Little Bit & & & & & Very, very much \\
\hline Do you feel: & frustrated? & 0 & 1 & 2 & 3 & 4 \\
\hline & angry? & 0 & 1 & 2 & 3 & 4 \\
\hline & nervous? & 0 & 1 & 2 & 3 & 4 \\
\hline & bored? & 0 & 1 & 2 & 3 & 4 \\
\hline & excited? & 0 & 1 & 2 & 3 & 4 \\
\hline & happy? & 0 & 1 & 2 & 3 & 4 \\
\hline & sad? & 0 & 1 & 2 & 3 & 4 \\
\hline
\end{tabular}


NOW I'D LIKE TO ASK YOU A FEW QUESTIONS ABOUT THE GAME.

1. Did you like the game? $\mathrm{Y} N$.

2. How did you feel while playing the game?

NOW YOU CAN CHOOSE 1 OF 4 DIFFERENT ANSWERS (use feelings
thermometer): 0

$\stackrel{0}{\text { Not Much at All }}$

$\begin{array}{lll}1 & 2 & \\ \text { A Little Bit } & \text { Some } & \\ \text { frustrated? } & 0 & 1 \\ \text { angry? } & 0 & 1 \\ \text { nervous? } & 0 & 1 \\ \text { bored? } & 0 & 1 \\ \text { excited? } & 0 & 1 \\ \text { happy? } & 0 & 1 \\ \text { sad? } & 0 & 1\end{array}$

3

A Lot Very, very Much

Did you feel:

sad? $\quad 0$

3. How did you feel after the game was over?

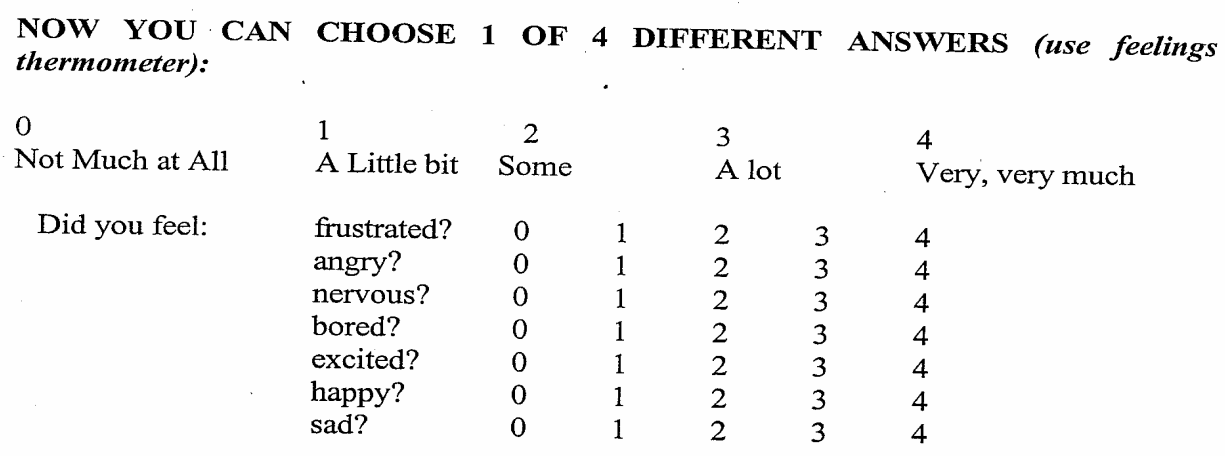




\section{Post-Game Deception Interview Questions}

Please ask the child these questions directly to determine whether the motivation they describe is instrumental versus hostile. Questions 1-4 will be scored as Instrumental for responses indicating a purposeful, goal directed quality and which demonstrate clear intent to win the game, and as Hostile for responses indicating a mean, vindictive, or primarily retaliatory purpose for aggressive responding. Write the child's response verbatim in the space provided.

1. Why do you think the other child took your money away from you?

Instrumental Hostile

2. Why do you think the other child sent you blasts of noise?

Instrumental Hostile

3. (only if in retaliation money condition) What were you thinking when you took money away from the other child? Why did you take money away from the other child?

Instrumental Hostile

4. (only if in retaliation sound condition) What were you thinking when you sent a noise to the other child? Why did you send a noise to the other child?

Instrumental Hostile 


\section{Appendix D}

\section{MHPG Assay Procedure}

\section{Prep Instrument (HPLC)}

Prepare catecholamine buffer (6\% methanol):

Sodium Acetate, anhydrous $16.4 \mathrm{~g}$

Citric Acid $9.6 \mathrm{~g}$

EDTA $100 \mathrm{mg}$

Octanesulfonic Acid 100mg

Methanol $120 \mathrm{~mL}$

Place $\sim 1800 \mathrm{~mL}$ DI water in a $2 \mathrm{~L}$ beaker and begin stirring. Add the above chemicals.

Adjust the $\mathrm{pH}$ to 4.7 with Acetic Acid (conc). Transfer to a $2 \mathrm{~L}$ volumetric flask and fill

to volume with DI water. Filter through a $47 \mathrm{~mm} 0.2 \mathrm{u}$ filter.

Equilibrate HPLC with the catecholamine buffer $(0.5 \mathrm{~mL} / \mathrm{min})$. Turn on electrochemical detector and allow to equilibrate. Turn on autosampler tray thermostat for $4^{\circ} \mathrm{C}$ so that the samples stay cold while waiting to be run. ECD at $+0.61 v$, spacer $50 u$, filter 1s, range 200nA, 25 degrees

C.

HPLC column used: Macherey-Nagel CC 250/4 Nucleodur 100-3 C18 ec. Part \# 761004.40

\section{Standard prep}

Make a standard curve for MHPG (does not need to contain IP b/c samples have an interfering peak at the IP retention time.)

Make an IP standard $1 \times 10^{-6} \mathrm{M}$ and $1 \times 10^{-7} \mathrm{M}$.

For MHPG standard curve, prepare in catecholamine buffer that does NOT contain methanol.

Prepare a $1 \times 10^{-1} \mathrm{M}$ by weighing $11.4 \mathrm{mg}$ MHPG into $0.5 \mathrm{~mL}$ buffer.

make the

following :

$10^{-3}=10 \mathrm{uL}$ of $10^{-1}$ into 990 uL buffer.

$10^{-4}=100 \mathrm{uL}$ of $10^{-3}$ into $900 \mathrm{uL}$ buffer

$10^{-5}=10$ uL of $10^{-3}$ into 990 uL buffer.

NOW FROM THESE STANDARDS, CREATE THE FOLLOWING STANDARDS FOR THE STANDARD CURVE $5 \times 10^{-6} \mathrm{M}=50 \mathrm{uL}$ of $1 \times 10^{-4} \mathrm{MHPG}+950 \mathrm{uL}$ buffer.

$1 \times 10^{-6} \mathrm{M}=100 \mathrm{uL}$ of $1 \times 10^{-5} \mathrm{MHPG}+900 \mathrm{uL}$ buffer.

$5 \times 10^{-7} \mathrm{M}=50 \mathrm{uL}$ of $1 \times 10^{-5} \mathrm{MHPG}+950 \mathrm{uL}$ buffer.

$1 \times 10^{-7} \mathrm{M}=100 \mathrm{uL}$ of $1 \times 10^{-6} \mathrm{MHPG}+900 \mathrm{uL}$ buffer.

$5 \times 10^{-8} \mathrm{M}=50 \mathrm{uL}$ of $1 \times 10^{-6}+950 \mathrm{uL}$ buffer.

\section{Sample prep}

Remove sample from freezer.

Spin down in centrifuge for 5 minutes.

Place samples in ice bucket.

We will use the Oasis, 1cc 30mg HLB cartridges for extraction (Waters part \# 186001879)

(the cartridges are allowed to dry in between steps, so no need to close each cartridge when empty)

Place 10 waste test tubes in the test tube rack that fits into the Baker SPE-10 (solid phase extraction apparatus) 
Place 10 Waters Oasis HLB cartridges on top.

Condition with $1 \mathrm{~mL}$ of methanol.

Add $1 \mathrm{~mL}$ of water.

Load $1 \mathrm{~mL}$ of sample or MHPG standard or IP

solution

Wash with $1 \mathrm{~mL}$ of $5 \%$ methanol in water.

(now open SPE apparatus and remove the test tubes, this is waste)

Put in new numbered test tubes to collect sample extractions.

Elute with $1 \mathrm{~mL}$ of methanol

Take the test tubes and quantitatively transfer (using methanol) to small screw cap vials that can be placed under hood in evaporator.

Evaporate down to dryness under

nitrogen.

Add $100 \mathrm{uL}$ of catecholamine buffer and vortex. Transfer to filter syringe and filter into an numbered HPLC vial.

Ready for analysis.

So also run I $\mathrm{mL}$ of IP $1 \times 10^{-7} \mathrm{M}$ through a cartridge- this will be conc to $1 \times 10^{-6}$ and run on HPLC and used for recovery.

Run the standard IP $1 \times 10^{-6} \mathrm{M}$ on the HPLC (without going through cartridge). Compare the two and calculate a recovery.

For samples, use $1 \mathrm{~mL}$ of saliva (or less if you don't have $1 \mathrm{~mL}$. Less than $0.5 \mathrm{~mL}$ is too little)

When calculating results, change the multiplier to reflect both amount of sample used and recovery. 
Appendix E

Self Behavior Rating Form

Instructions: Listed below are a series of statements describing behaviors that you may show. For each statement, please enter the number which best describes how often you show that behavior.

I

this often:

$1=$ Never
$2=$ Sometimes
$3=$ Very Often

1. Have a good sense of humor

2. Get mad when corrected

3. Deliberately play mean tricks on other children

4. Misbehave when my teacher's or parent's back is turned

5. Take things from other children without their knowledge

6. Need to be the leader all the time

7. Pick on kids smaller than me

8. Am a leader of playground games

9. Cause trouble but don't get caught

10. Blame others when I get into trouble

11. Get mad when I don't get my own way

12. Say mean things about other children behind their back

13. Invite playmates to join games or activities

14. Fight with other children for no good reason

15. Change the rules of the game to help myself win

16. Stay calm when little things go wrong

17. Get mad for no good reason

18. Do sneaky things

19. Have hurt others to win a game or contest

20. Am a poor loser

21. Get others to gang up on children

22. Volunteer to help classmates in class or on the playground

23. Share things with others

24. Tell people things that aren't true

25 . Write things on the walls

26. Won't admit that anything is ever my fault

27. Threaten others

28. Make friends easily 


\section{Appendix F}

Self Proactive and Reactive Aggression Scale

For each of the following statements, please circle the number that best applies to you. Use the scale below to determine the best applying number.

never true rarely true sometimes true usually true almost always true

$\begin{array}{lllll}1 & 2 & 4 & 5\end{array}$

1. When you have been teased or threatened, you get angry easily and strike back.

$\begin{array}{lllll}1 & 2 & 3 & 4 & 5\end{array}$

2. You always claim that other children are to blame in a fight and feel that they started the trouble.

$\begin{array}{lllll}1 & 2 & 3 & 4 & 5\end{array}$

3. When a peer accidentally hurts you (such as by bumping into him or her), you assume that the peer meant to do it, and then overreact with anger/fighting.

$\begin{array}{lllll}1 & 2 & 3 & 4 & 5\end{array}$

4. You get other kids to gang up on a peer that you do not like.

$\begin{array}{lllll}1 & 2 & 3 & 4 & 5\end{array}$

5. You use physical force (or threatens to use force) in order to dominate other kids.

$\begin{array}{lllll}1 & 2 & 3 & 4 & 5\end{array}$

6. You threaten or bully others in order to get your way.

$\begin{array}{lllll}1 & 2 & 3 & 4 & 5\end{array}$ 


\section{Appendix G}

\section{Self Reported Delinquency Scale}

Please read each of the questions below and indicate how often you have engaged in each behavior.

1. Have you driven a car without a driver's license or permit?

1. Very Often

2. Several times

3. Once or Twice

4. Never

2. Have you ever taken little things (worth less than \$2) that did not belong to you?

1. No

2. Once or Twice

3. Several times

4. Very Often

3. Have you bought or drunk beer, wine, or liquor?

1. Very Often

2. Several times

3. Once or Twice

4. No

4. Have you purposely damaged or destroyed public or private property that did not belong to you?

1. No

2. Once or Twice

3. Several times

4. Very Often

5. Have you skipped school without a legitimate excuse?

1. No

2. Once or Twice

3. Several times

4. Very Often

6. Have you defied your parents' authority (to their face)?

1. Very Often

2. Several times

3. Once or Twice

4. No 
7. Have you "run away" from home?

1. No

2. Once or Twice

3. Several times

4. Very Often

8. Have you taken part in "gang fights"?

1. Five or more times

2. Three or four times

3. Once or twice

4. No

9. Have you taken things of medium value (between $\$ 2$ and $\$ 50$ )?

1. No

2. Once or Twice

3. Several times

4. Very Often

10. Have you driven a car without the owner's permission?

1. No

2. Once or Twice

3. Several times

4. Very Often

11. Have you taken things of large value (over $\$ 50)$ ?

1. Very Often

2. Several times

3. Once or Twice

4. No

12. Have you used force (strong-arm methods) to get money from another person?

1. No

2. Once or Twice

3. Several times

4. Very Often

13. Have you used marijuana, LSD, or other dangerous drugs?

1. No

2. Once or Twice

3. Several times

4. Very Often 


\section{Appendix H}

\section{Life Events Checklist}

Below is a list of things that sometimes happen to people. Put a $\sqrt{ }$ in the space by each of the events you have experienced during the past year (12 months). For each of the events you check also indicate whether you would rate the event as a Good event or as a Bad event. Finally, indicate how much you feel the event has changed or has had an impact or effect on your life by placing a circle around the appropriate statement (no effect, some effect, moderate effect, great effect). Remember, for each event you have experienced during the past year, (1) place an " $V$ " in the space to indicate you have experienced the event, (2) indicate whether you viewed the event as good or bad event, and (3) indicate how much effect the event had on your life.

\section{Event}

1. Moving to a new home

2. New brother or sister

3. Changing to a new school

4. Serious illness or injury to family member

5. Parents divorced

6. Increased number of arguments between parents

7. Mother of father lost job

8. Death of a family member

9. Parents separated

10. Death of a close friend

11. Increased absence of parent from the home

12. Brother or sister leaving home (e.g., move out, go to school)

13. Serious illness or injury of close friend

14. Parent getting into trouble with law/police

15. Parent getting a new job

16. New stepmother or stepfather

17. Parent going to jail

18. Change in parents' financial status

19. Trouble with brother or sister

20. Special recognition for good grades

21. Joining a new club

22. Losing a close friend

23. Decrease in number of arguments with parents

24. Male: girlfriend getting pregnant

25. Female: getting pregnant

26. Losing a job

27. Making the honor role

28. Getting a job of your own

29. New boyfriend/girlfriend

30. Failing a grade

\begin{tabular}{|c|c|c|c|c|c|c|}
\hline$\sqrt{ }$ & $\begin{array}{r}\text { Ty } \\
\text { E } \\
\text { (circ }\end{array}$ & $\begin{array}{l}\text { e of } \\
\text { ent } \\
\text { one) }\end{array}$ & & to & fect of Ev & nt on \\
\hline & Good & $\mathrm{Bad}$ & None & Some & Moderate & Great \\
\hline & Good & $\mathrm{Bad}$ & None & Some & Moderate & Great \\
\hline & Good & $\mathrm{Bad}$ & None & Some & Moderate & Great \\
\hline & Good & $\mathrm{Bad}$ & None & Some & Moderate & Great \\
\hline & Good & $\mathrm{Bad}$ & None & Some & Moderate & Great \\
\hline & Good & $\mathrm{Bad}$ & None & Some & Moderate & Great \\
\hline & Good & $\mathrm{Bad}$ & None & Some & Moderate & Great \\
\hline & Good & $\mathrm{Bad}$ & None & Some & Moderate & Great \\
\hline & Good & $\mathrm{Bad}$ & None & Some & Moderate & Great \\
\hline & Good & $\mathrm{Bad}$ & None & Some & Moderate & Great \\
\hline & Good & $\mathrm{Bad}$ & None & Some & Moderate & Great \\
\hline & Good & $\mathrm{Bad}$ & None & Some & Moderate & Great \\
\hline & Good & $\mathrm{Bad}$ & None & Some & Moderate & Great \\
\hline & Good & $\mathrm{Bad}$ & None & Some & Moderate & Great \\
\hline & Good & $\mathrm{Bad}$ & None & Some & Moderate & Great \\
\hline & Good & $\mathrm{Bad}$ & None & Some & Moderate & Great \\
\hline & Good & $\mathrm{Bad}$ & None & Some & Moderate & Great \\
\hline & Good & $\mathrm{Bad}$ & None & Some & Moderate & Great \\
\hline & Good & $\mathrm{Bad}$ & None & Some & Moderate & Great \\
\hline & Good & $\mathrm{Bad}$ & None & Some & Moderate & Great \\
\hline & Good & $\mathrm{Bad}$ & None & Some & Moderate & Great \\
\hline & Good & $\mathrm{Bad}$ & None & Some & Moderate & Great \\
\hline & Good & $\mathrm{Bad}$ & None & Some & Moderate & Great \\
\hline & Good & $\mathrm{Bad}$ & None & Some & Moderate & Great \\
\hline $\mathrm{x}$ & Good & $\mathrm{Bad}$ & None & Some & Moderate & Great \\
\hline & Good & $\mathrm{Bad}$ & None & Some & Moderate & Great \\
\hline & Good & $\mathrm{Bad}$ & None & Some & Moderate & Great \\
\hline & Good & $\mathrm{Bad}$ & None & Some & Moderate & Great \\
\hline & Good & $\mathrm{Bad}$ & None & Some & Moderate & Great \\
\hline & Good & $\mathrm{Bad}$ & None & Some & Moderate & Great \\
\hline
\end{tabular}


31. Increase in number of arguments with parents

32. Getting a job of your own

33. Getting into trouble with police

34. Major personal illness or injury

35. Breaking up with boyfriend/girlfriend

36. Making up with boyfriend/girlfriend

37. Trouble with teacher

38. Male: girlfriend having abortion

39. Female: having abortion

40. Failing to make an athletic team

41. Being suspended from school

42. Making failing grades on report

43. Making an athletic team

44. Trouble with classmates

45. Special recognition for athletic performance

46. Getting put in jail

Other events which have had impact on your life. Please list and rate.

47.

48 .

49.

50 .

$\begin{array}{llllll}\text { Good } & \text { Bad } & \text { None } & \text { Some } & \text { Moderate } & \text { Great } \\ \text { Good } & \text { Bad } & \text { None } & \text { Some } & \text { Moderate } & \text { Great } \\ \text { Good } & \mathrm{Bad} & \text { None } & \text { Some } & \text { Moderate } & \text { Great } \\ \text { Good } & \mathrm{Bad} & \text { None } & \text { Some } & \text { Moderate } & \text { Great } \\ \text { Good } & \mathrm{Bad} & \text { None } & \text { Some } & \text { Moderate } & \text { Great } \\ \text { Good } & \mathrm{Bad} & \text { None } & \text { Some } & \text { Moderate } & \text { Great } \\ \text { Good } & \mathrm{Bad} & \text { None } & \text { Some } & \text { Moderate } & \text { Great } \\ \text { Good } & \mathrm{Bad} & \text { None } & \text { Some } & \text { Moderate } & \text { Great } \\ \text { Good } & \mathrm{Bad} & \text { None } & \text { Some } & \text { Moderate } & \text { Great } \\ \text { Good } & \mathrm{Bad} & \text { None } & \text { Some } & \text { Moderate } & \text { Great } \\ \text { Good } & \mathrm{Bad} & \text { None } & \text { Some } & \text { Moderate } & \text { Great } \\ \text { Good } & \mathrm{Bad} & \text { None } & \text { Some } & \text { Moderate } & \text { Great } \\ \text { Good } & \mathrm{Bad} & \text { None } & \text { Some } & \text { Moderate } & \text { Great } \\ \text { Good } & \mathrm{Bad} & \text { None } & \text { Some } & \text { Moderate } & \text { Great } \\ \text { Good } & \mathrm{Bad} & \text { None } & \text { Some } & \text { Moderate } & \text { Great } \\ \text { Good } & \mathrm{Bad} & \text { None } & \text { Some } & \text { Moderate } & \text { Great }\end{array}$

Good Bad None

Good Bad None

Some Moderate Great

Good Bad None Some Moderate Great 


\section{Appendix I}

\section{Community Violence Exposure}

\section{Directions:}

These questions ask about VIOLENCE. Violence is when somebody attacks or hurts another person. The questions are about things that may have happened at home, school, or in your neighborhood. Make sure you answer each question by putting a circle around the phrase that is most true for you.

Here is a practice question:

Sample: Have you ever eaten ice cream?
No, Never
One Time
A Few Times
Many Times
Every Day
0
1
2
3
4

\section{THESE QUESTIONS ASK ABOUT VIOLENCE AGAINST A} STRANGER. A STRANGER IS SOMEBODY YOU DON'T KNOW.

1. Have you ever watched somebody being beaten up on TV or in the movies?
No, Never
0
One Time
A Few Times
Many Times
Every Day
2
4

2. Has anyone ever told you that a stranger was beaten up?
No, Never
One Time
A Few Times
Many Times
Every Day
0
1
2
3
4

3. Have you ever seen a stranger being beaten up?
No, Never
One Time
A Few Times
Many Times
Every Day
0
1
2
3
4

4. Have you ever watched somebody being chased or seriously threatened on TV or in the movies?

No, Never

0

One Time
1

A Few Times

Many Times

Every Day

4

5. Has anyone ever told you that a stranger was chased or seriously threatened?
No, Never
One Time
A Few Times
Many Times
Every Day
0
1
2
3
4

6. Have you ever seen a stranger being chased or seriously threatened?
No, Never
One Time
A Few Times
Many Times
Every Day
0
1
2
3
4

7. Have you ever watched somebody being robbed or mugged on TV or in the movies?

No, Never

One Time

A Few Times

Many Times

Every Day 
8. Has anyone ever told you that a stranger was robbed or mugged?
No, Never
One Time
A Few Times
Many Times
0
1
2
3
Every Day
4

9. Did you see a stranger being robbed or mugged?
No, Never
One Time
A Few Times
Many Times
0
1
2
3
Every Day
4

10. Have you ever watched somebody being shot or stabbed on TV or in the movies?
No, Never
One Time
A Few Times
Many Times
Every Day

0

1

2

3

4

11. Has anyone ever told you that a stranger was shot or stabbed?
No, Never
One Time
A Few Times
Many Times
Every Day
0
1
2
3
4

12. Have you ever seen a stranger being shot or stabbed?
No, Never
One Time
A Few Times
Many Times
Every Day
0
2
3
4

13. Have you ever watched somebody being killed on TV or in the movies?
No, Never
One Time
A Few Times
Many Times
0
1
2
3
Every Day
4

14. Has anyone ever told you about a stranger being killed?
No, Never
One Time
A Few Times
Many Times
2
3
Every Day
4

15. Have you ever seen a stranger being killed?
No, Never
One Time
A Few Times
Many Times
3
Every Day
0
1
2

These questions ask about violence against familiar people. Familiar people are people you know, like friends, classmates, relatives, cousins, sisters, brothers, and parents.

16. Has anyone ever told you about somebody you know being beaten up?
No, Never
One Time
A Few Times
Many Times
Every Day
0
1
2
3
4

17. Have you ever seen somebody you know being beaten up? 

No, Never
One Time
A Few Times
$\underset{3}{\text { Many Times }}$
Every Day

18. Has anyone ever told you that somebody you know was chased or seriously threatened?
No, Never
0
One Time
A Few Times
$\underset{3}{\text { Many Times }}$
Every Day
4

19. Have you ever seen somebody you know being chased or seriously threatened?
No, Never
One Time
A Few Times
Many Times
2
Every Day
0
1
4

20. Has anyone ever told you about somebody you know being robbed or mugged?
No, Never
One Time
A Few Times
Many Times
Every Day
0
1
2
3
4

21. Have you seen somebody you know being robbed or mugged?
No, Never
One Time
A Few Times
Many Times
Every Day
0
1
2
3
4

22. Has anyone ever told you about somebody you know being shot or stabbed?
No, Never
One Time
A Few Times
Many Times
Every Day
0
1
2
3
4

23. Have you ever seen somebody you know being shot or stabbed?
No, Never
One Time
A Few Times
Many Times
0
1
2
3
Every Day
4

24. Has anyone ever told you about somebody you know being killed?
No, Never
One Time
A Few Times
Many Times
Every Day
0
2
3
4

25. Have you ever seen somebody you know being killed?
No, Never
One Time
A Few Times
Many Times
3
Every Day
0
2
4

These questions ask about violence that has happened to you.

26. Have you ever been beaten up (slapped, kicked, bitten, hit, punched)?
No, Never
One Time
A Few Times
Many Times
2
3
Every Day
4

27. Have you ever been chased (had somebody come after you to hurt you) or threatened ( or warned) to have your body badly or seriously hurt?
No, Never
One Time
A Few Times
Many Times
2
3
Every Day 
Psychobiological Mechanisms 92

28. Have you ever been robbed (or held up) or mugged?

$\begin{array}{ccccc}\text { No, Never } & \text { One Time } & \text { A Few Times } & \text { Many Times } & \text { Every Day } \\ 0 & 1 & 2 & 3 & 4\end{array}$

29. Have you ever been shot (hit with a bullet from a gun or stabbed with a knife?

No, Never

0
One Time

1
A Few Times 2
Many Times

3
Every Day

4 


\title{
Appendix J
}

Parent Permission Form for Hunton

\section{VIRGINIA POLYTECHNIC INSTITUTE AND STATE UNIVERSITY}

\author{
Permission Form for Participants of Investigative Projects \\ (Parent for Child)
}

\section{The Purpose of this Research/Project}

Your child has been invited to participate in a research study run through the Hunton Inc. and the Department of Psychology at Virginia Tech. The project studies emotional reactions in 7-16 year-old children who may have emotional or behavioral problems such as depressed mood, anxiety, conduct problems, or attentional difficulties. Approximately one hundred children are being asked to participate.

\section{Procedures}

As part of this study, your child will be asked to complete several computer tasks and questionnaires, described below. Physical responses in your child that show his/her emotional reaction to the computer tasks will also be measured. The entire session will last approximately 3 hours and will be conducted at Hunton Inc.

Physical responses are measured by changes in your child's heart rate, skin sweat, and in the activity of the hormone, cortisol, as well as in the neurochemical, norepinephrine. Cortisol and norepinephrine are natural chemicals in the body that guide certain body functions such as energy, and they can be measured through the saliva in the mouth. Changes in heart rate, sweat, cortisol, and norepinephrine occur when children feel they are stressed or nervous, but some children can manage these reactions more easily than others. Physical responses are important to measure because they can affect how a child acts and feels in daily situations that they may think are stressful (for example, when they compete with other children in games or when they take a test).

Because puberty can also affect your child's physical responses and behavior, this study will also measure your child's level of development. This will be done through a questionnaire completed by your child where your child will be asked if he/she has noticed any changes that occur as children become teenagers (for example, facial hair for boys or breast growth for girls). His/her height and weight also will be measured. We will also ask your child if he/she has asthma, heart problems, or any other physical illness because these can affect physical responses. Your child may not be able to participate if he/she has a severe illness.

Your child will be asked to complete an interview, several questionnaires, and two computer games. The interview will ask questions related to various mood and behavior problems, and will be videotaped so we can determine the interviewer's accuracy. The 
questionnaires will ask about your child's mood, behaviors, and views about his/her family. The first computer game is a card game where your child tries to earn the most points associated with different cards. In the second computer game, your child believes that he/she is playing against another child for points and that the child earning the most points wins the game. During the game, your child may give or receive a startling burst of noise or lose points on the computer. This makes the game similar to other computer games that are challenging and slightly stressful for children. Really, there is no other child playing the game with your child. Your child will simply play against the computer, but he/she believes that another child is also playing from another facility. We must pretend that another child is there in order to make the competition seem real so that the child will be most motivated to play. This is so we can measure physical responses that might occur in similar situations that children have with other children. We ask that you do not speak to the child about this game before he/she participates. Your child will be told about the fake opponent once the data collection is complete. At that time, your child will have the opportunity to remove his data from the study. Before and after the game your child will be asked some questions about his/her mood and thoughts about the game (for example, "How excited did the game make you?"). Your child's responses to these questions before and after the game, not during the game, will be audiotaped so that we may review them at a later time.

Your child's heart rate and sweating will be measured before and after the second computer game from a sensor placed on the skin over the collarbone, below the lower ribs, and on his/her hand. This is like procedures used in hospitals and involves no pain or risk for your child, although the sticker on the sensors may hurt like a band aid when removed from the skin. Cortisol will be measured in your child's saliva three times - once before and twice after the computer game. Norepinephrine is also measured at these three times, with one additional measure after the computer game. Saliva is collected by having him/her soak a cotton swab in the mouth and then place it in a small tube. Cortisol and norepinephrine are measured from the saliva collected in the tube.

\section{Risks}

The only risk of participating in this study is the possibility that your child might experience feelings of uneasiness during the computer task, which is mildly stressful. For example, your child may feel angry or upset when the "competitor" in the computer game removes points from him/her. Another example is that the loud noises from the game may startle your child. To minimize any discomfort, this study uses only procedures that have been successfully used before with no negative effects on participants. Furthermore, you are free to withdraw your child from this study at any time with no penalties. Your child is also told that he/she does not have to participate or may stop playing the game at any time if he/she wishes to do so. The child is also told that he/she does not have to answer any questions if he/she does not want to. Furthermore, in the event that the child reports that he/she is being harmed by others and/or a family member, we are required to report this information to the proper authorities, after which an investigation might occur.

\section{Benefits of this Project}


The benefit of this project will be a better understanding of emotional and behavioral problems and development in children. Note that there is no guarantee of benefits made to encourage you or your child to participate. The participation of your child is completely voluntary.

\section{Extent of Anonymity and Confidentiality}

Any information obtained during this research will be kept confidential. Situations where confidentiality must be broken include 1) if a previously unreported incident of child abuse is known or strongly suspected or 2) if a participant is believed to be a threat to him/herself or others. In these cases, the investigator must notify appropriate authorities, and you will be informed of the need to report. The authorities would be provided the information about the possibility of harm to the child or others that was obtained during the interviews or questionnaires (e.g., via self-report, audio tape).

Because we have obtained a Certificate of Confidentiality from the National Institutes of Health, we cannot be forced to disclose information that may identify the participant, even by court subpoena, in any federal, state, or local civil, criminal, administrative, legislative, or other proceedings. However, the Certificate does not prevent the participant or the participant's guardian from voluntarily releasing information about the participant's involvement in the research. Furthermore, the Certificate cannot be used to withhold information if the participant or guardian gives voluntary consent to an outside party to receive such information. Lastly, the Certificate does not prevent the investigator from disclosing the participant's information in order to prevent serious harm to the participant or others.

All information is coded after it is obtained so there is no way to associate you or your child by name with the information. Any information that has a name or code on it will be kept in locked files. Only designated research staff will have access to this information. Furthermore, all tapes will be destroyed after the information has been coded, about three months from now. At no time will information obtained from this study be released to anyone without your written consent, except under the conditions noted above. Results may be published or presented for scientific purposes, but your or your child's identity will not be revealed in any description or publication of this research.

\section{Compensation}

Your child will be invited to a party held at Hunton Inc. at the end of the data collection (approximately 4 months), where small prizes (e.g., notebooks, pencils, McDonald's gift certificates) and food will be provided.

\section{Freedom to Withdraw}


You are free to withdraw your child from this study at any time without penalty. Parents and children have the right to refuse to answer any questions or respond to any part of this study, and there would be no penalty.

There may be times that the investigator determines that your child cannot continue in the study. In these cases, you will be notified and the session will end.

\section{Approval of Research}

This project has been approved, as required, by the Institutional Review Board for Research Involving Human Subjects and the Department of Psychology at Virginia Polytechnic Institute and State University.

\section{Parent's Responsibilities}

I give my permission for my child to participate. I have the following responsibilities:

1. Give my permission for my child to complete psychological and physical assessments, consisting of computer tasks, questionnaires, and an interview.

2. Do not tell my child that there is no real competitor in the computer game before he/she plays.

\section{Permission}

I have read the preceding Permission Form and conditions of this project, or it has been read to me, and I understand its contents. Any questions I have about the study have been answered. If my child participates, I understand that he/she may withdraw at any time without penalty. I agree to abide by the rules of this project.

I give my voluntary permission for my child's participation in this project. A signed copy of this permission form will be given to me.

Should I have any questions about this research, I may contact any of these persons:
Dr. Angela Scarpa, Investigator, Department of Psychology
$231-2615$
Dr. Thomas H. Ollendick, Director, Child Study Center
231-6451
Dr. D.W. Harrison, Psychology Human Subjects Committee
$231-4422$
Dr. David M. Moore, Chair, IRB, Research Division
$231-4911$

Please indicate whether you ___ give permission or child's participation in the project. (Please check one.) do not give permission for your 
Psychobiological Mechanisms 97

Parent's/Guardian's Signature

Date 
Appendix K

Guardian Permission Form for Tekoa

\title{
VIRGINIA POLYTECHNIC INSTITUTE AND STATE UNIVERSITY
}

\author{
Permission Form for Participants of Investigative Projects \\ (Guardian of Child)
}

\section{ADOLESCENT'S NAME}

JURISDICTION:

\section{The Purpose of this Research/Project}

The above named adolescent has been invited to participate in a study run through the Tekoa Inc. and the Department of Psychology at Virginia Tech. The project studies characteristics of adolescents who may have behavioral problems. Approximately 30 adolescent males aged 12 to 16 are being asked to participate. Given some of the measures in the present study, adolescents who have asthma, severe heart conditions, or any other physical illness that can interfere with the assessment must be excluded. No adolescent will be excluded based upon race. Since the adolescent is presently in your custody as part of the Department of Social Services and housed at Tekoa Inc., we are asking for your permission to allow the adolescent to participate.

\section{Procedures}

As part of this study, the adolescent will be asked to complete a computer task and questionnaires, described below. Hormonal responses in the adolescent's saliva will also be measured before and after the computer game. The entire session will last approximately 1-1.5 hours after the assenting process and will be conducted at Tekoa Inc.

A natural chemical in the saliva called 3-methoxy-4-hydroxyphenyglycol (MHPG) will be measured through the saliva in the mouth. Saliva will be collected by having him soak a cotton swab in the mouth and then place it in a small tube. This will be done four times during the research session. Changes in this chemical occur when people feel they are stressed or nervous, but some people can manage these reactions more easily than others. Physical responses are important to measure because they can affect how an adolescent acts and feels in daily situations that they may think are stressful (for example, when they compete with other kids in games or when they take a test). No other chemicals will be measured in the saliva other than MHPG.

Because puberty can also affect physical responses and behavior of the adolescent in your custody, this study will also measure the adolescent's level of development. This will be done through a questionnaire completed by the adolescent in your custody where he will be asked if he has noticed any changes that occur as children become teenagers (for example, facial hair for boys). His height and weight will also be measured. We will also ask the adolescent in your 
custody if he has asthma, heart problems, or any other physical illness because these can affect physical responses. The adolescent may not be able to participate if he has a severe illness.

The adolescent in your custody will be asked to complete several questionnaires and a computer game. The interview will ask questions related to various mood and behavior problems. The questionnaires will ask about the adolescent's mood, behaviors, and views about his family. Specifically, questionnaires cover the adolescent's exposure to stressful events, anxiety, aggressive and delinquent behaviors depressive symptoms, and perceptions of abuse and neglect. Several questionnaires specifically assess the adolescent's abuse experiences and suicidal ideation. The computer game is called The Key Game and the adolescent will believe that he is playing against another adolescent across the internet for points. He will be told that the player earning the most points wins the game. During the game, the adolescent in your custody may give or receive a startling burst of noise or lose points on the computer. This makes the game similar to other computer games that are challenging and slightly stressful for youth. Really, there is no other adolescent playing the game with the adolescent in your custody. The adolescent in your custody will simply play against the computer, but he believes that another adolescent is also playing from another facility. We must pretend that another adolescent is there in order to make the competition seem real so that the adolescent will be most motivated to play. This is so we can measure physical responses that might occur in similar situations that kids have with other kids. We ask that you do not speak to the adolescent in your custody about this game before he participates. He will be told about the fake opponent once the data collection is complete. At that time, he will have the opportunity to remove his data from the study. Before and after the game he will be asked some questions about his mood and thoughts about the game (for example, "How excited did the game make you?").

\section{Risks}

One risk of participating in this study is the possibility that the adolescent might experience feelings of uneasiness during the computer task, which is mildly stressful. For example, the adolescent in your custody may feel angry or upset when the "competitor" in the computer game removes points from him. Another example is that the loud noises from the game may startle him. He may also feel emotional distress during the completion of some of the questionnaires. There may be other unknown risks not anticipated by the researchers, To minimize any discomfort, this study uses only procedures that have been successfully used before with no negative effects on participants. Furthermore, you are free to withdraw this adolescent from the study at any time with no penalties. This adolescent is also told that he does not have to participate or may stop playing the game at any time if he wishes to do so. The adolescent is also told that he does not have to answer any questions if he does not want to. Furthermore, in the event that the adolescent reports that he is being harmed by others and/or a family member, we are required to report this information to the proper authorities, after which an investigation might occur.

\section{Benefits of this Project}


The benefit of this project will be a better understanding of emotional and behavioral problems in adolescents. Note that there is no guarantee of benefits made to encourage you or the adolescent to participate. The participation of the adolescent is completely voluntary.

\section{Extent of Anonymity and Confidentiality}

Any information obtained during this research will be kept confidential. Situations where confidentiality must be broken include 1) if a previously unreported incident of child maltreatment is known or strongly suspected or 2) if a participant is believed to be a threat to $\mathrm{him} /$ herself or others. In these cases, the investigator must notify appropriate authorities, and you will be informed of the need to report. The authorities would be provided the information about the child maltreatment and/or harm to self/others that was obtained (i.e., via self-report).

Because we have obtained a Certificate of Confidentiality from the National Institutes of Health, we cannot be forced to disclose information that may identify the participant, even by court subpoena, in any federal, state, or local civil, criminal, administrative, legislative, or other proceedings. The researchers will use the Certificate to resist any demands for information that would identify the participant. However, the Certificate cannot be used to resist a demand for information from personnel of the United States Government that is used for auditing or evaluation of Federally funded projects.

A study identification number will be chosen randomly from a table of random numbers. This number will serve as the code number for all information collected from the participant. No identifying information will be recorded on any of the questionnaires. The Permission form, adolescent's Assent form, and staff's consent form will be locked in a separate cabinet from the coded questionnaires in another lock files. Only designated research staff will have access to coded information, while only the Investigators will have access to the signed forms. Furthermore, all completed questionnaires will be destroyed after the information has been coded, about three months from now. Information will not be released without written consent from the participant unless during the research session 1) a previously unreported incident of child abuse is discovered or strongly suspected or 2) the adolescent is believed to be a threat to himself or others. Other information cannot be voluntarily released by the experimenter. Results may be published or presented for scientific purposes, the adolescent's identity will not be revealed in any description or publication of this research.

\section{$\mathrm{XVI}$. Compensation}

There is no compensation for participating in this project. The adolescent's participation is completely voluntary. The adolescent's participation will not impact his/her progress at Tekoa Inc. nor will it affect Department of Social Services proceedings.

\section{Freedom to Withdraw}

You are free to withdraw the adolescent from this study at any time without penalty. Adolescents have the right to refuse to answer any questions or respond to any part of this study, and there would be no penalty. There may be times that the investigator determines that your adolescent cannot continue in the study. In these cases, the adolescent will be notified and the session will end. 
XVIII. Approval of Research

This project has been approved, as required, by the Institutional Review Board for Research Involving Human Subjects, the Department of Psychology at Virginia Polytechnic Institute and State University, and the Executive Director of Tekoa Inc.

XIX. Guardian's Responsibilities

I give my permission for the adolescent in my custody to participate. I give my permission for this adolescent to complete the questionnaires, play the game, and have his saliva collected for the purpose of measuring MHPG levels.

\section{$\mathrm{XX}$. Permission}

I have read the preceding Permission Form and conditions of this project, or it has been read to me, and I understand its contents. Any questions I have about the study have been answered. If the adolescent in my custody participates, I understand that he may withdraw at any time without penalty, including after completing the research session.

As the adolescent's guardian, I give my voluntary permission for his/her participation in this project. A signed copy of this permission form will be given to me.

I have received a copy of this form and should I have any questions about this research, I may contact any of these persons:

Dr. Angela Scarpa, Investigator, Department of Psychology

Dr. D.W. Harrison, Psychology Human Subjects Committee

Dr. David M. Moore, Chair, IRB, Research Division

231-4911

Please indicate whether you give permission or do not give permission for the adolescent's participation in the project. (Please check one.)

Guardian's Name (Printed) 


\section{Appendix L}

\section{Assent Form for Hunton}

\section{CHILD ASSENT TO PARTICIPATE IN A RESEARCH STUDY}

I have been asked to be in a study of behavior in children. My hormones called cortisol and norepinephrine will be measured when I play a computer game with others. I will be asked questions about the game. I am also asked to fill out questionnaires about myself and to play a computerized game. It will take about one hour to do all this.

For participating in the study, I will be invited to a party at the Hunton Inc. at the end of the data collection (approximately 4 months), where small prizes and food will be provided. If I am uncomfortable or feel any pain I should tell the experimenter so we can fix it or stop the study. Also, if I do not want to answer any questions that is okay too. If I decide to withdraw from the study any time after we begin, all I will need to do is tell the tester that I do not want to answer any more questions. If I withdraw, I will still be able to attend the party.

Anything I tell the tester is private. The testers have a form called a Certificate of Confidentiality from the National Institutes of Health. This means the tester cannot be forced to disclose information that may identify me, even by a court subpoena. However, the tester will still have to report if I am being hurt by others (including a parent) or if I am going to hurt myself or someone else.

If I have any questions now, I can ask the tester. If I have questions after the study is finished, I may call Angela Scarpa at 231-2615. I can stop being in the study at any time, and I can change my mind after I start. I have been given the opportunity to have my questions answered regarding my participation in this study.

I want to say "yes" to be in the study.

Child's Signature

Witness's Signature
Date

Date 


\section{Appendix M}

\section{Assent Form for Tekoa}

\section{ADOLESCENT ASSENT TO PARTICIPATE IN A RESEARCH STUDY}

I have been asked to be in a study of behavior in adolescents. A hormone called MHPG from norepinephrine will be measured when I play a computer game with others. Hormones are chemicals in the body that can be measured through my saliva (spit). I am asked to play a computer game with another adolescent. I will soak a cotton swab in my mouth and place it into a small tube to collect saliva once before and twice after the game. For everyone's protection, the tester will wear exam gloves to collect my saliva. I am also asked to fill out other questionnaires about myself. It will take about 1-1.5 hours to do all this.

Anything I tell the tester is private. The testers have a form called a Certificate of Confidentiality from the National Institutes of Health. This means the tester cannot be forced to disclose information that may identify me, even by a court subpoena. However, the tester will still have to report if I am being hurt by others (including a parent) or if I am going to hurt myself or someone else.

It is possible that during the session I may feel uncomfortable. For example, some of the questions may upset me or I may feel upset when playing the game. I know that I do not have to answer questions if I do not want to. I also do not have to play the game if I do not want to. I can also stop being in the study if I want. No penalties will occur if I want to stop.

If I have any questions now, I can ask the tester. If I have questions after the study is finished, I may call Angela Scarpa at 231-2615. I can stop being in the study at any time, and I can change my mind after I begin the surveys and after the research session has ended. I can withdraw by either telling the experimenter that I do not want to continue or by letting a Tekoa Inc. staff member know that I do not want to continue. Absolutely no penalties would occur for my decision to stop.

I have been given the opportunity to have my questions answered regarding my participation in this study and have received a copy of this form.

I want to say "yes" to be in the study.

Adolescents' Signature

Date 
Table 1

Means (SD in Parentheses), F Values, and Significance Levels by Site.

\begin{tabular}{|c|c|c|c|c|}
\hline Measures & Hunton $^{a}$ & Tekoa $^{b}$ & $t$ & $p$ \\
\hline \multirow[t]{2}{*}{ Age } & 11.89 & 15.21 & -5.35 & $.00 * *$ \\
\hline & $(2.22)$ & $(1.31)$ & & \\
\hline \multirow[t]{2}{*}{ Expressed Hostile Aggression $^{c}$} & 30.00 & 27.40 & .66 & .52 \\
\hline & $(31.29)$ & $(32.87)$ & & \\
\hline \multirow[t]{2}{*}{ Expressed Instrumental Aggression ${ }^{\mathrm{d}}$} & 13.42 & 30.00 & -1.92 & .08 \\
\hline & $(9.60)$ & $(25.71)$ & & \\
\hline \multirow[t]{2}{*}{ Baseline MHPG(mol/L) } & $3.80 \mathrm{E}-08$ & $2.69 \mathrm{E}-08$ & 1.69 & .10 \\
\hline & $(1.87 \mathrm{E}-08)$ & $(1.27 \mathrm{E}-08)$ & & \\
\hline \multirow[t]{2}{*}{ Post Game MHPG(mol/L) } & $3.73 \mathrm{E}-08$ & $2.78 \mathrm{E}-08$ & 1.61 & .11 \\
\hline & $(1.64 \mathrm{E}-08)$ & $(1.39 \mathrm{E}-08)$ & & \\
\hline \multirow[t]{2}{*}{ Post-10 MHPG(mol/L) } & $3.36 \mathrm{E}-08$ & $2.48 \mathrm{E}-08$ & 1.57 & .12 \\
\hline & $(1.55 \mathrm{E}-08)$ & $(1.55 \mathrm{E}-08)$ & & \\
\hline \multirow[t]{2}{*}{ Post-40 MHPG(mol/L) } & $3.13 \mathrm{E}-08$ & 2.09E-08 & 2.15 & $.04 *$ \\
\hline & $(1.36 \mathrm{E}-08)$ & $(1.14 \mathrm{E}-08)$ & & \\
\hline \multirow[t]{2}{*}{ SBR (Instrumental) } & 13.78 & 15.00 & -1.24 & .22 \\
\hline & $(3.23)$ & $(3.00)$ & & \\
\hline \multirow[t]{2}{*}{ SBR (Hostile) } & 9.06 & 9.08 & -.03 & .98 \\
\hline & $(2.55)$ & $(2.14)$ & & \\
\hline SBR (Total) & 22.82 & 24.08 & -.77 & .44 \\
\hline
\end{tabular}


(5.27)

PRA (Hostile)

PRA (Instrumental)

PRA (Total)

AEQ (Physical Punishment)

AEQ (Parental Rejection)

AEQ (Negative Atmosphere)

SRDS

LEC (sum good events)

LEC (sum bad events)

LEC (good life change score)

LEC (bad life change score)
7.67

(2.93)

4.30

(2.22)

11.96

(4.30)

1.78

(1.63)

.26

(.71)

1.37

(1.27)

16.57

(4.31)

5.46

(2.48)

6.24

(3.90)

5.61

(2.57)

6.22

(3.90)
(4.94)

$\begin{array}{lll}8.58 & -.98 & .33\end{array}$

(2.84)

$\begin{array}{lll}5.08 & -1.11 & .27\end{array}$

13.67

$-1.22 \quad .23$

(4.60)

3.75

$-2.85 \quad .01 *$

(2.41)

.92

$-2.30 \quad .03 *$

(1.51)

3.25

$-3.32$

$.00 * *$

(2.17)

29.58

$-8.03 \quad .00^{* *}$

(7.76)

3.33

2.76

$.01 *$

(2.14)

7.70

$-1.02$

.31

(5.29)

3.33

2.85

$.01 *$

(2.15)

7.60

$-.96$

.34

(5.21) 
Psychobiological Mechanisms 106

CREV (direct victimization)

$.00^{* *}$

(1.98)

(3.07)

Note. All means and standard deviations are non-transformed values. All statistics are based on transformed values. ${ }^{\mathrm{a}} N=54 .{ }^{\mathrm{b}} N=12 .{ }^{\mathrm{c}} N=15$ (Hunton) and 4 (Tekoa). ${ }^{\mathrm{d}} N=14$ (Hunton) and 4 (Tekoa). $* p<.05 . * * p<.01$. 
Table 2

Means (SD in Parentheses) for Mood Ratings Pre, During, and After Analog Aggression Task

\begin{tabular}{llll} 
Mood & Pre & During & After \\
\hline Frustrated & $.21(.57)^{\mathrm{a}}$ & $1.34(1.49)^{\mathrm{b}}$ & $.85(1.46)^{\mathrm{b}, \mathrm{c}}$ \\
Angry & $.13(.63)^{\mathrm{a}}$ & $.96(1.45)^{\mathrm{b}}$ & $.63(1.29)^{\mathrm{b}, \mathrm{c}}$ \\
Nervous & $.69(.96)^{\mathrm{a}}$ & $.69(1.23)^{\mathrm{c}}$ & $.28(.85)^{\mathrm{b}}$ \\
Bored & $.61(1.18)$ & $.46(1.09)$ & $.52(1.13)$ \\
Excited & $1.51(1.52)^{\mathrm{a}}$ & $2.01(1.67)^{\mathrm{b}}$ & $1.39(1.60)^{\mathrm{c}}$ \\
Happy & $2.10(1.55)$ & $1.75(1.64)$ & $1.72(1.56)$ \\
Sad & $.21(.75)$ & $.33(.89)$ & $.33(.93)$ \\
\hline
\end{tabular}

Note. Different letters (i.e., ${ }^{\mathrm{a}},{ }^{\mathrm{b}}$, and $^{\mathrm{c}}$ ) denote significant effects for paired sample t-test. 
Table 3

Zero-order Correlations between MHPG and Self-Reported Aggression.

$\begin{array}{llll}1 & 2 & 3 & 4\end{array}$

5

6

\begin{tabular}{|c|c|c|c|c|c|c|c|c|c|c|}
\hline 1. Baseline MHPG & 1.00 & & & & & & & & & \\
\hline 2. Post MHPG & $.75^{* *}$ & 1.00 & & & & & & & & \\
\hline 3. Post-10 MHPG & $.70 * *$ & $.79 * *$ & 1.00 & & & & & & & \\
\hline 4. Post-40 MHPG & $.57 * *$ & $.77 * *$ & $.75^{* *}$ & 1.00 & & & & & & \\
\hline 5. PRA-Instrumental & .14 & .15 & .08 & .20 & 1.00 & & & & & \\
\hline 6. PRA-Hostile & .13 & .10 & -.03 & .09 & $.44 *$ & 1.00 & & & & \\
\hline 7. PRA-Total & .16 & .14 & .02 & .16 & $.80 * *$ & $.89 * *$ & 1.00 & & & \\
\hline 8. SBR-Hostile & -.03 & .03 & .03 & .15 & $.53 * *$ & $.53 * *$ & $.63 * *$ & 1.00 & & \\
\hline 9. SBR-Instrumental & .13 & .10 & .09 & .07 & $.47 * *$ & $.44 * *$ & $.53 * *$ & $.68 * *$ & 1.00 & \\
\hline 10. SBR-Total & .04 & .06 & .06 & .12 & $.55^{* *}$ & $.54 * *$ & $.64 * *$ & $.94 * *$ & $.89 * *$ & 1.00 \\
\hline
\end{tabular}

Note. ${ }^{*} p<.05$ [2-tailed]. ${ }^{* *} p<.01$ [2-tailed]. PRA - Proactive and Reactive Aggression questionnaire. SBR - Self Behavior Rating questionnaire. 
Table 4

Means (SD in Parentheses) for MHPG Levels by Assigned Condition.

\begin{tabular}{lllll}
\hline & & \multicolumn{3}{c}{ Assigned Condition } \\
\cline { 3 - 5 } MHPG & No Retaliation $(N=27)$ & Hostile $(N=14)$ & Instrumental $(N=15)$ & Pooled \\
\hline Baseline & $4.08(2.01)$ & $3.64(1.61)$ & $2.75(1.40)$ & $3.62(1.82)^{\mathrm{a}}$ \\
Post & $3.79(1.37)$ & $3.74(2.10)$ & $3.04(1.56)$ & $3.57(1.62)^{\mathrm{c}}$ \\
Post-10 & $3.51(1.69)$ & $3.51(1.73)$ & $2.42(.79)$ & $3.21(1.57)^{\mathrm{d}}$ \\
Post- 40 & $3.27(1.40)$ & $3.09(1.52)$ & $2.31(.98)$ & $2.97(1.38)^{\mathrm{b}, \mathrm{d}}$ \\
Pooled & $3.66(.27)^{\mathrm{a}}$ & $3.49(.37)$ & $2.63(.36)^{\mathrm{b}}$ & \\
\hline
\end{tabular}

Note. All MHPG values are to the E-08. Different letters (i.e., ${ }^{\mathrm{a}}, \mathrm{b}^{\mathrm{b}}$, , and ${ }^{\mathrm{d}}$ ) denote significant or approaching significant effects for pairwise comparison tests. Significant differences were also found between the instrumental and no retaliation for baseline, post 10 , and post 40 MHPG levels. 
Psychobiological Mechanisms 110

Table 5

Zero-order Correlations between MHPG Levels, Self-Reported Aggression, and Rearing Environment Variables.

\begin{tabular}{llllllll} 
& PRA- & SBR- & Baseline & Post & Post 10 & Post 40 \\
& Total & Total & MHPG & MHPG & MHPG & MHPG \\
\hline Physical Punishment & .14 & .14 & .09 & .23 & .21 & .04 \\
Parental Rejection & .13 & .13 & -.02 & -.02 & -.02 & .01 \\
Negative Family & $.42 * *$ & $.30 * *$ & -.19 & -.02 & -.02 & .11 \\
\hline
\end{tabular}

Note. ${ }^{*} p<.05$ [2-tailed]. ${ }^{* *} p<.01$ [2-tailed]. 
Table 6

Zero-order Correlations between Mood Ratings and Self-Reported Aggression.

\begin{tabular}{lllllllllllll}
1 & 2 & 3 & 4 & 5 & 6 & 7 & 8 & 9 & 10 & 11 & 12 & \\
\hline
\end{tabular}

1. Frustrated before 1.00

2. Anger Before $\quad .51 * * \quad 1.00$

3. Frustrated during $\quad .35^{* *} \quad .21 \quad 1.00$

4. Angry during $\quad .41 * * \quad .28 * \quad .59 * * \quad 1.00$

5. Frustrated after $\quad .42 * * \quad .39 * * \quad .50 * * \quad .53 * * \quad 1.00$

$\begin{array}{lllllll}\text { 6. Angry after } & .50 * * & .33 * * & .45 * * & .62 * * & .88 * * & 1.00\end{array}$

$\begin{array}{llllllll}\text { 7. PRA-Total } & .13 & .18 & .37 * * & .48^{* *} & .30^{*} & .16 & 1.00\end{array}$

$\begin{array}{lllllllll}8 . P R A- & .04 & .03 & .30 * & .38 * * & .25 * & .09 & .80 * * & 1.00\end{array}$

Instrumental

\begin{tabular}{|c|c|c|c|c|c|c|c|c|c|c|}
\hline 9. PRA-Hostile & .17 & .24 & $.33 * *$ & $.43^{* *}$ & $.26^{*}$ & .17 & $.89 * *$ & $.44 * *$ & 1.00 & \\
\hline 10. SBR-Total & .16 & $.29 *$ & $.40 * *$ & $.44 * *$ & $.46^{* *}$ & $.43 * *$ & $.64^{* *}$ & .55 & $.54 * *$ & 1.00 \\
\hline 11.SBR- & .11 & $.31 *$ & $.30^{*}$ & $.38 * *$ & $.47 * *$ & $.42 * *$ & $.63^{* *}$ & $.53 * *$ & $.53 * *$ & $.94 * *$ \\
\hline
\end{tabular}


Psychobiological Mechanisms 112

Instrumental

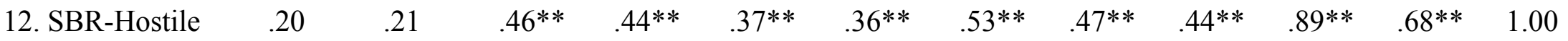
Note. ${ }^{*} p<.05$ [2-tailed]. ${ }^{* *} p<.01$ [2-tailed]. PRA - Proactive and Reactive Aggression questionnaire. SBR - Self Behavior Rating questionnaire. 
Table 7

Model Testing for Moderational Effects of Baseline MHPG on Negative Family Atmosphere and Total Aggression (PRA).

\begin{tabular}{|c|c|c|c|c|}
\hline Variable & B & SE B & $\beta$ & $\Delta \mathrm{R}^{2}$ \\
\hline Block 1 & & & & .03 \\
\hline Physical Punishment & .73 & .88 & .11 & \\
\hline Parental Rejection & 3.94 & 5.06 & .11 & \\
\hline Block 2 & & & & $.15^{* *}$ \\
\hline Physical Punishment & -.03 & .86 & -.00 & \\
\hline Parental Rejection & 1.06 & 6.14 & -.02 & \\
\hline Negative Family & 3.18 & 1.03 & $.43 * *$ & \\
\hline Block 3 & & & & $.06^{*}$ \\
\hline Physical Punishment & -.30 & .84 & -.05 & \\
\hline Parental Rejection & -.87 & 4.78 & -.02 & \\
\hline Negative Family & 3.66 & 1.03 & $.50 * *$ & \\
\hline Baseline MHPG & .62 & .30 & $.26^{*}$ & \\
\hline Block 4 & & & & .03 \\
\hline Physical Punishment & -.16 & .84 & -.03 & \\
\hline Parental Rejection & -2.48 & 4.89 & -.07 & \\
\hline Negative Family & 3.62 & 1.02 & $.49 * *$ & \\
\hline Baseline MHPG & .76 & .31 & $.32 *$ & \\
\hline Negative $\mathrm{x}$ Baseline & .62 & .47 & .18 & \\
\hline
\end{tabular}


Psychobiological Mechanisms 114

Note. $N=56$. PRA=Proactive and Reactive Aggression questionnaire. ${ }^{*} p<.05 .{ }^{* *} p<.01$. 
Table 8

Zero-order Correlations between Mood Ratings and Rearing Environment Characteristics.

\begin{tabular}{llll} 
& Physical & Parental & Negative \\
& Punishment & Rejection & Family \\
\hline Frustrated Before & .20 & .01 & .09 \\
Angry Before & .13 & $.32 * *$ & .13 \\
Frustrated during & .06 & -.07 & .08 \\
Angry during & .13 & -.01 & $.25^{*}$ \\
Frustrated after & .19 & .13 & $.24 *$ \\
Angry after & .12 & .08 & $.29 *$ \\
\end{tabular}

Note. ${ }^{*} p<.05$ [2-tailed]. ${ }^{* *} p<.01$ [2-tailed]. 
Table 9

Zero order correlations between Self-Reported Delinquency, MHPG levels, and Rearing Environment.

\begin{tabular}{|c|c|c|c|c|c|c|c|c|}
\hline & 1 & 2 & 3 & 4 & 5 & 6 & 7 & 8 \\
\hline 1. Physical Punishment & 1.00 & & & & & & & \\
\hline 2. Parental Rejection & .20 & 1.00 & & & & & & \\
\hline 3. Negative Family & $.28^{*}$ & $.38^{*}$ & 1.00 & & & & & \\
\hline 4. Delinquency & $.39 * *$ & $.25^{*}$ & $.52 * *$ & 1.00 & & & & \\
\hline 5. Baseline MHPG & .09 & -.02 & -.19 & -.10 & 1.00 & & & \\
\hline 6. Post MHPG & .23 & -.02 & -.02 & .01 & $.75^{* *}$ & 1.00 & & \\
\hline 7. Post $10 \mathrm{MHPG}$ & .21 & -.02 & -.02 & .06 & $.70 * *$ & $.78^{* *}$ & 1.00 & \\
\hline 8. Post $40 \mathrm{MHPG}$ & .04 & .01 & .11 & .03 & $.57 * *$ & $.77 *$ & $.75^{* *}$ & 1.00 \\
\hline
\end{tabular}

Note. ${ }^{*} p<.05$ [2-tailed]. ${ }^{* *} p<.01$ [2-tailed]. PRA - Proactive and Reactive Aggression questionnaire. SBR - Self Behavior Rating questionnaire. 
Psychobiological Mechanisms 117

Table 10

Model Testing for Moderational Effects of Baseline MHPG on Physical Punishment and SelfReported Delinquency.

\begin{tabular}{|c|c|c|c|c|}
\hline Variable & $\mathrm{B}$ & SE B & $\beta$ & $\Delta \mathrm{R}^{2}$ \\
\hline Block 1 & & & & $.18 * *$ \\
\hline Physical Punishment & 4.60 & 1.37 & $.42 * *$ & \\
\hline Block 2 & & & & .02 \\
\hline Physical Punishment & 4.85 & 1.37 & $.44 * *$ & \\
\hline Baseline MHPG & -.59 & .51 & -.14 & \\
\hline Block 4 & & & & .00 \\
\hline Physical Punishment & 4.83 & 1.41 & $.43 * *$ & \\
\hline Baseline MHPG & -.58 & .53 & -.14 & \\
\hline Punish x Baseline & -.07 & .91 & -.01 & \\
\hline
\end{tabular}

Note. $N=56 .{ }^{* *} p<.01$. 
Psychobiological Mechanisms 118

Table 11

Model Testing for Moderational Effects of Post Levels of MHPG on Parental Rejection and SelfReported Delinquency.

\begin{tabular}{|c|c|c|c|c|}
\hline Variable & B & SE B & $\beta$ & $\Delta \mathrm{R}^{2}$ \\
\hline Block 1 & & & & .05 \\
\hline Parental Rejection & 14.10 & 8.44 & .22 & \\
\hline Block 2 & & & & .01 \\
\hline Parental Rejection & 14.27 & 8.66 & .22 & \\
\hline Post MHPG & -.34 & 1.13 & -.07 & \\
\hline Post 10 MHPG & .72 & 1.13 & .15 & \\
\hline Post 40 MHPG & -.18 & 1.28 & -.03 & \\
\hline Block 3 & & & & $.18^{*}$ \\
\hline Parental Rejection & 11.09 & 8.54 & .17 & \\
\hline Post MHPG & -.63 & 1.08 & -.14 & \\
\hline Post 10 MHPG & 1.559 & 1.11 & .32 & \\
\hline Post 40 MHPG & -1.17 & 1.29 & -.21 & \\
\hline Rejection $\mathrm{x}$ Post & -7.15 & 14.19 & -.20 & \\
\hline Rejection $\mathrm{x}$ Post 10 & 35.64 & 12.62 & $1.10^{* *}$ & \\
\hline Rejection $\mathrm{x}$ Post 40 & -35.55 & 16.75 & $-.72 *$ & \\
\hline
\end{tabular}

Note. $N=56 .{ }^{*} p<.05 .{ }^{* *} \mathrm{p}<.01$. 
Table 12

Model Testing for Moderational Effects of Post Levels of MHPG on Physical Punishment and Self-Reported Delinquency.

\begin{tabular}{lcccc}
\hline Variable & B & SE B & $\beta$ & $\Delta \mathrm{R}^{2}$ \\
\hline Block 1 & & & & $.18^{* *}$ \\
Physical Punishment & 4.70 & 1.37 & $.42^{* *}$ & \\
Block 2 & & & & .02 \\
Physical Punishment & 5.23 & 1.48 & $.47^{* *}$ & \\
Post MHPG & -1.17 & 1.06 & -.25 & .06 \\
Post 10 MHPG & .07 & 1.05 & .01 & \\
Post 40 MHPG & 1.07 & 1.22 & .19 & \\
Block 3 & & & & \\
Physical Punishment & 6.37 & 1.59 & $.57^{* *}$ & \\
Post MHPG & -1.80 & 1.14 & -.39 & \\
Post 10 MHPG & .13 & 1.05 & .03 & \\
Post 40 MHPG & 1.32 & 1.30 & .24 & \\
Punish x Post & -.16 & 1.76 & -.02 & \\
Punish x Post 10 & 3.21 & 1.98 & .44 & \\
Punish x Post 40 & -1.63 & 2.00 & -.21 & \\
\hline Note. N $56 . * * p<.01$. & & & \\
\end{tabular}

Note. $N=56 .{ }^{* *} p<.01$. 
Figure 1

Proposed Model for Present Project

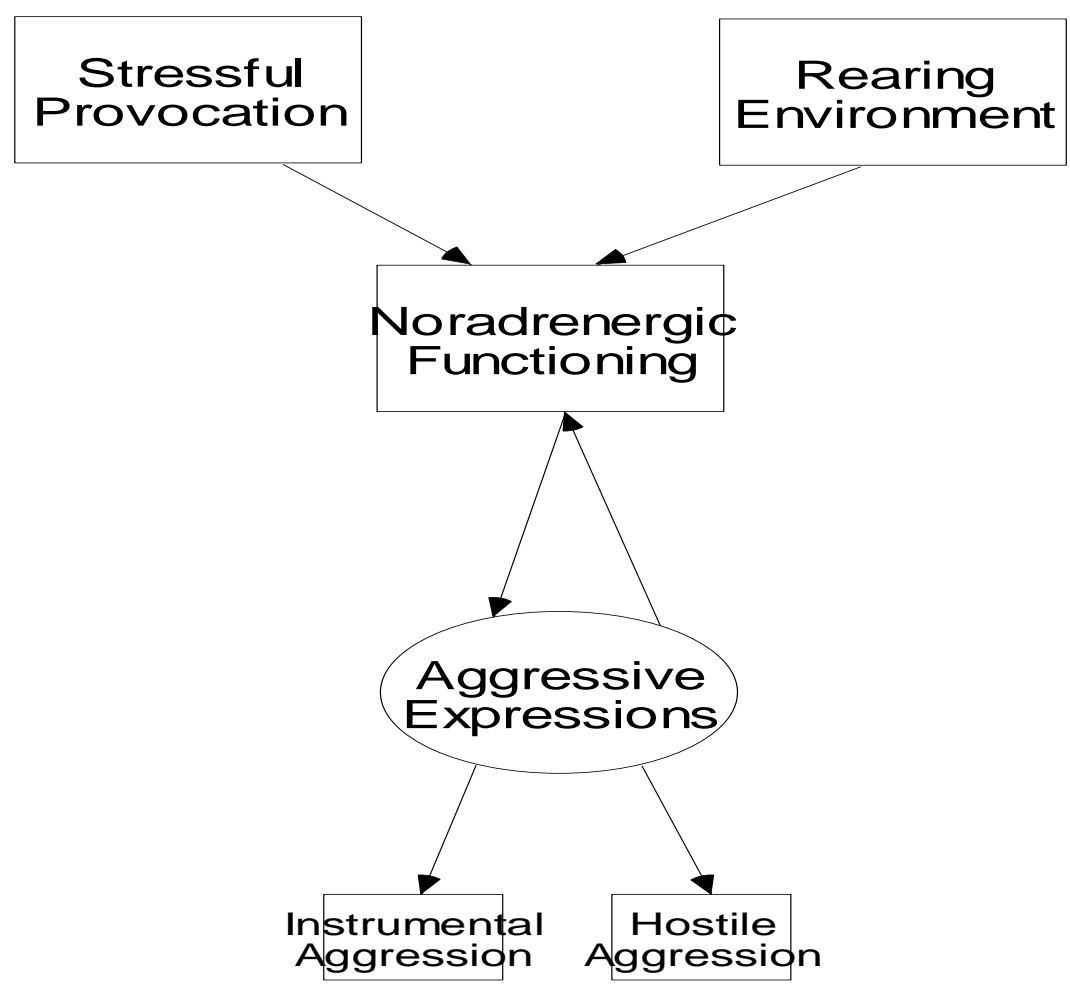




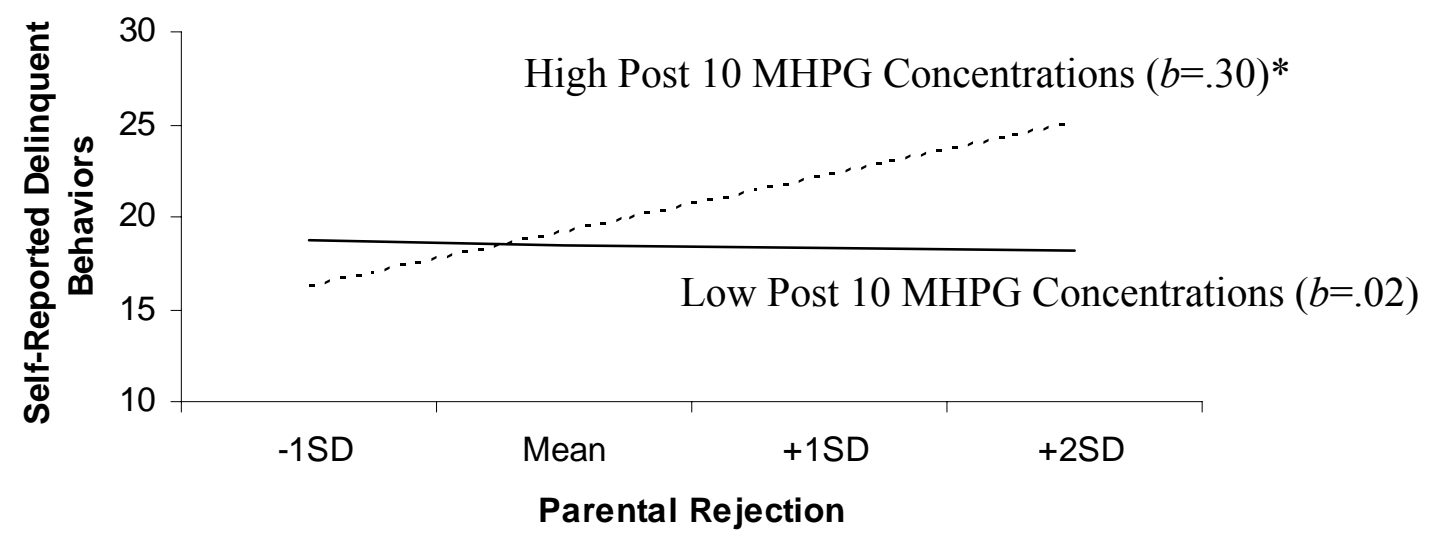

Figure 2. Regression lines for High and Low Post 10 MHPG Concentrations on the Relationship between Parental Rejection and Self-Reported Delinquent Behaviors. $b=$ standardized coefficient. ${ }^{*} \mathrm{p}<.05$. 
Psychobiological Mechanisms 122

VITA

$\begin{array}{ll}\text { Name: } & \text { Sara Chiara Haden } \\ \text { Place of Birth: } & \text { Washington, D.C. } \\ \text { Date of Birth: } & \text { March 21, 1977 }\end{array}$

Education:

Italian Credit: Lorenzo De’Medici, Florence, Italy, May 1998.

B.A.: Psychology, Minor: Italian, University of Virginia, Charlottesville, VA, May 1999.

M.A.: Psychology, University of Massachusetts Dartmouth, North

Dartmouth, MA, Advisor: Mahzad Hojjat, Ph.D., June 2002.

Ph.D.: Psychology, Virginia Polytechnic Institute and State University, APA accredited Clinical Psychology, Blacksburg, VA, Dissertation: Psychobiological Mechanisms of Aggression in Youth. Advisor: Angela Scarpa, Ph.D., anticipated May 2007.

\section{Grants and Honors:}

University of Massachusetts Dartmouth, University Scholarship, 1999-2000, 2001-2002.

University of Massachusetts Dartmouth, Chancellor's Centennial Scholarship, \$1,000, 2000-2001.

Aggressive components of sexual aggression. Grant awarded by the Association for the

Treatment of Sex Abusers, \$11,255, 2001-2002.

Graduate Galper Fund Award. \$300, 2003-2004, 2004-2005.

Second place award winner for Social Sciences research at the Virginia Tech Graduate Student Assembly Research Symposium, Blacksburg, Va. \$250, 2004.

Graduate Student Assembly. Virginia Polytechnic Institute and State University. Graduate Research Development Project grant. \$375. 2004.

Division 53 Society for Clinical Child and Adolescent Psychology Research Award. \$750. 2005.

Outstanding Graduate Student in the College of Science. Virginia Polytechnic Institute and State University. 2005.

Clinical Child Research Fund Award. Department of Psychology. Virginia Polytechnic Institute and State University. \$600. 2005.

Ph.D. Fellow. AdvanceVT, National Science Foundation. 2005-2006.

American Psychology Foundation. Council of Graduate Departments of Psychology (COGDOP) Scholarship, 2005.

Safe Zone Recognition Award for Teaching, Virginia Polytechnic Institute and State University. 2005.

\section{Clinical Practicum Experience:}

Graduate Clinician, Psychological Services Center/Virginia Polytechnic Institute and State University, Director: Lee Cooper, PhD, LCP. Supervisors: George Clum, PhD, LCP (540-231-5701), Lee Cooper, PhD, LCP (540-231-6914), and Angela Scarpa (540-231-2615). Supervised hours: 965. September 2002 - August 2005. Provided psychotherapy to a range of clientele, including adults, adolescents, children, and older adults. Employed different treatment modalities including individual, couple, family, and group psychotherapy. Utilized a variety of treatment approaches including cognitive behavioral, behavioral, family systems, interpersonal, supportive, and parent management training. Client population comprised of primarily Caucasians and African-Americans. Problems treated include Major Depression, Generalized Anxiety, Post Traumatic Stress, Social Anxiety, Specific Phobias, Adjustment Disorders, 
Conduct Disorder, anger management problems, and parent management issues. Developed and implemented treatment plans. Presented cases to supervisor and team of graduate clinicians. Prepared progress notes, intake and discharge summaries. Completed comprehensive psychological assessments for adults and prepared assessment reports. Participated in weekly team and individual supervision. Served as graduate supervisor for first year clinical students leading parent management training group, as well as individual, family, and couples psychotherapy cases.

Graduate Clinician - Extern, Bland Correctional Center/Virginia Department of Corrections (DOC), Supervisors: Rob Ritchey, M.S. LCP (276-688-3341 x5083) \& William Lee, Ph.D., LCP. (540-561-7050 x5017). Supervised hours: 246. June 2004 -April 2005. Provided mental health services to light medium security male offenders. Worked with primarily African-American and Caucasian males diagnosed with substance abuse disorders, various comorbid conditions, and Axis II disorders (Antisocial, Borderline, Narcissist, Histrionic, and psychopathic characteristics). Co-led cognitive therapy and rational emotive therapy groups. Conducted full psychological assessments using various structured and standardized instruments (WASI-4, PAI, Bender). Prepared evaluation reports for other mental health counselors and the psychiatrist. Conducted brief clinical assessments on suicidality, parasuicidality, and violence risk. Provided individual treatment to inmates. Interventions focused on adjustment to prison, treatment resistance issues, changing criminal attitudes, and planning for release, as well as treatment for various mood, anxiety, and substance use related disorders. Conducted mental health screening for Virginia inmates in the receiving unit via clinical interviewing and the Mini Mental Status Exam. Recommended proper facility placements within the Department of Corrections based on mental health needs.

Psychoeducational Group Leader, Cook Counseling Center/Virginia Polytechnic Institute and State University, Director: Sherry Lynch Conrad (540-231-6557), PhD, LCP. Supervised hours: 3. January 2004 - May 2004. Planned and conducted a weekly group on stress management for college-aged men and women utilizing various cognitive-behavioral techniques.

Group Psychotherapy Graduate Clinician, Cook Counseling Center/Virginia Polytechnic Institute and State University, Director: Rita Klein, PhD, LCP. (540-231-6557). Supervised hours: 5. September 2003 - December 2003. Attended, observed, and prepared notes for 'Group Processes' psychotherapy group for seven college-aged men and women with anxiety-related problems. Participated in meetings regarding skills for leading group psychotherapy and processing of each group session.

\section{Other Clinical Experience:}

Clinical Research Assistant, Child Study Center, Virginia Polytechnic Institute and State University. Supervisor: Thomas Ollendick, PhD. LCP. (540-231-8276). Supervised Hours: 76. 2002-2005. Conducted diagnostic interviews using the Anxiety Disorders Interview Schedule (ADIS) for children/adolescents ranging from 8 to 17 years of age for a granted funded project through the National Institute of Mental Health, "Childhood and Adolescent Phobia Project." Conducted ADIS-Parent and ADIS-Client interviews with parents of children.

Psychiatric Aide, Western State Hospital. Advisor: David Rawls, PhD, LCP. (540-332-8215). Summer 2001. 10-week internship in acute admissions forensic unit of state psychiatric hospital. Collaborated with the psychiatrist, clinical psychologist and social worker in an effort to determine incoming patient's prominent psychiatric symptoms, current judgment and insight, and risk of danger to self and others. Interacted with acutely psychotic, schizophrenic, anxiety and mood disorders male patients. Discussed behaviors for intervention and recommended psychology follow-up plans. Observed formal forensic evaluations including competency to stand trial and mental status at time of the offense, as well as courtroom proceedings for insanity trials. Helped to determine evaluation outcomes. Gained practice in 
writing formal court evaluation letters. Co-led educational group "Competency to Stand Trial" for patients.

Clinical Research Assistant, Institute of Law, Psychiatry, \& Public Policy / Fluvanna

Correctional Center for Women, University of Virginia. Director: Janet Warren,

D.S.W., (434-924-5435). 1999-2000. Trained in use of Psychopathy Checklist-Revised and Historical, Clinical, and Risk Management-20. Assisted in the evaluation of female inmates for a grant funded project through the National Institute of Justice, "Women's Coping in Prison."

Telephone Counselor, Local Crisis Intervention Hotline, Charlottesville, VA, 1997. Answered telephone calls for Central Virginia's confidential hotline (after completing an intensive five month training program) dealing with suicide prevention, victims of assault, criminal offenders and other crisis situations.

\section{Research Experience:}

Research Assistant, Violence and Victimization Lab, Virginia Polytechnic Institute and State University. Directors: Angela Scarpa, PhD., Estimated Research Hours: 3000. 2002-present. Assisted in several large scale research projects. Work as a research assistant on a variety of research projects. Interviewed parents and children for the "Childhood Aggression" project examining predictors of proactive and reactive aggression in children aged 7 to 13 years. Collaborated with local community agencies to continue data collection in socially disadvantaged neighborhoods. Helped with grant submissions to the National Institute of Health and National Institute of Justice in order to expand the project. Analyzed data for the "Community Violence" project examining outcomes of exposure to different forms of community violence experienced by undergraduate men and women. Helped develop and begin data collection for the "Women's Sexual Revictimization" project evaluating predictors of revictimization prospectively in female undergraduate population. Designed new project entitled "Sex Differences in Juvenile Delinquency and Aggression" comparing various predictors of delinquent behavior in a sample of children referred to residential treatment centers for conduct problems. Collaborated with the Department of Social Services and other community agencies. Collected data from children and mental health workers. Worked with an undergraduate honor's student to develop a project examining the impact cardiovascular exercise has on reports of aggression, depression, and frontal lobe functioning with a sample of elderly adults in an assisted living facility, "The Effects of Cardiovascular Exercise on the Cognitive Functioning of Older Adults." Assisted student in writing research proposal, actual data collection, and data entry/analysis.

Research Assistant, Child Study Center, Virginia Polytechnic Institute and State University. Directors: Thomas Ollendick, PhD. \& Lars Göran-Öst, PhD., Estimated Research Hours: 1500. 2002-present. Assisted in the data collection for a cross-cultural study funded by the National Institute of Mental Health, "Childhood and Adolescent Phobia Project," examining the efficacy of different therapeutic techniques for treating childhood phobias. Conducted diagnostic interviews using the Anxiety Disorders Interview Schedule (ADIS) with children/adolescents ranging from 8 to 17 years of age and their parents. Supervised by Dr. Thomas Ollendick (540-231-8276). Gathered physiological data using Ambulatory Monitoring System (AMS) equipment. Presented diagnostic findings at weekly consensus meetings.

Research Assistant, Department of Institutional Research, University of Massachusetts

Dartmouth / Foundation Coalition. Director: Emily Fowler M.A. \& Judith Sims-Knight, Ph.D., Estimated Research Hours: 1000. 2000-2002. Assisted in the evaluation of programs in the College of Engineering funded by the Foundation Coalition. Prepared faculty and student assessments focusing on students' cooperative learning skills. Provided extensive literature searches and feedback for faculty. Entered and analyzed class assessment data. Participated in weekly meetings. 
Research Assistant, Department of Psychology, University of Massachusetts Dartmouth. Directors: Judith Sims-Knight, Ph.D. and Raymond Knight, Ph.D. Estimated Research Hours: 300. Summer 2001. Analyzed findings of the Multidimensional Assessment of Sex and Aggression (MASA) instrument. Conducted extensive factor analyses (i.e., principal component analyses). Compared and reported results across comparison populations. Created and established reliable scales.

Research Assistant, Institute of Law, Psychiatry, \& Public Policy / Fluvanna Correctional Center for Women, University of Virginia. Director: Janet Warren, D.S.W., Estimated Research Hours: 500. 1999-2000. Collected data for the "Women's Coping in Prison" project funded by the National Institute of Justice. Organized measures for Axis I and Axis II disorders. Interviewed inmates. Met with psychiatrists and lawyers to discuss the welfare of female inmates.

Research Assistant, Department of Psychology, University of Virginia. Directors:

Michael Kubovy, Ph.D. and Sergei Gepshstein, Ph.D., Estimated Research Hours: 200. 1998 - 1999. Prepared and organized lab experiments in cognitive psychology; provided student instructions. Participated in weekly presentations. Contributed to Kubovy, M. \& Gepshstein, S. (April 2000). The emergence of visual objects in space-time.

\section{Teaching Experience:}

Graduate Student Instructor - Forensic Psychology, Virginia Polytechnic Institute and State University, Summer 2005 - present. Plan and instruct advanced senior seminar writing intensive course in forensic psychology. Design seminar focusing on select topics within forensic psychology including criminal responsibility, recovered memories, forensic evaluation, mental health issues, juvenile justice, and specific criminal populations. Develop class plans, syllabus, lectures, class activities, and grade papers and presentations.

Guest Lecturer, Virginia Polytechnic Institute and State University, Fall 2005. Presented lecture, "Psychological, biological, and physiological components of aggression in youth" to graduate Psychophysiology course.

Graduate Student Instructor - Psychological Disorders of Children, Virginia Polytechnic Institute and State University Fall 2004 - Spring 2005. Planned and instructed advanced course in psychology. Course surveyed various disorders of children, including their assessment and empirically validated treatments. Developed class plans, syllabus, lectures, and graded assignments.

Graduate Student Instructor - Psychology of Learning, Virginia Polytechnic Institute and State University, Fall 2003 - Summer 2004. Planned and instructed own course. Course focused on the principles of learning as well as the behavioral perspective. Developed class plans, syllabus, lectures, and graded assignments.

Graduate Teaching Assistant - Introductory Psychology, Virginia Polytechnic Institute and State University, Fall 2002 - Spring 2003. Classes covered a range of topics including behaviorism, depression, health psychology, and biopsychology. Administered and graded quizzes/essays.

Guest Lecturer, University of Massachusetts Dartmouth, Spring 2002. Presented lecture, "Betrayal in Close Relationships" to undergraduate Social Psychology course. 
Instructor, Central Virginia Regional Jail, Orange, VA. Director: Brenda Baker, 1999-2000. Taught classes in anger management, money management, job finding and coping skills to male and female inmates of Central Virginia Regional Jail.

\section{Professional Experience:}

Employment Case Manager, Offender Aid and Restoration/Jefferson Area Community

Corrections, Charlottesville, VA. Directors: Patricia Smith and Laurie Cooke, 1999-2000. Provided job readiness and life skills training to offenders while incarcerated and once released back into the community. Coordinated housing, food, transportation and substance abuse counseling. Managed the Job Training Partnership Act financial aid program. Presented community resources to pre-release prison inmates at various Virginia prisons.

Court Services Case Manager, Offender Aid and Restoration/Jefferson Area Community Corrections, Charlottesville, VA. Directors: Patricia Smith and Laurie Cooke, 1998-1999. Improved probation services for non-violent offenders by managing restitution payments, community service hours and other court requirements. Established client offender goals and monitored their progress. Provided status reports to the Court, including testimony. Planned offender transition back to the mainstream.

\section{Published Works:}

\section{Peer-Reviewed Articles:}

Gillman, T., Haden, S.C., \& Scarpa, A. (in press). Understanding and treating the juvenile firesetter: A review. The Forensic Examiner.

Scarpa, A., \& Haden, S.C. (in press). Community violence victimization and aggressive behavior: The moderating effects of coping and social support. Aggressive Behavior.

Haden, S.C., \& Scarpa, A. (in press). The noradrenergeric system and its involvement in aggressive antisocial behavior. Aggression and Violent Behavior.

Scarpa, A., Haden, S. C., \& Hurley, J. D. (2006). Community violence victimization and symptoms of posttraumatic stress disorder: The moderating effects of coping and social support. Journal of Interpersonal Violence, 21(4), 446-469.

Haden, S.C., \& Hojjat, M. (2006). Aggressive responses to betrayal: The effects of type of relationship, victim's sex, and nature of aggression. Journal of Social and Personal Relationships, 23. 101116.

Scarpa, A., Hurley, J. D., Shumate, H.W., Haden, S.C. (2006). Lifetime prevalence and socioemotional effects of hearing about community violence. Journal of Interpersonal Violence, 21. 5-23.

Haden, S.C., \& Scarpa, A. (2005). Childhood animal cruelty: A review of research, assessment, and therapeutic issues. The Forensic Examiner, 14(2), 23-32.

\section{Published Abstracts:}

Haden, S.C., Whitmore, M.J., Scarpa, A., Friedman, B., \& Ollendick, T.H. (2004). Familial environment and parental psychopathology impacts children's basal cortisol level. Psychophysiology, 41(Suppl. 1), S77.

Book Chapters:

Haden, S.C. (2003). Introduction to research methods. In P.K. Lehman, C.S. Dula, \& J.W.Finney (Eds.), (2003). Introductory psychology recitation reader. McGraw-Hill: USA.

\section{Works in Progress:}

Scarpa, A., Tanaka, A., \& Haden, S.C. (2006). Biosocial bases of reactive and proactive aggression: The roles of community violence exposure and heart rate. Manuscript submitted for publication. 
Haden, S.C. \& Hojjat, M. (2006). Perceptions of Betrayal: Impact of type of relationship, sex of the perceiver, and sex of the transgressor. Manuscript submitted for publication.

Scarpa, A., Hurley, J. D., \& Haden, S. C. (2006). Community violence victimization and symptoms of depression: The moderating effects of coping and social support. Manuscript submitted for publication.

Scarpa, A., VanVoorhees, L., McDonald, S., Shumate, H., Haden, S.C., \& Ollendick, T.H. (2006) Being hot-tempered: Emotional, behavioral, and autonomic functioning in child reactive and proactive aggression. Manuscript submitted for publication.

Haden, S.C., Whitmore, M.J., Ollendick, T.H., \& Herrington, J. (2006). The impact of familial environment on basal cortisol levels of children with anxiety disorders.

\section{Presentations:}

Haden, S.C., Herrington, J., \& Scarpa, A. (2006, November). The impact of childhood maltreatment on depression in at-risk male youth: The role of aggressive behaviors. Poster to be presented at the $40^{\text {th }}$ Annual Convention of the Association of behavioral and Cognitive Therapies, Chicago, IL.

Francisco, J., Haden, S.C., \& Scarpa, A. (2006, November). The relationship between depression and aggression in an at-risk sample of boys. Poster to be presented at the $40^{\text {th }}$ Annual Convention of the Association of behavioral and Cognitive Therapies, Chicago, IL.

Haden, S.C., \& Scarpa, A. (2006, July). The interactive roles of parental rejection and noradrenergic activation on aggression in at-risk youth. Paper to be presented at the meeting for the International Research Society on Aggression, Minneapolis, MN.

Aycock, R., Haden, S., Wells, A., \& Scarpa, A. (2006, May). Characteristics of child sexual abuse experiences and survivors' resistance strategies. Poster to be presented at the $18^{\text {th }}$ Annual Convention of the American Psychological Society, New York, NY.

McDonald, S. Haden, S., \& Scarpa, A. (2006, May). Young adults' exposure to community violence: Psychological outcomes of family and stranger violence. Poster to be presented at the $18^{\text {th }}$ Annual Convention of the American Psychological Society, New York, NY.

Edmonds, G., Haden, S., Wells, A., \& Scarpa, A. (2006, May). Prevalence of sexual victimization experiences in a college female sample. Poster to be presented at the $18^{\text {th }}$ Annual Convention of the American Psychological Society, New York, NY.

Haden, S.C., Tanaka, A., \& Scarpa, A. (2005, November). The interaction of community violence exposure and heart rate on child reactive and proactive aggression. Posterpresented at the $39^{\text {th }}$ Annual Convention of the Association of Behavioral and Cognitive Therapies, Washington, D.C. Haden, S.C., Scarpa, A., \& Tanaka, A. (2005, June). Children's aggression: the impact of parenting practices and community violence. Poster presented at the 2005 Meeting of the International Society for Research in Child and Adolescent Psychopathology. New York, NY. McDonald, S.E., Pendleton, D.C., Tyrrell, J.M., Haden, S.C., \& Scarpa, A. (2005, May). Psychophysiological correlates of laboratory proactive and reactive aggression. Poster presented at the $17^{\text {th }}$ Annual Convention of the American Psychological Society, Los Angeles, CA.

Tanaka, A., Haden, S.C., \& Scarpa, A. (2005, May). Effects of heart rate on community violence exposure and proactive aggression. Poster presented at the $17^{\text {th }}$ Annual Convention of the American Psychological Society, Los Angeles, CA.

Wells, A., Haden, S.C., \& Scarpa, A. (2005, May). College women's experience of sexual and non-sexual victimization. Poster presented at the $17^{\text {th }}$ Annual Convention of the American Psychological Society, Los Angeles, CA.

Haden, S.C., Yoder, M., \& Scarpa, A. (2005, March). School bullies: their school victimization experiences and present psychological distress. Poster presented at the $75^{\text {th }}$ Annual Meeting of the Eastern Psychological Association, Baltimore, MD. 
McDonald, S.E., Pendleton, D.C., Tyrrell, J.M., Haden, S.C., \& Scarpa, A. (2005, March). Autonomic activity and laboratory proactive and reactive aggression. Poster presented at the 2005 Southeastern Psychological Association.

Haden, S.C., Whitmore, M.J., Scarpa, A., Friedman, B.H., \& Ollendick, T.H. (2004, October). Familial environment and parental psychopathology impacts children's basal cortisol. Poster presented at the 2004 Society for Physiological Research Conference, Santa Fe, NM.

Haden, S.C., \& Scarpa, A. (2004, November). Community Violence Victimization and Aggression: The Moderating Effects of Coping and Social Support. Poster presented at the 2004 Annual Meeting of the American Criminological Society, Nashville, TN.

Haden, S.C., Hojjat, M., Ouimet, C., \& Yock, S. (2004, July). Young adults' hypothesized responses to betrayal in romantic relationships and close friendships. Poster presented at the 2004 International Association for Relationship Research Conference, Madison, WI.

Page, M., Hojjat, M., \& Haden, S. C. (2004, September). Reactions to actual and hypothetical betrayals across relationships. Poster presented at the New England Social Psychological Association, Storrs, CT.

Haden, S.C., Scarpa, A., \& Hurley, J. (2004, May). Community violence victimization and depressed mood: the moderating effects of coping and social support. Poster presented at the $16^{\text {th }}$ Annual Convention of the American Psychological Society, Chicago, IL.

Haden, S.C., Scarpa, A., \& Clum, G. (2003, April). The role of trauma characteristics in sexual and nonsexual traumas: Predicting post-traumatic stress disorder severity. Paper presented at the $75^{\text {th }}$ Eastern Psychological Association, Washington, D.C.

Haden, S.C., Scarpa, A., Jones, R.T., \& Ollendick, T. (2003, November). Late adolescents' trauma experiences and posttraumatic stress disorder symptoms: Friends matter. Poster presented at the $37^{\text {th }}$ Annual Convention of Child and Adolescent Anxiety Special Interest Group of the American Association for Behavioral Therapy, Boston, MA.

Haden, S.C., Scarpa, A., Jones, R.T., \& Ollendick, T. (2003, May). Prediction of posttraumatic stress disorder in young adults: Survivors of intentional and unintentional stressors. Poster presented at the $15^{\text {th }}$ Annual Convention of the American Psychological Society, Atlanta, GA.

Weaver, C., Hurley, J.D., Shumate, H., Haden, S., \& Scarpa, A. (2003, May). Lifetime prevalence and socioemotional effects of hearing about community violence. Poster presented at the $15^{\text {th }}$ Annual Convention of the American Psychological Society, Atlanta, GA.

Haden, S.C., \& Hojjat, M. (2003, March). Aggressive responses to serious transgressions. Paper presented at $74^{\text {th }}$ Annual Meeting of the Eastern Psychological Association, Baltimore, MD.

Haden, S.C., Knight, R.A., \& Sims-Knight, J. (2002, Oct). Aggressive Components of Sexual Aggression. Poster presented at the $21^{\text {st }}$ Annual Association for the Treatment of Sexual Abusers, Montréal, Quebec Canada.

Hojjat, M., \& Haden, S. C. (2002, July). Motive, Personality, and Relationship Betrayal. Poster presented at 2002 International Conference of Personal Relationships (ICPR), Nova Scotia, Canada.

Powers, T., Sims-Knight, J., Topciu, R., \& Haden S. C. (2002, June). Assessing team functioning in engineering education. Paper presented at the 2002 American Society for Engineering Education Annual Conference and Exposition, Montreal, Canada.

Haden, S.C. (2002, March). Perceptions of betrayal across relationships: motives, types, gender differences, and personality dimensions. Paper presented at $73^{\text {rd }}$ Annual Meeting of the Eastern Psychological Association, Boston, MA.

Haden, S.C. (2001, Dec). Perceptions of betrayal across relationships: motives, types, gender differences, and personality dimensions. Paper presented at University of Massachusetts Dartmouth Psychology Department Colloquium.

Powers. T., Sims-Knight, J., Haden, S.C., \& Topciu, R. (2001, August). Assessing and enhancing team functioning with college students. Poster presented at $109^{\mathrm{th}}$ American Psychological Association (APA) conference, San Francisco, CA.

Haden, S.C., \& Hojjat, M. (2001, June). Betrayal in relationships. Poster presented at 3rd 
Annual International Network on Personal Relationships (INPR) - International Society for the Study of Personal Relationships (ISSPR) Joint Conference, Prescott, AZ.

Haden, S.C., \& Hojjat, M. (2001, May). Betrayal in relationships. Poster presented at $7^{\text {th }}$

Annual University of Massachusetts, Dartmouth Sigma Xi Research Exhibition, North Dartmouth, MA.

Haden, S.C., \& Hojjat, M. (2001, April). Betrayal in relationships. Poster presented at

$72^{\text {nd }}$ Annual Meeting of the Eastern Psychological Association, Washington, D.C.

\section{Membership in Organizations:}

Association for Behavioral and Cognitive Therapies

American Psychological Association

American Psychological Society

American Society of Criminology

Eastern Psychological Association

International Society for Research on Aggression

Sigma Delta Epsilon

Sigma Xi

Society of Clinical Child and Adolescent Psychology

Society of Clinical Psychology 